\title{
INVESTIGATING USER PERSPECTIVES ON MIXED-REALITY GAMES FOR PEOPLE WHO DRIVE MOBILITY DEVICES
}

\author{
by \\ Gregory Dolinar \\ B.A. University of Guelph, 2011 \\ A thesis \\ Presented to Ryerson University \\ In partial fulfillment of the \\ Requirements for the degree of \\ Masters of Management Science \\ In the program of \\ Management of Technology and Innovation \\ Toronto, Ontario, Canada, 2014 \\ @ Gregory Dolinar 2014
}




\section{AUTHOR'S DECLARATION}

I hereby declare that I am the sole author of this thesis. This is a true copy of the thesis including any required final revision, as accepted by my examiners. I authorize Ryerson University to lend this thesis to other institutions or individuals for the purpose of scholarly research. I further authorize Ryerson University to reproduce this thesis by photocopying or by other means, in total or in part, at the request of other institutions or individuals for the purpose of scholarly research. I understand that my thesis may be made electronically available to the public. 


\begin{abstract}
Video games are not being designed to address the needs of the disabled user. As a result, people with mobility disabilities are being left out of game play experiences. As the population ages, more and more people will require mobility devices such as powered wheelchairs and scooters to support their mobility needs. This thesis explores the types of games mobility device users would like to play using their input to influence game development. Past gaming and play experiences are explored as a component useful to the production of a new game design. A Crowdsourcing technique called, an Idea Jam, is used to collect the data relevant to the game design. The Idea Jam for mobility games explores the type of game genres and functionality (game objectives, characters, input/output, audience integration and rewards) mobility device users would be willing to consider in a game and why. It also explores the impact of having users participate at early stages of game design on the actual functionality and development of an actual mobility game. The main findings show that Crowdsourcing is a viable method for collecting data on game development that mobility device embodiment plays a role in the way people view games and that people with mobility devices can impact game design at the beginning stages of development.
\end{abstract}




\section{Acknowledgements}

I would like to thank many people for their support over the past years who have assisted me with completing my thesis at Ryerson University. First and foremost is my supervisor, Dr. Deborah Fels, who without her guidance, help and support, this thesis would not have been possible. Deborah provided me with the resources and support to make this thesis possible. I will always be thankful for her belief in people and the great work, which is accomplished at the Inclusive Media Design Centre. I am proud to be a part of this work.

In addition, I would like to thank my parents, John and Dora Dolinar and my grandmother, Maria Dolinar for providing me with emotional, moral and financial support as well as encouragement to produce a piece of work of which I am proud. I would also like to thank my girlfriend, Nicole Connolly. She supported me in all my decisions and was kind enough to provide well-thought out suggestions and emotional support throughout my research.

I would like to express my sincere gratitude to all the friends and colleagues I made at Ryerson, specifically Tonga Pham for her wisdom and knowledge, which guided me through Ryerson and the MBA portion of the MMSc. I would also like to thank the IMDC lab for providing me with the administrative support, software and financial resources to complete my research. 


\section{Table of Contents}

THE POWERED TO PLAY DESIGN PROCESS ........................................................................ i

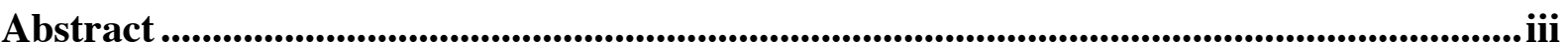

Acknowledgements.................................................................................................................................. iv

Chapter 1. Introduction ............................................................................................................................... 1

Chapter 2. Literature Review ................................................................................................................ 4

2.1 Introduction ................................................................................................................................. 4

2.2 PMD Usage ….............................................................................................................................. 5

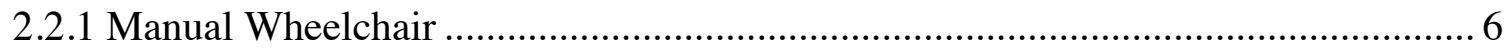

2.2.3 Scooter (Powered Chairs) ……………………......................................... 8

2.2.4 Using Scooters for games.................................................................................... 10

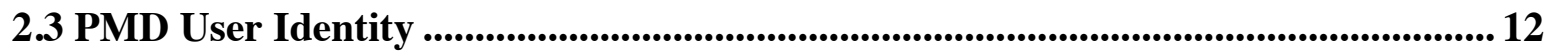

2.4 Models of Disability ...................................................................................................... 15

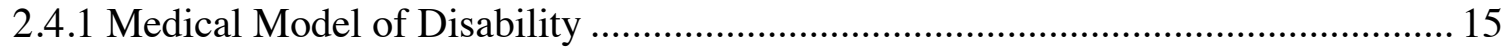

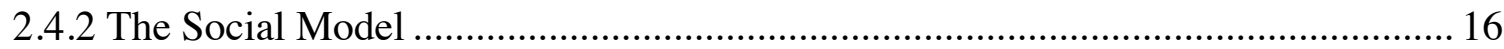

2.5 Design Applications and Theories ...................................................................................... 17

2.5.1 Idea Jams - Crowdsourcing Design.................................................................. 20

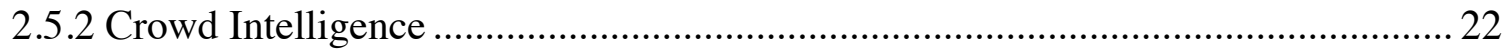

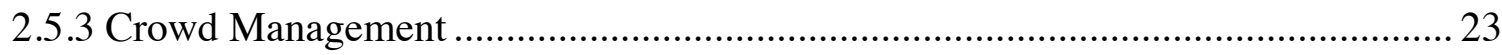

2.6 Gaming Applications and Accessibility ............................................................................... 24

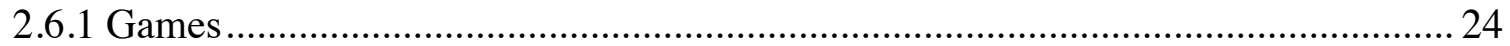

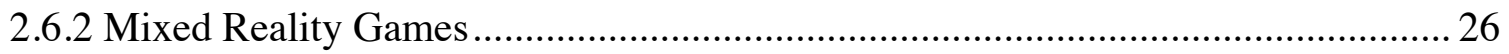

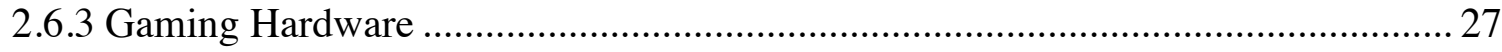

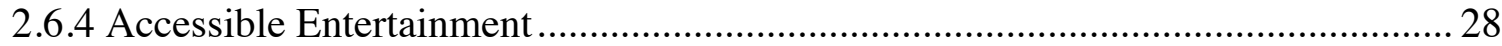

2.6.5 Cross-Generational Gaming ............................................................................. 30

2.7 The Social Aspects of Virtual Games ................................................................................ 32

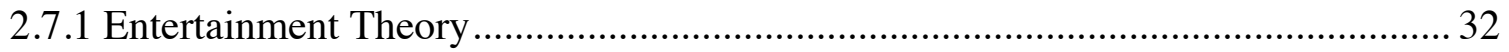




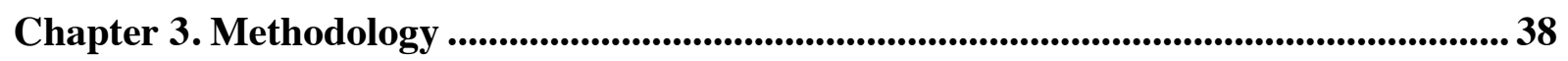

3.1 Research Questions ......................................................................................................................... 38

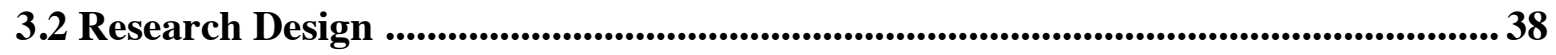

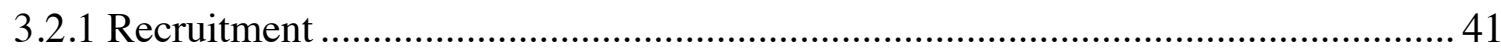

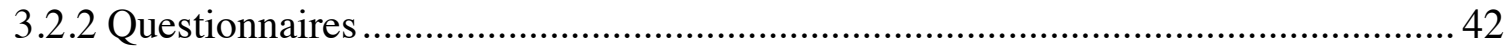

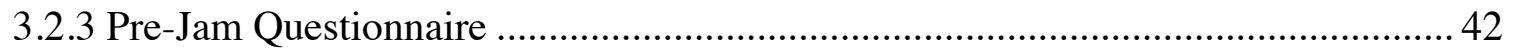

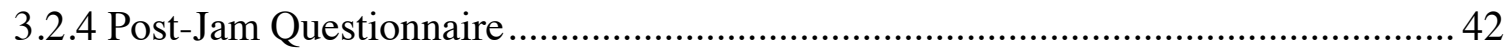

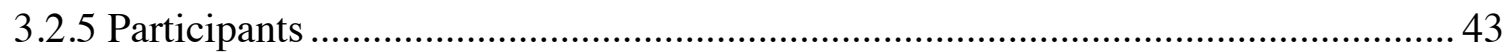

3.3 Data Analysis .....................................................................................................5 50

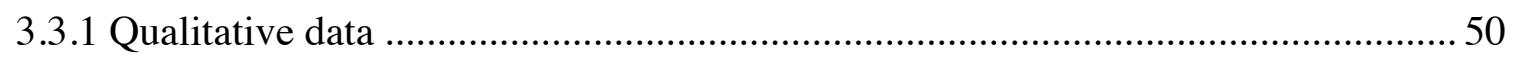

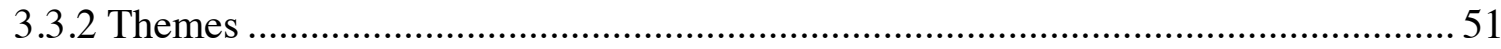

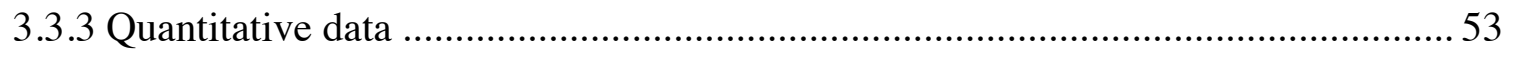

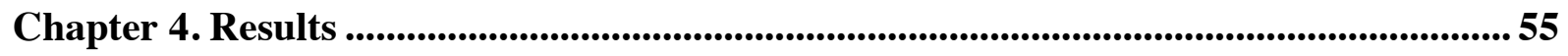

4.1.1 Between themes for all participants .......................................................... 55

4.2 Descriptive Analyses ..................................................................................................................56

4.2.1 Differences in theme comments Between MPMD and TPWHL groups .............. 58

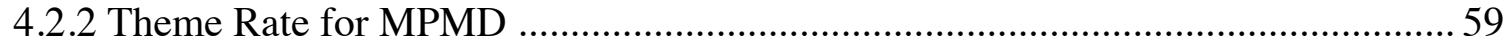

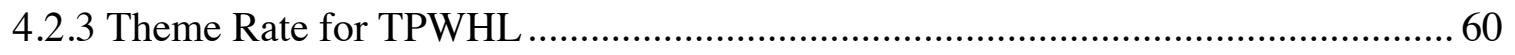

4.3. Post study Questionnaire Analysis .................................................................................. 62

4.4 Crosstabulation Analysis .......................................................................................................... 70

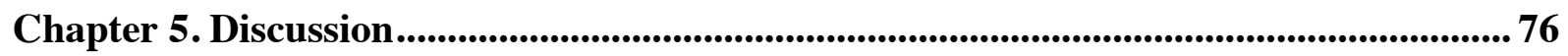

5.1 Idea Jam Process ...................................................................................................................... 77

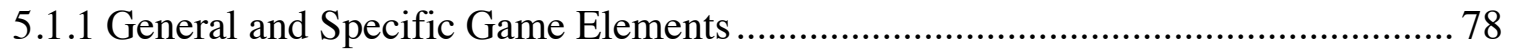

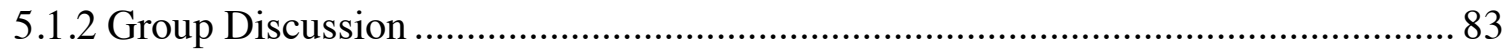

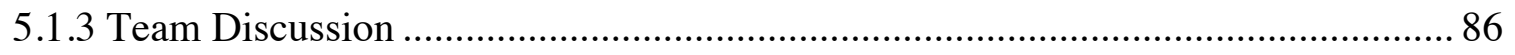

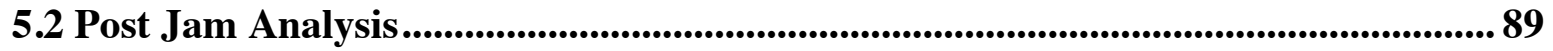

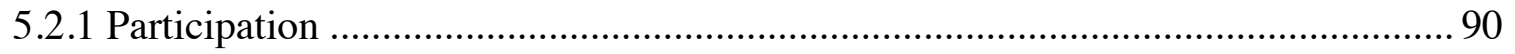

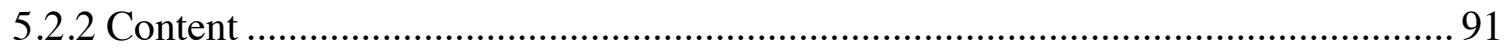

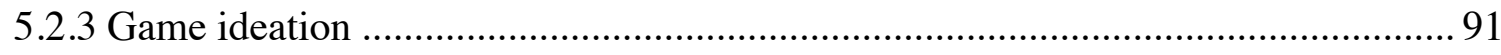

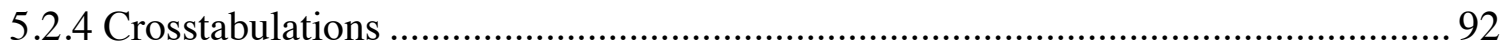


5.3 Capture the Flag ..................................................................................................................93

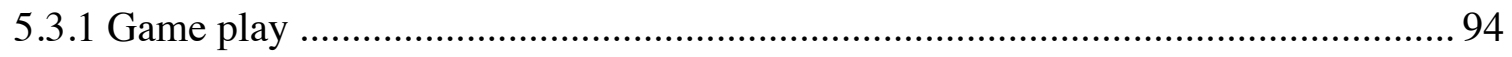

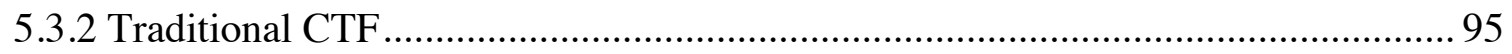

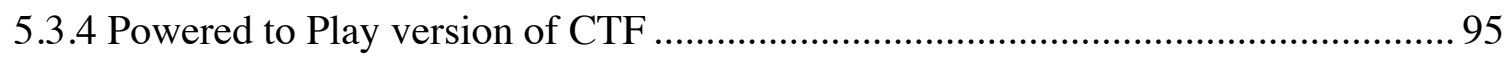

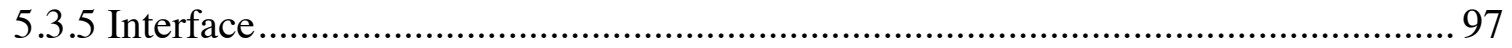

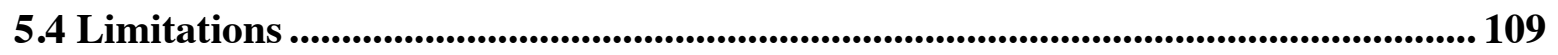

5.5 Study Limitations ....................................................................................................................... 109

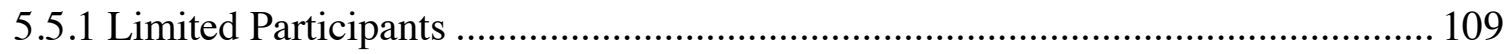

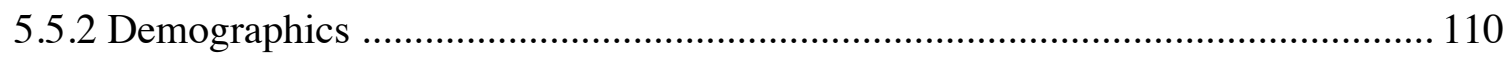

5.6 Methodology Limitations.......................................................................................................... 111

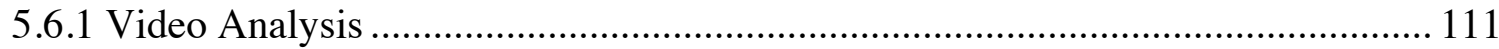

5.6.2 Idea Jam Consistency …………………………..................................... 112

Chapter 6. Contributions, Conclusion \& Future Directions.................................................... 116

6.1 Contributions ........................................................................................................................ 116

6.2 Conclusion ........................................................................................................................... 117

6.3 Future Directions ................................................................................................................................. 119

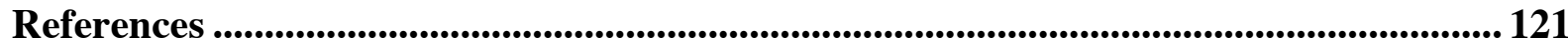




\section{Table of Figures}

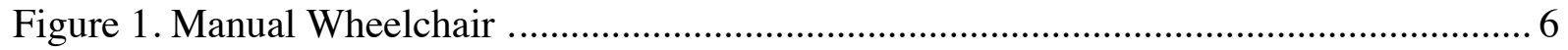

Figure 2. Powered Wheelchair ..................................................................................... 7

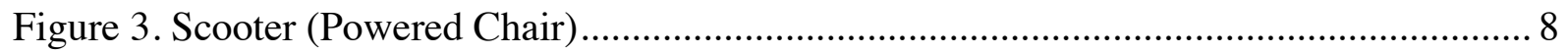

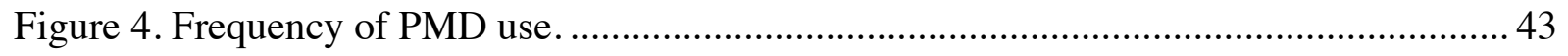

Figure 5. Frequency of educational attainment ....................................................... 44

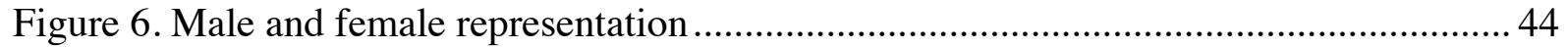

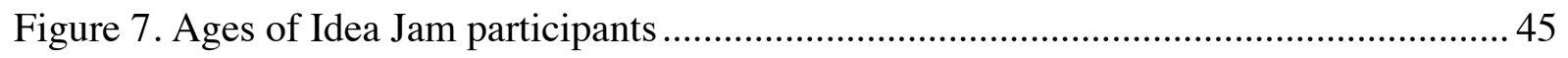

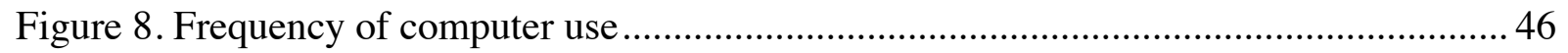

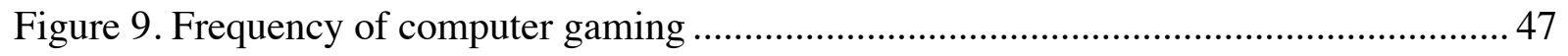

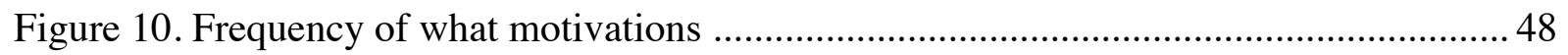

Figure 11. Total comment rate per captia for ALLP ......................................................57

Figure 12. Comment rates per capita for MPMD \& TPWHL .............................................58

Figure 13. Comment rate per capita for MPMD themes .................................................. 59

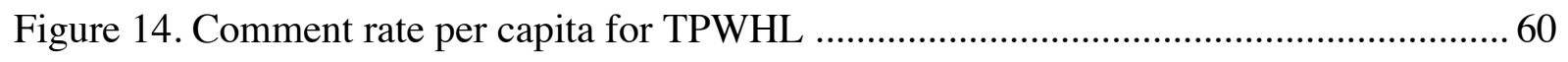

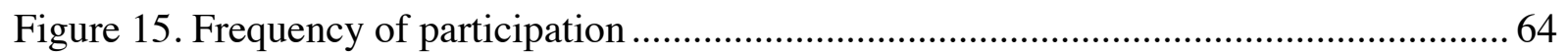

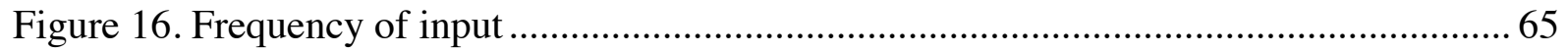

Figure 17. Frequency of how much participants liked the game discussed ........................ 66 
Figure 18. Frequency of how much participants liked the characters discussed

Figure 19. Frequency of how much participants liked the game was discussed................... 68

Figure 20. Frequency of how much fun participants found their expirence ........................69

Figure 21. Frequency of the participants level of enjoyment.......................................... 71

Figure 22. Enjoyment compared to liking the idea of the game …................................... 72

Figure 23. Enjoyment compared to liking the characters discussed ................................. 73

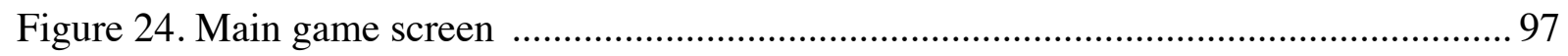

Figure 25. A smartphone used by Powered to Play players ........................................ 104

Figure 26. Idea Jam Contributions in Powered to Play ................................................ 107 


\section{List of Tables}

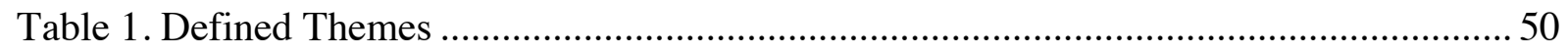

Table 2. Values used in the Comment Rate Calculations .................................................. 53

Table 3. ALLP Kruscal-Wallis theme ranks ................................................................ 55

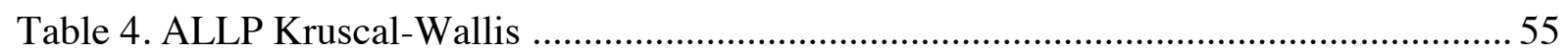

Table 5. Total Number of Comments for all Themes ........................................................ 55

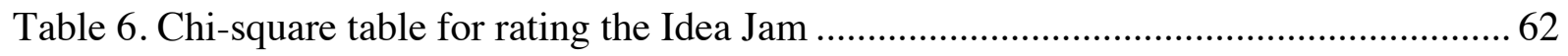

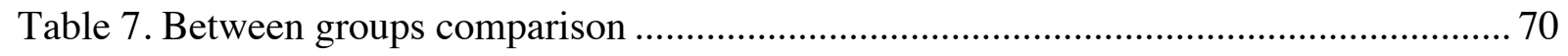

Table 8. Occurrences for the Level of Enjoyment ........................................................ 71

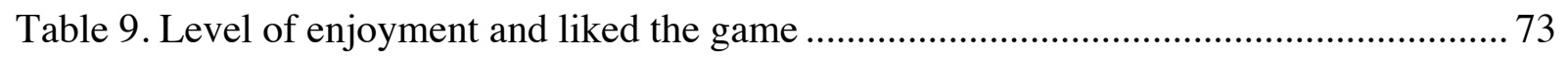

Table 10. Level of enjoyment and liked the characters discussed ..................................... 74 


\section{Chapter 1. Introduction}

Part of living life to the fullest includes enjoyment and entertainment, and games can be one avenue towards this goal. However, because many games are not accessible, people with disabilities are excluded from this opportunity for themselves as well as within their social circles. As modern technologies have evolved over the past several decades, new technologies have changed the way people interact with one another and how they are entertained. One of the primary methods of entertainment using technology has been computer gaming. Although computer games have become more accessible through keyboard shortcuts, close captioning and various interface developments, there is still much work to be done to include the disabled gamer. The Social Model of disability identifies systemic barriers, negative attitudes and exclusion by society, as the main contributors in disabling many individuals (Hughes \& Paterson, 1997). While many people have physical, intellectual or psychological limitations or impairments, the impairments themselves do not lead to a disability unless there are barriers within a society that prevent these individuals from participating because of these limitations (Carleton \& Michalko 2000). These barriers could be attitudinal, physical, sensory, systemic, social, etc.

Although computer games have been shown to facilitate non-entertainment requirements, such as social interaction, reduction of isolation and improvement of health and self-esteem (Khoo et al. 2008), very few studies have focused on the entertainment and social opportunities for people with disabilities who play games. My research explores an aspect of computer gaming, known as mixed-reality, for people who drive powered mobility devices (PMD) such as powered scooters/chairs and powered wheelchairs. Mixed-reality games offer a multiuser, team-oriented structure for cooperative play. Mixed-reality games also offer a return to physical and social 
gaming while maintaining physical and virtual elements of play, such as playing games in the outdoors while using virtual realities (Cheok, 2006). This return to the physical aspects of play enable PMD users to take advantage of some of the more traditional aspects of play and think about these aspects in the game development stage, such as the importance of socialization or learning.

For people with mobility disabilities and who drive PMDs, opportunities can be developed for users to take advantage of their PMDs in a gaming role. The game design process followed in this thesis provided insight and design advice for a game developed, called Powered to Play. Powered to Play is a capture-the-flag (CTF) game developed, drawing upon previous efforts in mixed reality game play with smartphones. Powered to Play was designed as a multiplayer mixed reality game played in teams and modeled after the well-known CTF game (see Section 5 for a description of the game developed and its rules). In this thesis, the results of five Idea Jams with people who drive PMDs are collected and studied to offer insights for the development of Powered to Play. Framed by Inclusive design and Entertainment theories, my research addresses mixed reality gaming design for a diversity of user's needs, including alternative input and output devices, accessible information interaction, and inclusive play with non-mobility device users, such as friends and family. My exploratory research questions were thus:

(1) What game genres and functionality (game objectives, characters, input/output, audience integration and rewards) would participants who use powered mobility devices be willing to consider and use in indoor/outdoor spaces? 
(2) What is the impact of having users participate at early stages on the design of game functionality and priorities?

In this research there were four main contributions. These included:

1) Crowdsourcing offers an effective means to gather data useful for game development from people who use powered mobility devices.

2) Identity plays a role in how PMD users provide input into game design ideas. Identity is related to how much a user has embodied their PMD. For instance, users who had used their PMD devices from birth had difficulty thinking about themselves as a separate entity from their PMD. This difference of identity played a role on how much the user was able to contribute to game development ideas.

3) Having PMD users contribute to game development at the beginning stages of design can provide an instrumental role in creating a more inclusive game.

4) Collecting PMD perspectives are in line with Inclusive design principles and that these users can provide feedback and suggestions that designers may overlook, making game development more user-centered. This process can also provide game developers with more ideas on how to create an inclusive game.

The contents of this thesis are arranged as follows: Chapter 2 consists of the literature review, in which the theoretical basis current circumstances of PMD users are addressed, and previous studies are introduced. Chapter 3 addresses the methodology used in this research. The research questions, research design, and data analysis are included in this chapter. Chapter 4 displays the results found in this research. Chapter 5 is the discussion and limitations of the results and offers some explanations for findings to the research questions. Chapter 6 discusses my contributions, 
concludes the thesis and offers some future directions for the research. At the end of the thesis, the appendices and references can be found.

\section{Chapter 2. Literature Review}

\subsection{Introduction}

This chapter presents the literature explaining the background information regarding the theoretical framework of Powered to Play's development process. It includes a section providing background information pertaining to PMD usage, such as the way PMDs are used by their users and the different types of PMDs available to people. Factors that affect PMD user's perception of identity are explored in the second section, where a brief history of the Medical and Social Model of Disability explores how PMD users interact with their communities in terms of the economic, political, and social and entertainment environments they live in. In addition, a summary of design theories used for the development of the Powered to Play project were included in the third section, Design Application and theories, discussing Inclusive design, and Crowdsourcing. In the fourth section, Games and Accessibility are addressed which provides an overview of what is a game and how play is an internal part of the gaming experience. It explores the concept of a Mixed-Reality game, some of the hardware used in games and how entertainment can be made more accessible. In the final chapter, the Social Aspects of Playing Virtual Games are explored which provides an overview of why people play games. How Entertainment theory and Flow theory play a role in why people play games and some of the underlying reasons Idea Jam participants were motivated to express their ideas for game play are examined here. 


\subsection{PMD Usage}

This section provides a discussion regarding how individuals use PMD's, how these devices are perceived by their users, and how communities and society at large view mobility devices and the people who use them. According to Statistics Canada (2012), 3.4 million people in Canada have some type of disability, approximately 220,000 of these individuals live in Ontario (15.4\%) and of these individuals 16,000 of them have a mobility disability (7.1\%). However, the distribution of PMD use within this group of people with mobility disabilities is not available.

In this section archival materials, oral accounts and secondary analyses are used to illustrate an understanding of PMD's usage and explore the relationships between social and technological issues PMD users encounter. Some of the issues discussed in this chapter include the types of PMDs available to users, the environments the devices are typically used in, the aspects of independence the devices can offer, and how PMDs can be used for entertainment purposes.

PMD's are a form of assistive technology in that they provide people with mobility issues (e.g., those who have difficulty walking or moving about in a large physical space) with a system to enable independent movement within their physical space (Woods \& Watson, 2003). For example, PMD's enable people without stamina for walking, or lacking the arm and shoulder flexibility for using crutches to still travel on sidewalks across longer distances (RousseauHarrison et al. 2012). PMD's are an intermediary between the user, their environment and the tasks the user is fulfilling (Reid \& Angus, 2003). 
The design of the PMD reflects the tasks and environmental requirements of the user (Reid et al. 2003). For example, if a person is mainly confined to an indoor environment, a wheelchair which is highly manoeuvrable could be a good fit for a user considering the small movements required to get around obstacles such as tables, chairs and carpets (Koon, 2003). However, the traditional wheelchair with small sized front wheels could be difficult to use outside because of uneven terrain such as sidewalks and pathways, and where travel distances are far (Koon, 2003). For example, wheelchairs may be useful for playing games like chess or checkers in a indoor environment whereas if a player is required to travel long distances outdoors to play a game, a scooter may be a more useful option.

PMD's are usually prescribed to users according to their ability level and the tasks the user is trying to accomplish. The different environments require different demands from the PMD's. There are three main types of PMDs available to the mobility impaired: the scooter, the powered wheelchair and the manual wheelchair.

\subsubsection{Manual Wheelchair}

As seen in Figure 1, manual wheelchairs are devices that require human power to move them (Koon, 2003). 


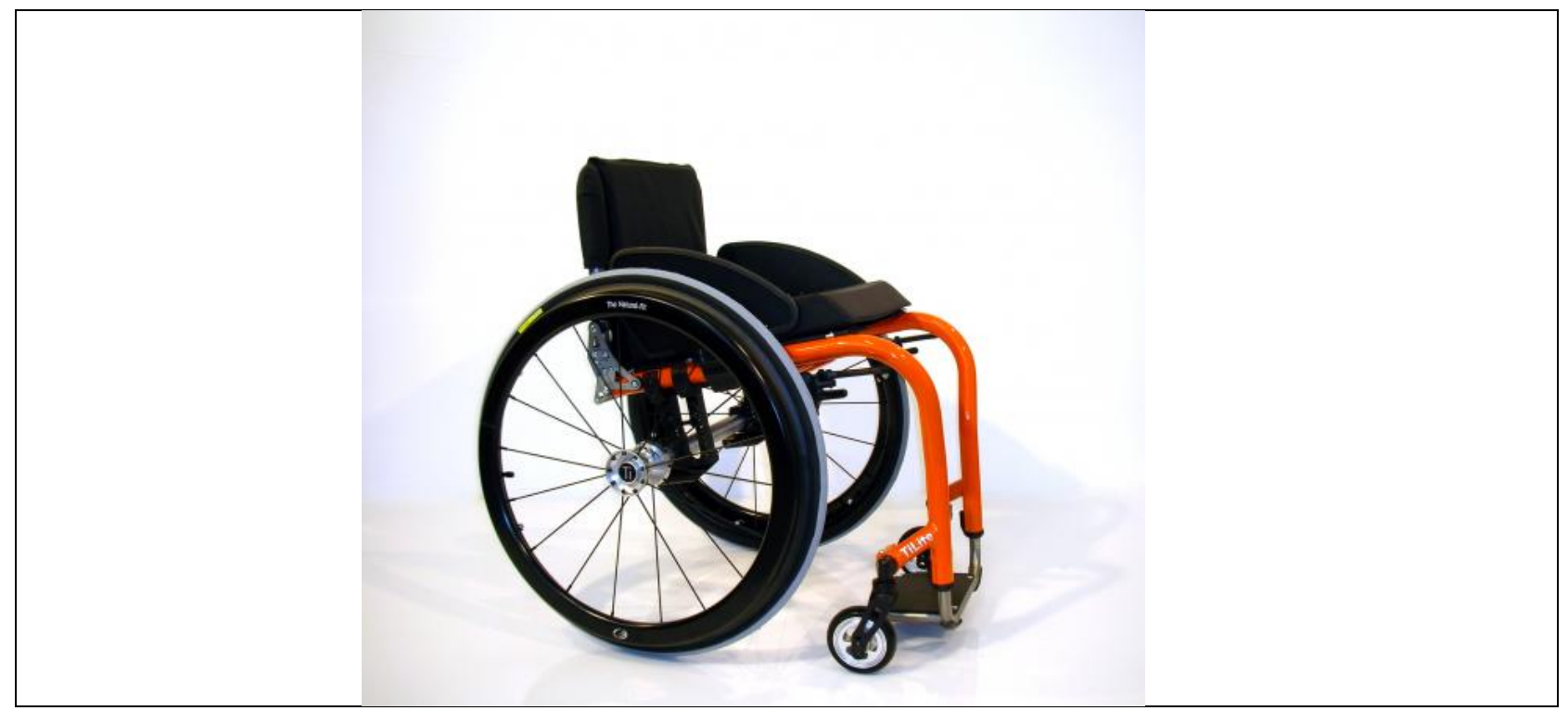

Figure 1: Manual Wheelchair (Norco, 2009).

Manual Wheelchairs can be foldable or rigid framed. The user propels a manual wheelchair by turning the rear wheels, although there is some variation in design. These chairs incorporate a seat, footrests and four wheels: two smaller diameter caster wheels in the front and two large wheels at the back. They are optimal for indoor use due to their agility because the two large wheels provide the user precise control over the devices speed and direction (Koon, 2003). The two large wheels also provide the user with instantaneous response for tight space manoeuvring. The manual wheelchair also has hand rims on the two larger rear wheels and two push handles at the top of the seat to allow for manual propulsion by a second person. Most PMD's are a variation of this basic design (Koon, 2003).

\subsubsection{Powered Wheelchair}

Powered wheelchairs, as illustrated in Figure 2, are typically wheelchairs with an electric motor and batteries that provides the power to move the wheelchair. 


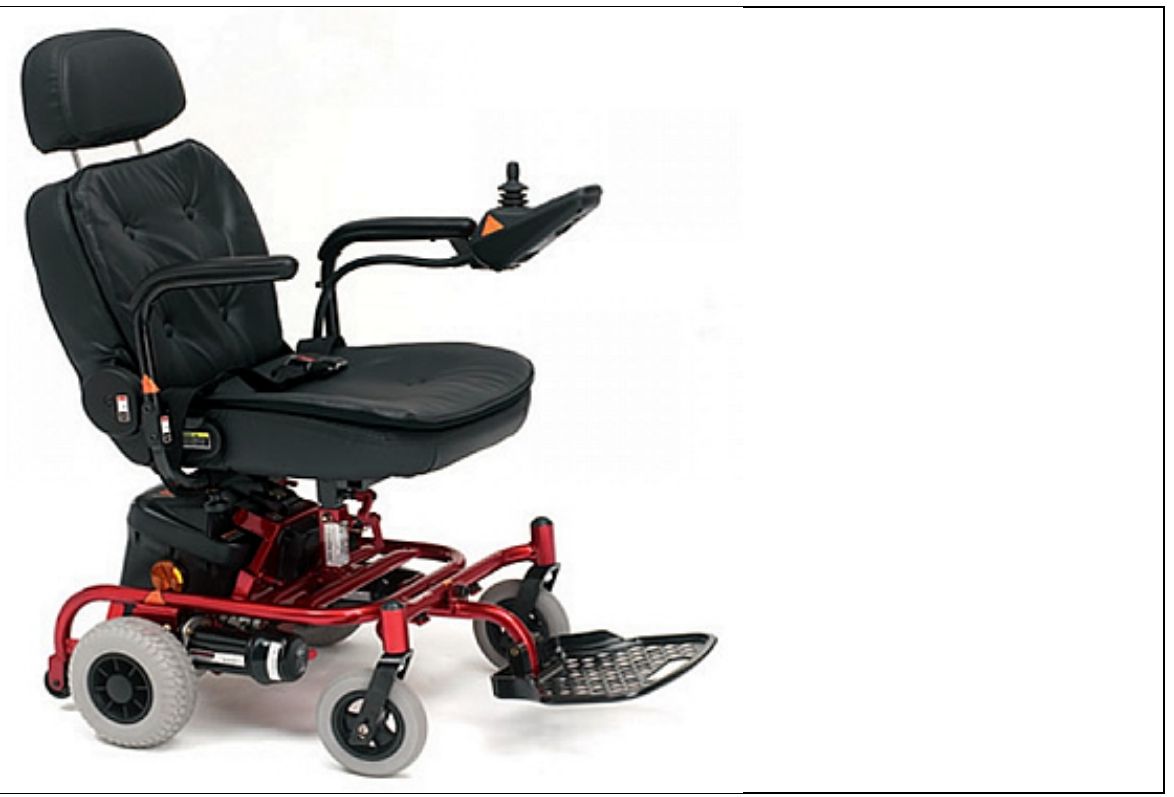

Figure 2: Powered Wheelchair (UK Wheelchairs, 2011).

The motor is usually allocated to the rear wheels although there are many variations. As a result of the motor and batteries, the wheelchairs are heavy and bulky making them difficult to transport. Such wheelchairs are usually prescribed to users with greater mobility limitations and/or who do not have the strength or dexterity to move a manual chair (Koon, 2003). A powered wheelchair can be used in indoor and outdoor environments although it is not optimal for either. The device is normally controlled via a joystick mounted on the armrest, although variations exist for unique user circumstances (Koon, 2003). A display regarding the on/off status of the wheelchair and the battery status is also present in front of the user.

\subsubsection{Scooter (Powered Chairs)}

Scooters typically have a seat over three to four wheels and have a flat area below the chair for a footrest (see Figure 3) (Woods \& Watson, 2003). 


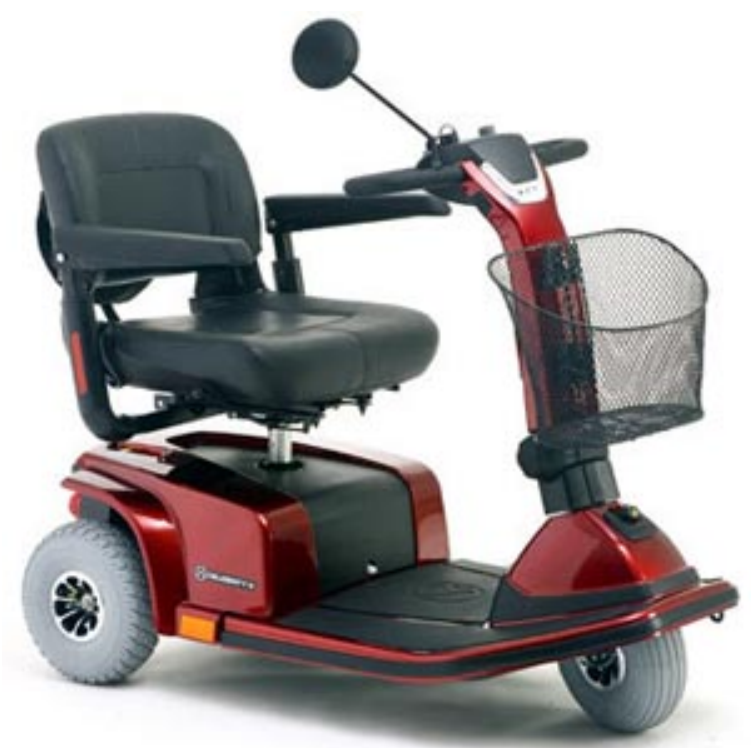

Figure 3: Scooter (Powered Chairs) (Care2, 2011).

Handlebars, which allow the user to drive the device, are in front of the users. The seat is adjustable so that a user can be seated comfortably and can see in front and to the sides of the device. Scooters have a battery-powered electric motor similar to a powered wheelchair. Using the handlebar-mounted buttons, switches and levers, the user can control the forward/reverse directions and the device's speed with their hands and fingers (see Figure 3) (Koon, 2003). There is also a display on the handlebars for informing users of remaining battery power, speed, turning signals, and device on/off status. The scooter is usually turned on/off with a key.

Scooters can be referred to as motorized chairs, powered mobility devices and gophers (in this thesis they are typically referred to as PMDs) (Koon, 2003). However, common characteristics of scooters include being battery-powered with a maximum speed of 10 kilometers per hour (Woods et al. 2003). On average, most scooter users ride their mobility devices three to five times each week, travelling two to five kilometers from their homes per ride (Wressle \& Samuelsson, 2004). Edwards \& McCluskey (2010) found that by matching PMD user's needs to 
their devices ensured that people were provided with the best possible opportunity to overcome barriers in their communities and take part in society. Whether this was from taking part in employment opportunities or being provided transportation to visit friends and family, the PMD offered a meaningful method for people to engage with their community. Rousseau-Harrison et al. (2012) found that the level of satisfaction people have from using their PMDs improved over time after adoption in areas such as positive changes in daily activities, physical expectations, impact on social roles and emotional changes. However, the wider personal, social and environmental implications specifically the use of PMDs for entertainment purposes, has received little attention in the literature.

Although scooters are typically used to assist users with outdoor activities and are primarily used by older adults, people use scooters for many other reasons. These include coping with mobility restrictions when travelling longer distances (Rousseau-Harrison et al., 2012) and maintaining independence, for instance when travelling longer distances alone (Wiart et al., 2004). Mobility scooters are increasingly being used by many people with mobility limitations to replace walking activities such as travelling between different locations, visiting friends and family, as well as for enjoyment (Wressle \& Samuelsson, 2004). For instance, people use PMDs for activities such as going on hikes or for walks with family and friends.

\subsubsection{Using Scooters for games}

As more people use scooters, there is a growing need to understand emerging social, health, transport and the entertainment possibilities of scooter use. Although to date, most of the scholarly research on PMD users is framed by the Medical Model as described in Section 2.4.1 (LaPlante \& Kaye, 2010) where PMD users tend to be defined by their disability (such as 
disabilities like arthritis, stroke, multiple sclerosis or paralysis) rather than their capabilities as expressed in the Social Model of disability as described in Section 2.4.2. The Social Model of disabilities could be used to consider how PMD users can be part of a society and are entitled to use their PMD for enjoyment and entertainment purposes. For example, it is not uncommon for athletes with disabilities to use PMDs for sporting activities; athletes use specialized sport wheelchairs that meet the speed and agility requirements of sports such as basketball, rugby, tennis, racing and dancing (Woude et al., 2006). For example, racing wheelchairs include tubular tires, lightweight rims, precision hubs, larger wheels and smaller push-rings (Brubaker, 1986). These PMDs have one sole-purpose, to optimize an individuals racing ability. Not only does the design of the PMD not address the "disability" as specified in the medical model, but the PMD is only designed for a racing function over PMD utility. Being involved in sports has broader implications and advantages for an athlete. Some of these advantages include the physical and mental capabilities, which can be developed during play and participation, many may in turn which improve a player's overall lifestyle and positive outlook on life (Woude et al., 2006).

An option that could be considered as part of the notion that PMD's can be used for multiple purposes is using them to play games. Because of the scooters advantages for outdoor activities it is possible that they offer some of the same advantages to users as sporting activities. However, creating games specifically for scooter users are required in order to consider these possibilities. Powered to Play is a representative example, which attempts to explore some of the crossover benefits of game play on participants using PMDs not well referenced in the literature. 


\subsection{PMD User Identity}

In this section, I consider how PMD's are embodied by their users: how PMD's play a role in the users life and the role of autonomy PMD's can provide. As a PMD becomes embodied by the user it changes their perspective and outlook on life. Increased autonomy is often a product of increased PMD use and changes how a user thinks about their PMD and life.

Mobility is generally defined as the ability to get from one location to another independently (Finlayson \& van Denend, 2003). There are many psychological as well as physical implications associated with the capability of being mobile (Wiart et al., 2004). For instance, increased mobility using PMD's can influence a person's self-image, self-esteem, opportunities to socialize with others leading to reduced isolation, decreased fear of rejection and abandonment, and stress (Wiart et al., 2004).

However, mobility can influence a person's perception of himself or herself in positive and negative ways. When a person acquires a mobility disability, the way a person reacts is often a reflection of the effect the disability has on the person's livelihood. All people react differently and since a disability usually changes a person profoundly, coping with disability can influence the personality of a person with a disability (PwD). Not only does the individual's outlook on life change but also that person's identity changes. A disability can impact the characteristics by which a person is recognized or known. PwDs have different amounts of time and responsibilities to adapt to their new identity among their families and friends, which can influence the positive and negative perception of disability through their PMD use. These roles may be much different from the user's past mobility capabilities and perception of themselves (Charlton \& Michalko, 2000). 
Reid et al. (2002) illustrated that the support of family and friends could provide a profound impact on the positive or negative attitude the individual has towards his/her PMD. Family and friends play a large role in determining the extent to which the individual remains social and included (Wiart, 2004). For example, PMD's often take more effort to transport making it more difficult for PMD users to visit family and friends. As a result, many PMD users require some time to adapt to and accept their devices, unless they have used the device from birth. Taleporos \& McCabe (2002) examined the self-esteem of individuals using PMD's to illustrate that selfesteem was higher for people who had been using PMD's longer than six years compared with those using their PMD under five years.

According to Rousseau-Harrison (2012), PMD users often embodied their PMD's as part of their identity after they had used their devices for some time (e.g., after five years of mobility use). For example, one individual stated that without his mobility device he would be confined to a bed (Rousseau-Harrison, 2012). Some users also referred to their mobility device as a new body part, for example, stating that the device was "now my legs" and a part of who they were. Sapey et al. (2006) explored this perspective further and found that device use is a part of rebuilding identity. Users usually established a link between their old selves and their new abilities in order to achieve full embodiment. The link is often a story identifying how the person's new abilities changed their outlook on life. For example, mothers who started using a PMD stated how positive the PMD was in allowing them to participate in household activities and their families after being isolated by a disability (Reid et al., 2003). Another example illustrates how PMDs provided younger children the opportunity to play with other children of the same age without adult interference (Wiart, 2004). Without the PMD the child was forced to either propel his or her own wheelchair or be pushed by a friend or adult (Wiart, 2004). This left 
the child less able to participate in many events autonomously. The ability to do things autonomously is strongly correlated with positive perceptions of self for PMD users over the long-term (Wiart, 2004).

Autonomy is provided to users through more than the functionality of a device or assistive technology. Autonomy is provided to users by the way products are designed (Kane, 2011). The design of a product can reflect a users identity by providing them with an improved sense of self worth and self-esteem. For example, Ravneberg (2009) reported that a young female who was hard of hearing wanted her hearing aids to look and feel more like earrings to express her identity and become part of her own fashion. Making the hearing aids more expressive not only provided the woman with a higher self-esteem and self-worth but it also provided the user to reflect her identity in the products she wore, emphasizing her autonomy.

Symbolic Interactionism Theory (SIT) demonstrates how people interact with others through objects (Solomon, 1983). Using SIT, it could be argued that the hearing aid user who wanted her hearing aids to be similar to earrings did so because her emotional state, self-confidence and identity were prescribed by the integration of the hearing aids into an acceptable form to support her desired physical appearance. It would seem then that a person's autonomy is affected by how a person is able to present themselves to others through the objects they use or consume.

As a contemporary designer, the job of the designer is to recognize that the products a person uses means more to the individual than the functionality of the product. This means that as products play an increasing role of a person's identity that the expression of a person must also reflect the person's autonomy. SIT theorizes that products are consumed based on their social meaning rather than on their functional utility. Consumption is an integrated 
part of social life, the "experiential view" emphasizes that using products are based on fantasies, feelings and fun (Solomon, 1983). As PMDs and games offer users new capabilities they would not have experienced otherwise they could be provided with more autonomy. This autonomy will be the product of using PMDs for a new purpose and allowing PMD users the opportunity to express themselves through game play.

\subsection{Models of Disability}

This section provides an overview of the Medical Model of Disability and The Social Model of Disability. It explores how PMD users interact with their communities in terms of the economic, political, social and their entertainment prospects. In this section, archival materials, oral accounts and secondary analyses are used to illustrate an understanding of PMD community outlook and explore the relationships between PMD users and their communities.

\subsubsection{Medical Model of Disability}

The Medical Model of Disability is a socio-political model of illness founded on how a person's physical condition reduces their quality of life (Brisenden, 1986). The Medical Model focuses on curing or managing illnesses from a clinical perspective. The model focuses on identifying the illness, understanding the disability and learning how to control and manage it. The model is based on the assumption that there are solutions to health problems and ailments (Brisenden, 1986). As a result, it assumes that disabilities require repair (Charlton \& Michalko 1998). This intrinsic assumption creates several problems for people with disabilities. The most prevalent is that people with disabilities have a different perception of their disabilities than most medical practioner's (Charlton \& Michalko, 1998). The foremost perspective being that human bodies are one part of a whole patient. A patient has social, economic and political components 
in addition to their physical anatomy. By dissecting the human being into intricate parts, such as cells, organs and bones the Medical Model assumes patients are viewed as parts of a whole instead of as full individuals (Brisenden, 1986).

In a society where medical practitioners' operate as a mediatory between resources and patients this assumption can make it difficult for people with disabilities to assert their entitled rights to social, entertainment, political and economic resources. Without support from society the burden of disability is placed on the individual. For example, many people require the disability label to obtain extra income support, assistive technology acquisition or educational support (Bevin, 2009). Without a medical practitioner supporting an individual's needs for these resources, people with disabilities often have to go without. As a result, many disabled individuals are left behind in terms of their social, entertainment, educational and their economic needs (Lipson \& Rogers, 2000). For instance, PMD users may not be provided the same entertainment opportunities as their peers since entertainment resources such as games or gaming technologies may be viewed as a "luxury" by medical practitioners and a society. The Medical Model negates the patient's needs for entertainment and designates such needs as outside the scope of medical care. To justify the need for equality, the Social Model of disability, which provides a more comprehensive view of the individual and their needs should be considered instead.

\subsubsection{The Social Model}

The Social Model of disability is a reaction to the dominant medical model of disability. It identifies systemic barriers, negative attitudes and exclusion by society as the main contributors in disabling individuals. Many PMD users have become frustrated with the Medical Model 
because it fails to provide a holistic method of 'treatment' to their perceived 'illnesses'. PMD users indicate that treating illnesses is a part of a broader approach to healing which includes the economic, political and social factors consistent with a patient's well-being (Brisenden, 1986). What underpins the Social Model of Disability is equality. Equality is underpinned by entitlements to equal rights and accessibility to participation in economic, political, environmental, social and entertainment opportunities within the communities people with disabilities live in (Charlton \& Michalko, 2000).

Hughes \& Paterson (1997) suggests that many PMD users support the Social Model of Disability seeing their impairments such as physical, intellectual or psychological limitations as part of their identity. Instead, they view disability as a consequence of how people become isolated and excluded from full participation in their communities whether the exclusion be from technologies, services, activities or environments (Hughes \& Paterson 1997). This research explores access to social and entertainment resources, specifically within technology and computer gaming. The Social Model of disability provides PMD users a rationale for why entertainment, such as games are products they should be able to access like everyone else. Furthermore, the Social Model makes it clear that by removing the barriers from society, people with disabilities are granted greater access to economic, political, social and entertainment opportunities in their society, a benefit to all.

\subsection{Design Applications and Theories}

This section provides an overview of design theories used as a basis for the development of the Powered to Play project including my component of it. It explores how design theories produce more effective information systems and products (Walls, 1992). More effective design 
processes include the motives and perceptions of people using products and services. Theories of design are atypical because they prescribe how something can be done. The primary design theories discussed in this section include: Inclusive design and Crowdsourcing.

Inclusive design focuses on factors that cause "design exclusion" (Keates \& Clarkson, 2003). Design exclusion occurs when designers unintentionally create a product or service, which restricts certain individuals from using it (Keates \& Clarkson, 2003). Inclusive design involves identifying the needs of individuals and creating solutions to deal with those needs. As a result, specified measurements of success must be used to ensure that the design has considered the stipulated requirements of the individual's diverse set of needs. Inclusive design was developed as a reaction to the Design-for-all theory, which assumes that products or services can be developed for all users. Inclusive design theory disputes the concept of designing for all and instead promotes the idea of "designing for one" (Kane et al., 2011). The rationale behind this dispute is that Inclusive design establishes that it would be impossible for a designer to imagine all the possible exclusions of a product can create. As a result, "designs cannot scale to address the needs of every individual with abilities different than the societal average. Instead, "abilitybased systems that can observe and accommodate users directly have a much better chance at scaling to the majority of users" (Kane et al., 2011, p.g. 6).

In addition, in Inclusive design users are considered at the beginning of the design process rather than at the end (a centric design process). As a result, inclusive design offers a framework and starting point to focus on the user's abilities and design for the specified ability-based user group. Idea Jams embody the use of inclusive design by enabling participants the opportunity to contribute to the design of a product in the beginning of the design process, allowing them the 
opportunity to voice their abilities and opinions on the type of product they would like to use, which in my research study is a mixed-reality game (a type of video game).

The concept of Inclusive design is based on a barrier-free concept and when applied to video game design is used to provide people with better access to a gaming environment. Since Inclusive design objectives are to reduce the physical and attitudinal barriers between all different types of people and provide specific user group's access to products, it provides the motivation for including PMD users in the production of entertainment products. Games, like other products, should be built with target users in mind. To achieve this goal designers who use Inclusive design are required to understand the user's needs that include PWD, how they can be met, and the effectiveness of the product, thing or environment in meeting those needs or if any improvements can be made to the product or thing currently in use.

In my research, Inclusive design is used to understand how PMD users think they can use the environment to their advantage when playing a game. For instance, PMD use could affect which types of outdoor games they enjoy based on their capabilities and limitations. These capabilities and limitations may influence the type of games users want to develop and the functionality, genres and priorities they wish to see in a game developed for them. Participants could be in the unique position to empathize with other participants who may have experienced similar mobility problems or limitations. As a result, from their similar experiences they may offer compelling rationales for different game designs based on their common viewpoints. Using an inclusive design approach in my research offers an outlet for enabling people with disabilities the ability to influence how game designs are developed. 


\subsubsection{Idea Jams - Crowdsourcing Design}

Crowdsourcing is taking a job traditionally performed by a specific agent, such as a person working within a specific organization, and delegating it to an undefined, generally large group of people in the form of an open call outside of the organizational context (Howe, 2006). It can involve a division of labour, a quest to apply specific requests or a general search for answers to a question. The crowd (typically strangers) can consist of an online community, employees from a business or even a group of people meeting together face-to-face (Howe, 2006). The process combines the efforts of the many where each contributor adds a small portion to a greater result. The word Crowdsourcing comes from the "crowd" meaning the undefined public and sourcing refers to delegating a task, which is the work being commissioned to the public (Howe, 2006). There are two main types of Crowdsourcing in which these activities occur, in the implicit and explicit settings. The explicit setting is where people can share ideas, build artefacts and edit other people's work. In the implicit setting people usually do not have the full picture to what the work they are doing contributes towards, since they might be working as part of a larger project or working on a project for a third party (Howe, 2006). The people who contribute to Crowdsourcing activities are motivated through two main reasons: intrinsic motivations such as social contact, intellectual stimulation and entertainment or extrinsic motivation such as monetary gain (Kee, 2010).

Currently, most Crowdsourcing activities reside on the Internet, which provides an open platform where individuals tend to be more open because they are not physically judged or scrutinized (Byren, 2013). As a result people often are comfortable with sharing their opinions and can pay more attention to the project instead of to communication with other individuals (Byren, 2013). 
There are three major forms of Crowdsourcing identified by Byren (2013):

"1. The prediction market, which functions similar to a stock market where individuals open an account and buy and sell shares, such as the winner of a presidential contest."

(Predictive markets are speculative markets created for the purpose of making predictions. For example, predictive markets can be used by gaming companies to take into consideration the sales of video games in the future as a current valuation of the company's stock. This valuation is based on the predictive value of how many video games the company believes will be sold in the future and how likely an investor believes the company will reach that target when buying the stock, determining how much they are willing to pay for it).

2. "Crowdcasting is essentially problem-solving, in which someone with a problem broadcasts it to a large, undefined network of potential solvers who then attempt to solve that problem.

3. Idea Jam is a brainstorming session closely resembling crowdcasting, however, with an undefined result. It is used to generate new ideas of any kind instead of solving a particular problem" (P.g. 9).

Idea Jams enable a cost-effective way to innovate new ideas, solutions, services and products (Byren, 2013). For most organizations, they offer a method of gathering new ideas while obtaining goodwill and positive public relations with users or consumers (Howe, 2009). Idea Jams enable organizations to accomplish this by reaching out to consumers and providing them 
with an outlet for communicating their opinions and ideas about a product. The outreach provides users with the opportunity to connect with a product through discussion and potential to see their ideas implemented. Brabham (2012) also emphasizes that Idea Jams ensure that people are engaged in the innovation process, since the more intimate setting of having a small group of people share ideas illustrates transparency and openness. This provides the participants with intangible values such as the experience, emotions, accessibility and identity with the product or the ideas developed.

Crowdcasting and Idea Jams are more relevant in the innovation and development of new products, such as a mixed-reality game for PMD users. Crowds can consist of anyone including self-selected professionals to ordinary individuals (Brabham, 2012). Boudreau \& Lakhani (2013) also point out that having participants in Idea Jams with people from different backgrounds can benefit designers since complex solutions to problems can often come from experts in other fields.

\subsubsection{Crowd Intelligence}

The value of Crowdsourcing, particularly in Idea Jams, is well articulated by (Byren, 2013): "The power of Crowdsourcing lies in its ability to draw from a diverse (set of) intellectual backgrounds where networking technologies link the widest possible range of information, knowledge and expertise" [pg. 14]. Homogenous groups can be more cohesive which allow their members to become more dependent on the group, falling into a certain pattern of thoughts and a sense of their group's superiority, a phenomenon known as "groupthink" (Byren, 2013).

In Crowdsourcing, the crowd is not as affected by the group, thus ensuring a level of diversity in opinion in Crowdsourcing sessions. Byren (2013) further illustrates that intelligence alone 
does not provide a good solution to many problems because the collective performance of a large group will have more experiences and knowledge than a smaller group of professionals. As a result, a smaller group narrows possible solutions whereas a larger group allows for more possible solutions. Crowdsourcing implies that every individual has a more complex set of skills than what can be shown by education and qualification" (Howe, 2009). Von Hippel (2005) also supports this view by exemplifying how users can combine their unique skills to innovate unfamiliar products operating in a decentralized way. "Decentralization is important for collective wisdom because it combines and aggregates diversity, specialization and independence, which increases the information in the system as a whole" (Byren, 2013,pg. 14).

\subsubsection{Crowd Management}

Howe (2009) states that for an Idea Jam to operate well it requires a close collaboration between the crowd and the people who manage it. The crowd requires rules and prerequisites to operate within. For example, the needs of the crowd must be focused and the group of people seeking a solution to a problem must communicate how the crowd's ideas will be used. The ideas must be moderated and decisions made on what ideas to aggregate into solutions. It is still possible that groupthink could occur if there are self-proclaimed experts or if the group is not open to new ideas. In the Powered to Play Idea Jams it is important to provide participants with a guiding overview of how their contributions were going to be used and applied to the game being developed.

Finally, it was important to recognize in the Crowdsourcing process that many ideas and solutions that come out of the Idea Jam were likely to fail. Participants of the Powered to Play Idea Jams were notified that it was alright if their ideas did not seem plausible to develop in a 
game and all ideas were worthy of consideration. Participants were told that the objective of the Idea Jam was to initiate new ideas to be developed not to create a game within the session. Furthermore, having a high acceptance rate of failures can be a good sign of fostering innovation within a group or organization (Howe, 2009).

\subsection{Gaming Applications and Accessibility}

This section provides an overview of games, video games and how play is an internal part of the gaming experience. It explores the concept of a mixed-reality game, some of the hardware used in these types of games and how entertainment can be made accessible.

\subsubsection{Games}

A game is a form of structured play (McLaughin et al., 2012). A game is usually played for the participant's enjoyment and is sometimes used for the participant's education (McLaughin et al., 2012). Games are distinct from art and work, which is usually done for payment, aesthetics or ideological expression (Yuan et al., 2011). There are numerous benefits to people who play games. Yuan et al. (2011) suggests that games provide mental or psychological stimulation to players. Many games aid the participant's development of practical skills; they serve as a form of exercise or perform educational, situational or psychological roles (Weiss et.al, 2003).

The key components of games are the goals, rules and interaction of the game. Games goals are the objectives of how a game can be completed, whether by scoring points, solving puzzles or following a storyline. The rules of a game include the context in which the goals can be pursued, for instance, in a soccer game players are not allowed to use their hands to score points. While the interaction of a game includes how the participant interacts with the game, whether it is on a physical field or on a computer screen to be played upon. Games can include socializing 
with others, the plot, narrative, story, setting, user interface, items and gaming character which all interact with players to provide them feedback on how the goals of the game are being achieved.

Games offer participants a system in which players interact with each other or with game elements to solve an artificial challenge (Breen, 2009). To make a game fun, play is usually involved. Structured play is defined by goals and parameters within a specific context (Rieber, 1996). Unstructured play is without rules and includes the imagination. Play promotes adaptive behaviours and mental states of happiness or fulfillment (Rieber, 1996).

Much of the literature on play describes one of the following themes: 1) play as a mode of progression or as a way in which a person learns; 2) exploring aspects of power relations, such as how different hierarchies work in social play; 3) fantasizing about different aspects of life, such as future events like a wedding or parental role; and 4) exploration of self, such as exploring personal interests or hobbies (Rieber, 1996).

Play often has the following qualities: 1) the activity has an intrinsic motivation; 2) the activity is voluntary; 3) there is some type of activity achieved by being involved; and 4) there is some portion of imagination incorporated into the game (Rieber, 1996). Much of the utility of games can be drawn from a game's micro-world where players can simulate actions without the danger of real world consequences. This world requires the players to make choices, which are supported by the game system, and the outcomes are meaningful to the goals in the game (Chen, 2007). 


\subsubsection{Mixed Reality Games}

The utility of offering players the opportunity for social interaction in multiplayer game play was not lost on early researchers of mixed reality games. One example was the development of the game called Pirates! (Bjork et al. 2001), which aimed at creating a social, context-aware mixed reality game duel combat. Another game called Game-City (Cheok et al. 2002) was used to play a city-wide multiplayer treasure hunting game where players were required to hunt for physical treasure boxes containing virtual treasures. A mobile mixed reality version of capture the flag by Cheok et al. (2006) was also developed to explore social co-located roleplaying.

In the development of Powered to Play many of the game components were designed on the elements of prior mixed-reality work. For example, the geo-location, virtual gaming elements, smartphones and the use of publicly available digital services were developed based on the taxonomy developed by (Benford et al. 1998) in conjunction with the Idea Jam drivers of this game. Their taxonomy proposes to create a shared mixed reality based on the construction of transparent boundaries between real and virtual spaces. The taxonomy is based on the shared spaces of transportation, artificiality and specificity.

Transportation refers to the extent to which a group of participants and objects leave behind their local space and enter into some new remote space to meet with others. For example, a faceto-face meeting in augmented reality is where a meeting takes place in a physical world and in a virtual space (Schlieder et al., 2006). The meeting of people in the augmented reality is virtual while gathering participants at their computers is real. Without the participants using their computers in the physical world there would be no meeting in the virtual space. Artificiality 
refers to the extent to which space is either synthetic or based on the physical world. For example, video conferencing streams real images from the physical world. While Specificity refers to the level of support for fundamental physical spatial properties such as containment, topology, distance, orientation and movement in regards to the space in which a user navigates. In Powered to Play these domains are illustrated in the game play, interface and the platform in which the player works within. The domains are represented by: 1) the transportation through the physical environment in which the game is played; 2) the artificiality through the interface where the player is viewing the networked locations of other entities on a screen; and 3) the specificity through the platform of the game, which encompasses the location of the entities within the virtual space (Benford et al. 1998).

\subsubsection{Gaming Hardware}

Various types of physical interaction are required for people to play games. (Barlet \& Spohn, 2011). Players must control input and output systems (i/o), such as keyboards, mice, switch inputs, vocal joysticks, brain wave controllers, eye controllers, or mouth controllers to play. Despite availability of alternative input and output devices, disabled audiences can often be limited in their ability to access all of the choices efficiently and effectively, excluding them from many game play experiences (Atkinson et al., 2006). There are some alternative options available for disabled users such as one-switch controllers that can be adapted for game input or magnified displays for game output, however, the majority of games are difficult to modify once they are fully developed (Bartlet \& Spohn, 2011).

Although some modifications are possible for games, such as through mods or reverse engineering most games remain inaccessible for the disabled user. Powered to Play confronts this 
failure by addressing the modification question in the design stage of the game development. Idea Jams are used to include participant concerns and ideas in the game development process which can then be addressed in the design of the game at the beginning stages of development, instead of ad hoc changes being made for people with disabilities after the product has already been developed. Approaches to game design that are accessible and inclusive, such as accessible game design and entertainment particularly for children, are appearing in response to increased awareness of these issues (Bartlet \& Spohn, 2011). However, accessible gaming remains under explored for adult PMD users, this includes both input and output features for games which can include people with physical limitations.

\subsubsection{Accessible Entertainment}

Accessible entertainment is based on providing pleasurable activities and experiences for all people regardless of their abilities. Accessible entertainment, specifically computer games when designed inclusively, can provide social, rehabilitation, creative opportunities and personal autonomy for people with disabilities (Gamberini et al,. 2006). It is well known that people with disabilities want to have the social opportunity to take part in computer games. For example, Flynn et al., (2010), found that approximately 50\% of people with a disability, especially older adults, used a mobility assist of some kind to play computer games and would play more games if games were more accessible to them. Evidently there is a large market of potential gamers willing to play but are shut out of the video game market due to a disability.

Although virtual games have become more accessible through a variety of changes such as keyboard shortcuts, close captioning and various interface developments, there is still much work to do for the disabled gamer (Bartlet \& Spohn, 2011). For example, the study by Flynn et al., 
(2010) demonstrates that approximately 24.7 million people in the USA have never been given the opportunity to play a video game because of a disability. One contributing factor to the poor pace of game development for accessible entertainment is lack of game development purpose. For example, many games have been developed for non-entertainment purposes, such as PMD adoption. Examples include games such as GameWheels (Fitzgerald et al., 2006) which is a game developed to help wheelchair users learn how to drive; the tool is clinical in nature and restricted to wheelchairs. Another study called Virtual Reality Wheelchair Soccer (Rossol et al. 2011) was created to help aid patients become accustomed to wheelchair use and aid in their rehabilitation.

However, games for PMD users have not been designed from the ground up to be used for entertainment specifically. One of the primary challenges in facilitating the development of virtual entertainment for PMD users is the widespread misconception of PMD user interest in games. This is compounded by a lack of designers and stakeholders willing to design in ways that are inclusive or universal (Abascal \& Nicolle, 2005). The Powered to Play project is a step towards exploring how a group of individuals with a PMD play games, what characters they enjoy, how they feel about playing games and how to improve their gaming experience. It is well established that players with disabilities would appreciate games with a more "universal game design" as exemplified by the demographic surveys clarified by Flynn (2010). In these surveys participants were keen to reference how they were restricted from playing games they desired to play and how these games could be made more accessible to them.

To create more inclusive opportunities for PMD game play, games should not only aspire to be fun, they should also account for differences in needs, abilities and interests of 
adults, including using larger fonts, alternative input and output modalities (Crawford et al., 2008) and slower pacing (Clark et al., 2003), having fewer distractors, and including other age generations (Gamberini et al,. 2006). Powered to Play attempts to take into consideration many of these a accessible principles by asking PMD users how a game can be developed with the disabled user in mind.

\subsubsection{Cross-Generational Gaming}

Video games are increasing in popularity, specifically for older adults and people with disabilities. Flynn (2010) found that the average age of an online gamer is 34 years old with an average of 12 years of experience of playing games. The average age of the typical gamer consumer is getting older and these individuals will begin experiencing more disabilities as they age. There are many benefits of playing video games for older adults including opportunities for social interaction (Shim et al., 2011), reduced isolation due to socio-environmental factors, and improving physical wellbeing, self-esteem, feelings of success, self-expression and achievement (Khoo et al., 2008). Given that there are so many benefits, it would seem that not only would older people want to play games but also that they are a worthwhile target audience for game development.

Currently, however, social interaction for older adults is their primary motivation for game play. In study called Table Talk Poker by Shim et al. (2011), 50 elderly (over the age of 60) participants were studied playing an online poker program. What researchers found was that participants were not as interested in playing the rounds of poker as they were in the instant messaging boards or the option to video chat with one another. In this game poker was not played in continuous rounds, but instead time was given between each round so that participants 
could have a chance to socialize, highlighting the importance of socialization in games for older adults.

However, only $29 \%$ of gamers are over the age of fifty. What is it about current games that are not attracting older adults? One of the stated desires of for game play is that they are seeking ways to interact with younger generations (Barlet \& Spohn, 2011). New games in which diverse age groups and people with different capabilities can interact together in a virtual space are increasingly becoming mainstream. For example, approximately $67 \%$ of American households participate in some type of virtual gaming (Barlet \& Spohn, 2011). Age Invaders is a game that offers an example of how children and older adults are interacting with one another and creating friendships within a virtual space. The mixed-reality game uses a physical platform, and requires and encourages physical body movements for players of different age groups to try and avoid being targeted by other player's lasers and to avoid being shot by opposing players on the game board (Khoo et al., 2008). The virtual component of this game is played on a giant screen whereby the participants of the game have to physically move themselves out of the way to avoid being shot by an opponent. This game adapts the game play according to the age of the player, making it easy for anyone to learn the game (Khoo et al., 2006).

Providing older gamers with diverse gaming roles, such as being a coach, teacher, peer, mentor, and/or learner (Shim et al,. 2010) helps older participants engage with others in new ways. For example, Derboven et al., (2011) found that intergenerational gaming had therapeutic effects on older adults by giving them a motive for socializing. In their study, grandparents were paired with grandchildren and the pairs memorized a shopping list before going shopping in a virtual grocery store together. The objective of the game was to try and remember as many items 
on the list as possible. This gaming experience cognitively challenged the older participants, as well as challenged them to partner and socialize with individuals in different age groups.

Similarly in a study by Voida \& Greenberg (2011), different age groups were provided the opportunity to take on diverse gaming roles and support one another, giving each age group unique learning opportunities when playing games. This was characterized by the comfortable meeting place offered by the games virtual reality and the competition offered through the game play. In this study 36 participants were asked to play a variety of games, such as basketball, golf, baseball and many other games in pairs of two or three individuals consisting of different age groups. It was found that the different age groups offered unique insights into gaming strategies. For example, children were given the opportunity to lead others and practice leadership roles while grandparents were given the opportunity to play explorative roles they might not typically have played if playing independently.

\subsection{The Social Aspects of Virtual Games}

This section provides an overview of why people play games; how Entertainment theory and Flow theory play a role in why people play games and some of the underlying reasons Idea Jam participants were motivated to express their ideas for game play.

\subsubsection{Entertainment Theory}

People play games for many reasons, for the: adrenaline rush, adventure, mental challenge, the structure, solitude or the social aspect of playing with others. People play games for many types of experiences, to overcome difficult challenges, to seek relief from every-day worries or to pursue puzzles (Nilsen et al., 2004). To discover what makes a good game, a games value is derived from how it makes its users think and feel (Vorderer et al., 2004). The way games make 
their participants think and feel is based on the way they are consumed and the way games are consumed is linked to Entertainment theory. Games are a form of entertainment and there are many reasons people wish to be entertained.

Video games are associated with many positive attributes including the improvement of an individual's pleasure and aroused behaviour (Khoo et al., 2008) where pleasure is the feeling of satisfaction or enjoyment while arousal is the feeling of being awakened or responding to an emotion. By understanding a user's preference for entertainment, designers can work knowing user preferences and what elements they would like to experience. For example, Vorderer et al., (2004) illustrated females and males do not have the same gaming preferences and as a result, there are different product lines for video games targeted for male and female users. Although in this example, the difference in user preferences are based on gender, there are many variables, which can influence the experience that a player takes away from a gaming interaction. This means that designing for particular user groups such as males or females can provide a significant impact to the games design. This is also true for the PMD user group.

The more meaning derived from a player's experience with a game provides a him/her with the enjoyment or entertainment he/she gains from interacting with a product, such as a video game. If a game is not developed for a disabled user they might miss out on some aspects of a game (due to a limitation or disability), neglecting the player the full experience derived from the game and decreasing the games meaningfulness. In addition, meaningfulness is required for players to continue an activity, such as game playing. Vorderer et al., (2004) developed a model for entertainment motivation on entertainment theory where enjoyment was defined as a pleasant experiential state. The state of pleasure consists of physiological, cognitive, and affective 
components a player feels while playing the game. Vorderer's model can be described through two dimensions: the enjoyment and appreciation the player experiences while interacting with the game.

Appreciation is influenced by three factors: relatedness, competence, and autonomy (Gibson, 2006). Relatedness refers to how the game relates to the player's personal experiences while competence refers to how the skills and abilities of the players are applied in the game. Finally, the autonomy of the game is based on how the interaction of the game makes its players think and feel about themselves. How the player thinks and feels about himself or herself in relation to their independence affects the players perception of their feelings of satisfaction, arousal and positive self-actualization through self-expression in the game play experience.

Enjoyment is influenced by comprehension and pleasure. The comprehension of the game is based on how the player understands the games interaction and how it progressively is associated with the challenge and gratification of the game goals being fulfilled. This pleasurable experience is more intuitive to the nature of the game and its consumption. It is also linked to Csikszentmihalyi's theory of flow since enjoyment is the result of engagement in an activity. Furthermore, the questionnaires used in my research are designed to follow the principles of entertainment theory and the theory of flow by answering questions based on the participants ' level of enjoyment in the Idea Jam experience' or how participants "liked the games discussed."

The theory of flow analyzes the aspect of what makes activities enjoyable through the pursuit and focus required in a game (Csikszentmihalyi, 1990). One of the primary goals of game development is to influence individuals to function at their fullest capacity and making the game play its own intrinsic reward. 
The concept of flow was developed by Csikszentmihalyi (1990). Flow is described as a cognitive state of intense euphoria which a person gets when being highly concentrated on a task or activity (Johnson \& Wiles, 2003). The concept of flow was developed in an attempt to understand human happiness and is used to represent the optimal human experience when taking part in an activity or task. The activities that induce flow are autotelic, meaning that they are done for their own intrinsic rewards with no concern for current or future benefit. Thus, people continue to take part in flow-oriented activities simply to continue doing them for the enjoyment they receive from performing them. One of the primary goals of a game developer is to create a game whereby the game play becomes its own intrinsic reward or induces the player into a state of flow when they are playing.

Csikszenmihalyi developed the concept of flow by studying top performers such as athletes or artists from a variety of different fields. His intention was to understand the type of mindset people experienced when they were in their optimal state of performance. From his analysis he was able to conclude that people often described their happiest experiences in terms of being in a flow-like state (Csikszentmihalyi, 1990). From this analysis, Csikszentmihalyi was able to conclude that while in the state of optimal experience, a person is more motivated, happy and efficient in the activity as they are increasingly absorbed by it (Johnson \& Wiles, 2003). However, the state of flow is more than simply experiencing pleasure, it requires a players full attention when he/she is interacting with the activity (Sweetster \& Wyeth, 2005).

There are nine conditions found by Csikszentmihalyi (1990) that describe flow. First, most flow-oriented activities have tangible goals and rules, which are required to partake in that activity. For example, games have rules, such as there are no hands allowed in soccer or in 
Powered to Play where the player requires health to capture their opponents flag. Second, it is important that those goals provide the person with immediate feedback from the experience. However, this does not mean that flow states are inherently limited to physical activities but rather, third that a person's skills and abilities must be sufficient to face the challenge the person is experiencing during that activity (Csikszentmihalyi, 1990). If the activity is too difficult, people experience anxiety, while if it is too easy, the participant becomes bored and tires of the activity's pursuit. Fourth, flow can only be achieved when there is a congruent match between a person's skill and the challenge administered by the activity. At the point of congruence the person would enter into the state of flow.

Fifth, when a person enters the state of flow they often lose their sense of time, and distractions from other sources become limited, allowing for an enjoyable experience. For example, in Powered to Play the participant could be attempting to capture an opposing team's flag by avoiding opponents on their smart phone app and by dodging opponents in the physical world through one-on-one combat. Each of these challenges is a type of goal within the game, which would be required to be overcome by the player. While a player works to achieve all of these goals they would be improving many skills and potentially undergoing self-growth, such as improving driving skills. Seventh, the player would also likely experience a loss of selfconsciousness as they intensely focus on achieving these goals. Although the player loses selfconsciousness it does not mean the mind is absent from the behaviours associated with the activity. For example, a Powered to Play player may not necessarily be focusing on moving towards the flag and consistently making the movements to pick-up the flag when it is in reach, rather this may be an automatic response for good players. Instead, the player may be focusing on the higher functions of the task such as understanding where they are in relation to their 
teammates in an attempt to anticipate their opposing team's actions to play the game to their own team's advantage. Eighth, to maintain their state of flow, players require being in a position of control or at least the perception of control. For example, the Powered to Play player would need to believe that he has control over his PMD to make the required movements to get to the flag and manoeuvre through opposing team members in an attempt to capture it. Ninth, the experience of flow must provide the participant with an intrinsic reward. Participants must continue to interact with the activity for their own enjoyment.

Each of the flow conditions does not need to be present in order for a person to experience flow when engaging in an activity. However, for the game developers of Powered to Play the goal is to produce a game with as many of these flow elements as possible. For example, the game requires a challenging activity that requires skill for the players to navigate and overcome, such as attempting to capture their opponent's flag. The tasks in the game will require clear goals and immediate feedback, such as how the players will instantaneously receive points when the players capture their opponent's flag. Finally, to capture their opponent's flag the players will be required to use much of their concentration to meet the goals of the game, losing selfconsciousness, their sense of time and their perceived sense of control over the actions they are fulfilling in the process. 


\section{Chapter 3. Methodology}

\subsection{Research Questions}

This research aims to examine the types of games and game elements PMD users would prefer to have developed based on their input. This research also considers the impact of having PMD users participate in the early stages for design of an actual game developed. The two research questions are:

1. What game genres and functionality (game objectives, characters, input/output, audience integration and rewards) would PMD users be willing to consider and use in indoor/outdoor spaces?

2. How do these preferences and user input influence the design of actual game functionality and priorities?

\subsection{Research Design}

In order to examine research question one, five Idea Jam sessions were organized to elicit user ideas about games and game play functionality. Idea Jams are a type of focus group in which stakeholders actively contribute ideas to a specific challenge (Byren, 2013). They are also a type of Crowdsourcing activity, which is the act of taking a job traditionally performed by a designated agent (usually an employee in a company) and delegating it to an undefined, generally large group of people in the form of an open call (Howe, 2006). Internal Crowdsourcing refers to an organization extending its problem-solving to a large and diverse group of self-selected contributors, known as agents, and that extends beyond the formal internal boundaries of the organization (Byren, 2013). For my research I used an internal Crowdsourced methodology where the organization is the Inclusive Media Design Centre at Ryerson University 
and the agents solving the problem are the researchers who opened the discussion to the participants in the study.

According to Yuen et.al (2011), using a Crowdsourcing methodology can offer a more representative sample of participants for research. Crowdsourcing can increase generalizability by attracting a more diverse population to a study based on the participant's age, gender, ethnicity, nationality, education level, employment status and profession (Behrend et. al 2011). An example of a Crowdsourcing application used to recruit research participants is Mechanical Turk (Behrend et al., 2011). In Mechanical Turk, research participants can complete surveys or be recruited to attend an in-person study. Crowdsourcing can also offer more reliable data than a traditional focus group or completing a survey, by enticing participants to take part in a study for motivations other than financial compensation. For instance, although most participants in Behrend et. al (2011) "indicated that financial incentives were the primary reason" (P.g. 809) for engaging in Crowdsourcing activities, educational and entertainment benefits were also listed. Whereas financial compensation for traditional focus groups would be more common since participants would normally be recruited from a target population and asked to answer specific questions pertaining to a study. In Crowdsourcing the different motivations or enjoyment for participating in a study such as the Idea Jams reported in this thesis, may mean that participants would be more actively engaged and willing to contribute their own ideas.

In my thesis, an Idea Jam as a form of Crowdsourcing was used as an user-centred exploratory research method rather than a formal focus group because it enabled researchers to gain a more diverse demographic from a very small PMD population in Southern Ontario, Canada, and encourage ideation which is not usually a goal of focus group methodologies. The 
wide demographic PMD sample used in this studies Idea Jams increased perspectives for ideation for the game design process by incorporating thoughts and suggestions from PMD participants of all ages, ethnicity, nationality, educational level, employment status and profession. The primary use of focus groups is on exploring the opinions of participants, whereas for Idea Jams it is to allow participants to explore their ideas in free association with their peers (Morgan, 1998). Moreover, since focus groups typically use a set of questions for asking participants in a study about their thoughts or experiences, asking questions can narrow the scope of ideation for game development by framing a discussion. Instead, I wanted participants to be involved in creating and discussing ideas and the Idea Jam methodology allowed participants an opportunity to accomplish this objective.

The Idea Jam's data was then used to inform the development of an actual mixed reality game. Demonstrating how the principles of the Social Model of disability can be applied in game design (research question two). The research is thus discussed in two main sections: 1) collection and analysis of Idea Jam data; and 2) discussion of the Idea Jam results as applied to the development of the actual mixed reality game, 'Powered to Play'.

Idea Jam sessions consisted of three phases: 1) a pre-Jam questionnaire, 2) a discussion of game preferences and ideas for a game specifically oriented to PMD users which was video recorded; and 3) a post Jam questionnaire. Qualitative data were analyzed using a thematic analysis to find the predominant game themes that participants brought up in the Idea Jams. This quantitative data were analysed through non-parametric (Mann-Whitney, chi-square) and descriptive (median, mean and standard deviation) statistical methods and the results were used to create the Powered to Play game. 


\subsubsection{Recruitment}

Prior to participant recruitment, an ethics application was submitted to and approved by the Ryerson Research Ethical Board (REB) (see Appendix 1). Participants were first contacted with a short research outline through personal contacts and email lists provided by various sources such as Variety Village. If people were interested in participating, they were invited to an Idea Jam session at a location convenient to them. Only adults who used a PMD were recruited in this study. Participants self-identified as PMD users; there was no specific experience requirement of PMD usage.

Once at an Idea Jam session, participants were provided with an information form that provided more detailed information including study summary and study process. After being informed about the study participants were asked to sign the consent form for the study (see Appendix 2) and begin their Idea Jam session.

Idea Jams were held at three different locations: Variety Village, the Sunny View Public School and at Ryerson University. The first location, Variety Village, is a recreational facility, which offers programs for people with disabilities (Variety, 2013). Three Idea Jams were held at this location, consisting of six participants in total.

The second location used was Sunnyview Public School where the Toronto Powered Wheelchair Hockey League (TPWHL) practiced and played games. The Sunnyview TPWHL brings players together to play competitive floor hockey. It is a program run for young adults who have limited upper body strength and mobility (TPWHL, 2013). Two Idea Jams were held at this location and approximately 15 participants were involved. The TPWHL Idea Jams had participants who used powered wheelchairs exclusively while the other four Idea Jams had 
participants who used both types of powered mobility devices (using either a powered wheelchair or a scooter).

Finally, the last location of the Idea Jam sessions was held at Ryerson University. Ryerson is a university in Toronto, Ontario. At Ryerson approximately three individuals participated in one Idea Jam session.

\subsubsection{Questionnaires}

Participants in the Idea Jams completed one pre and one post Jam questionnaire.

\subsubsection{Pre-Jam Questionnaire}

The pre-questionnaire had 16 questions that asked about demographic information and participants' expectations and experience with games. There were six questions for demographic information: age, sex, educational attainment, level of experience participants had with their PMD and two open questions about the participants positive or negative feelings towards their PMD. Next, there were four questions regarding participant's familiarity with technology including computers, video games, and the types of video games they played and how often they played them. Finally there were six questions that asked participants about games including how often they played physical games, the types of games they played, the motives they had for playing games, if they had ever played a game while using their scooter and what video game characters they liked the most (see Appendix 3 for the pre Jam questionnaire)

\subsubsection{Post-Jam Questionnaire}

The post-questionnaire (See Appendix 3) had 20 questions about participants' evaluations of the Idea Jam broken down into five sections. The first section contained ten questions relating to 
gathering opinions about participant's Idea Jam experiences, seven questions in the second section related to how much impact the Idea Jam made on participants', if there was enough time and what they found most and least rewarding about the Idea Jams. The third section consisted of one question in the post-jam questionnaire asked participants what they thought of the games discussed in the Idea Jam and if they would consider playing them. The fourth and final section consisted of two questions in the post-jam questionnaire asked what types of games the participants might like to explore in future work and if the participants had any comments or concerns. There were three ways of completing the pre and post jam questionnaires: 1 . answer the questionnaire online and send it back to the researcher; 2 . answer it through phone interview; or 3. answer the questionnaire at the Idea Jam with the help of a researcher. Participants were able to choose the most convenient method for them.

\subsubsection{Participants}

Twenty-seven participants completed the pre-Jam questionnaire, however, six participants had to drop out for personal or transportation reasons. As a result, twenty-one participants took part in the Idea Jam sessions. Of those twenty-one Idea Jam participants, eleven participants returned their post-jam questionnaire after the Idea Jams. Most of the participants who did not return their post-jam questionnaires were required to leave the sessions early to catch transportation from the Idea Jam location. Once the participants left the session, the only form of communication to reach the participants was through email, which was not enough of a motivator to obtain the outstanding post-jam questionnaires. The distribution of age, gender, PMD usage, motivations for game play, level of familiarity with computers, video games and the types of games played by participants can be seen in Figures 4-10. Note: long descriptions of the graphs are available to make this document more accessible to people with print disabilities. 
Figure 4 shows the use patterns of participants' PMDs. Most of the participants, 21 of 27 (78\%) used their PMDs all the time; 5 of 27 (19\%) used their PMDs only for travelling long distances; 1 of 27 (4\%) used their PMD only when sick or tired and finally 3 of $27(11 \%)$ used their PMD only while at work.

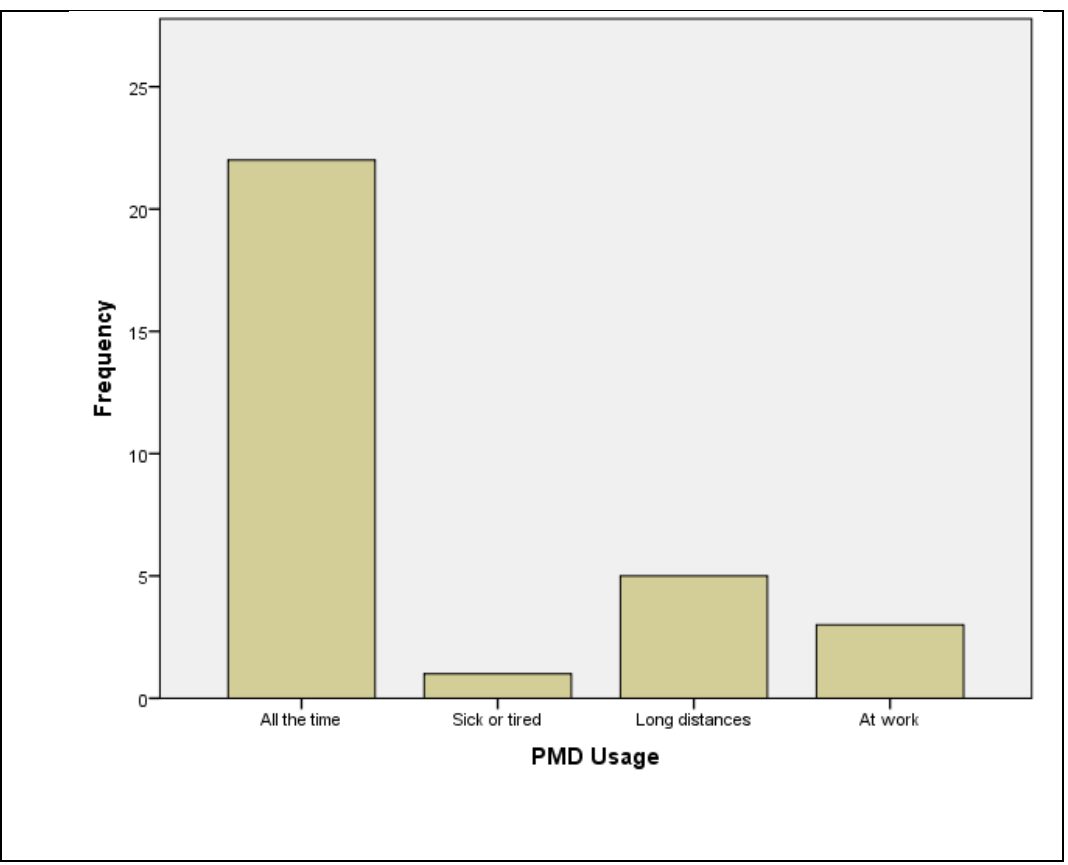

Figure 4: Frequency of PMD use.

As seen in Figure 5, the level of education among all groups was fairly high. Some of the participants, 3 of $27(11 \%)$ had completed a graduate school degree; 8 of $27(26 \%)$ had achieved a undergraduate degree; 7 of 27 (30\%) had achieved a college diploma; 8 of $27(30 \%)$ had achieved a high school diploma and finally only 1 of $27(4 \%)$ had achieved an elementary school diploma. 


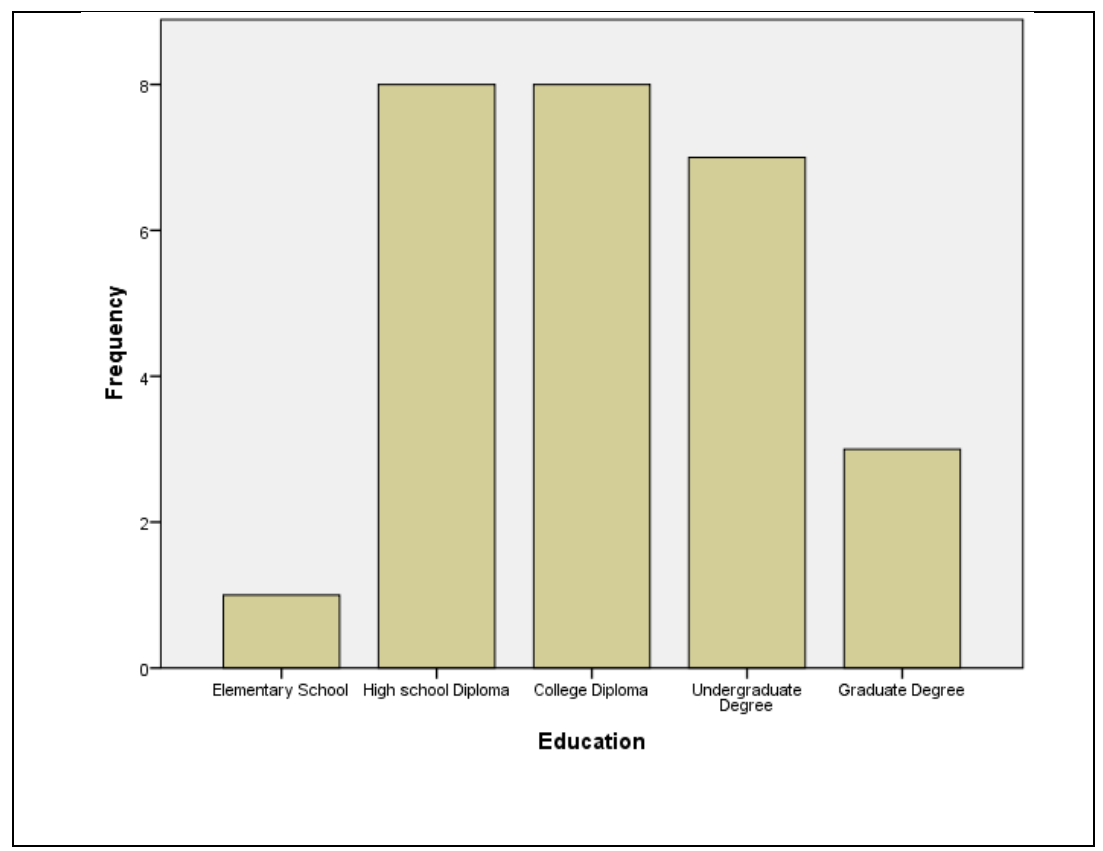

Figure 5: Frequency of educational attainment.

In the study there was a near equal representation between the sexes, 14 of 27 (52\%) male and 13 of $27(48 \%)$ female.

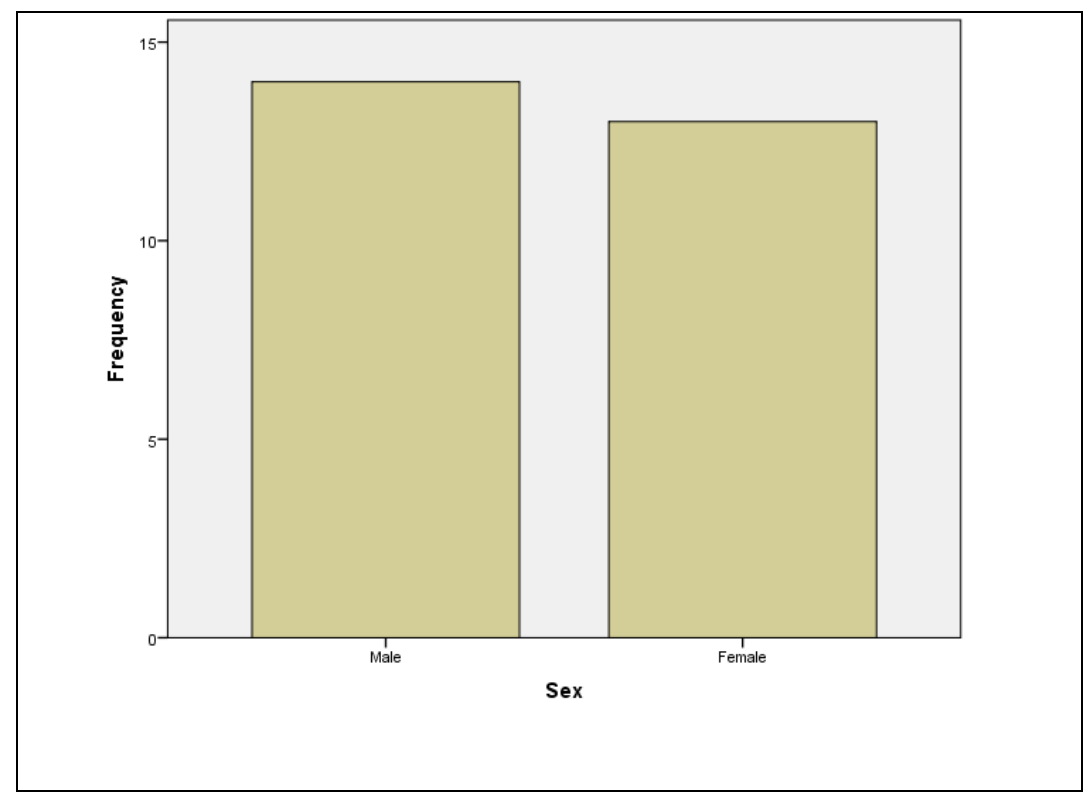

Figure 6: Male and female representation. 
The largest number the participants, 10 of 27 (37\%) were in the age range of 55-65 years; 4 of $27(15 \%)$ were between the ages of $45-55 ; 2$ of $27(7 \%)$ were between the ages of 35-45; 7 of 27 (26\%) were between the ages of 25-35 and 4 of 27 (15\%) participants were between the ages of 18- 25 (see Figure 7).

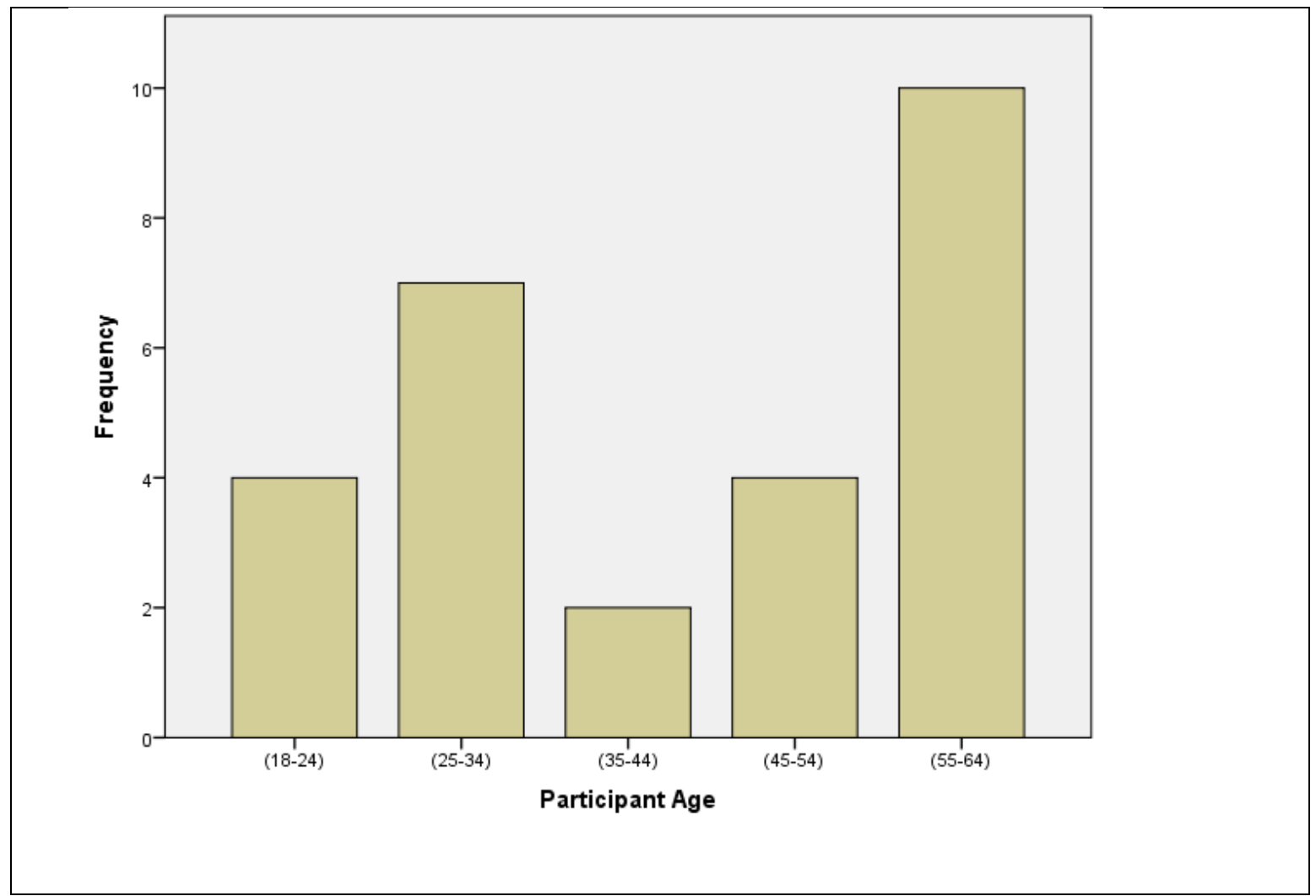

\section{Figure 7: Ages of Idea Jam participants .}

The majority of the participants, 23 of $27(85 \%)$ used a computer daily while 3 of $27(15 \%)$ had never used a computer, and 1 of $27(4 \%)$ used a computer every 1-2 days. 


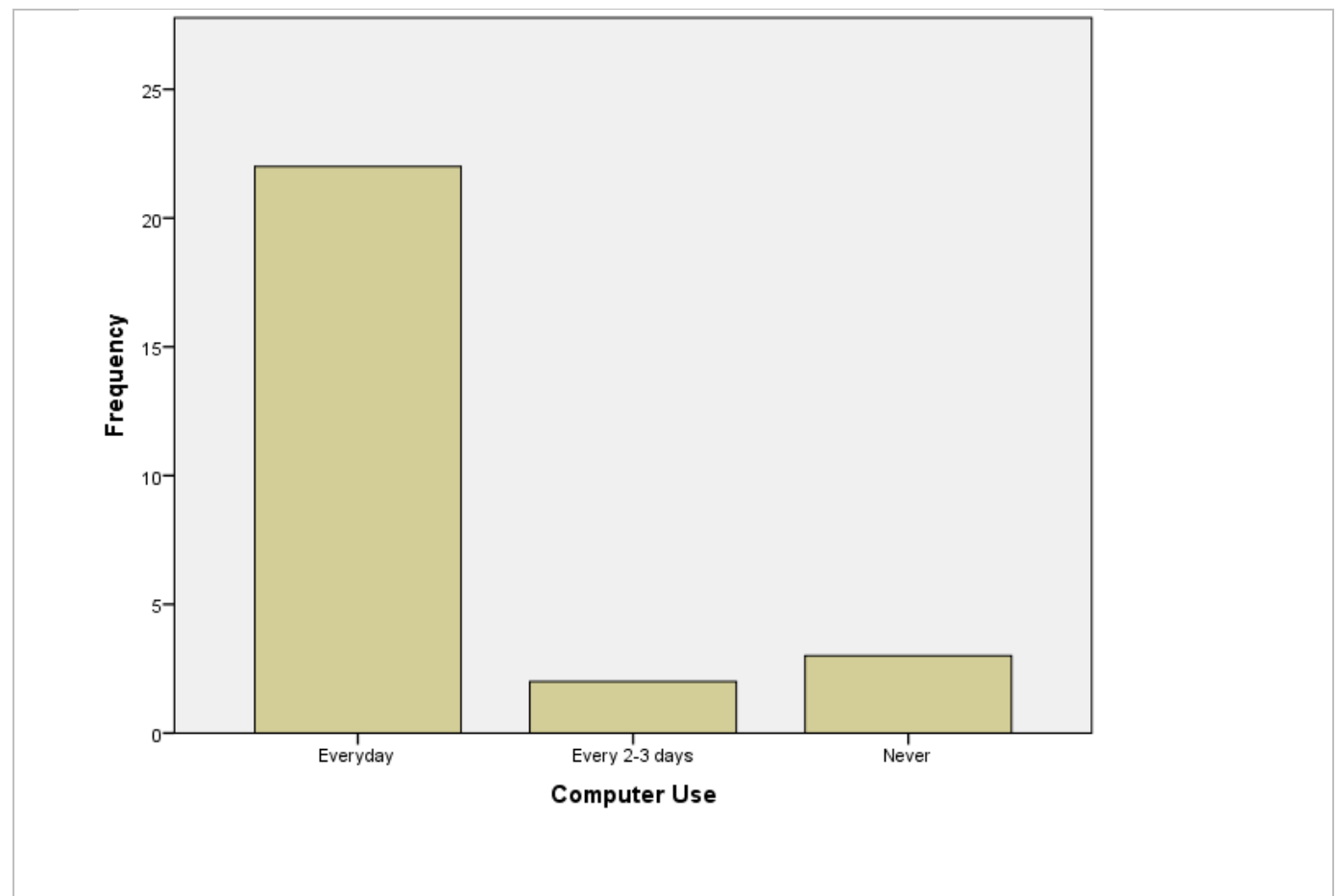

Figure 8: Frequency of computer use.

Most of the participants, 9 of $27(33 \%)$ did not play online games; 2 of $27(7 \%)$ played once a month; 2 of 27 (7\%) played once a week; 6 of $27(22 \%)$ played every 2-3 days and finally 8 of 27 (30\%) played every day. 


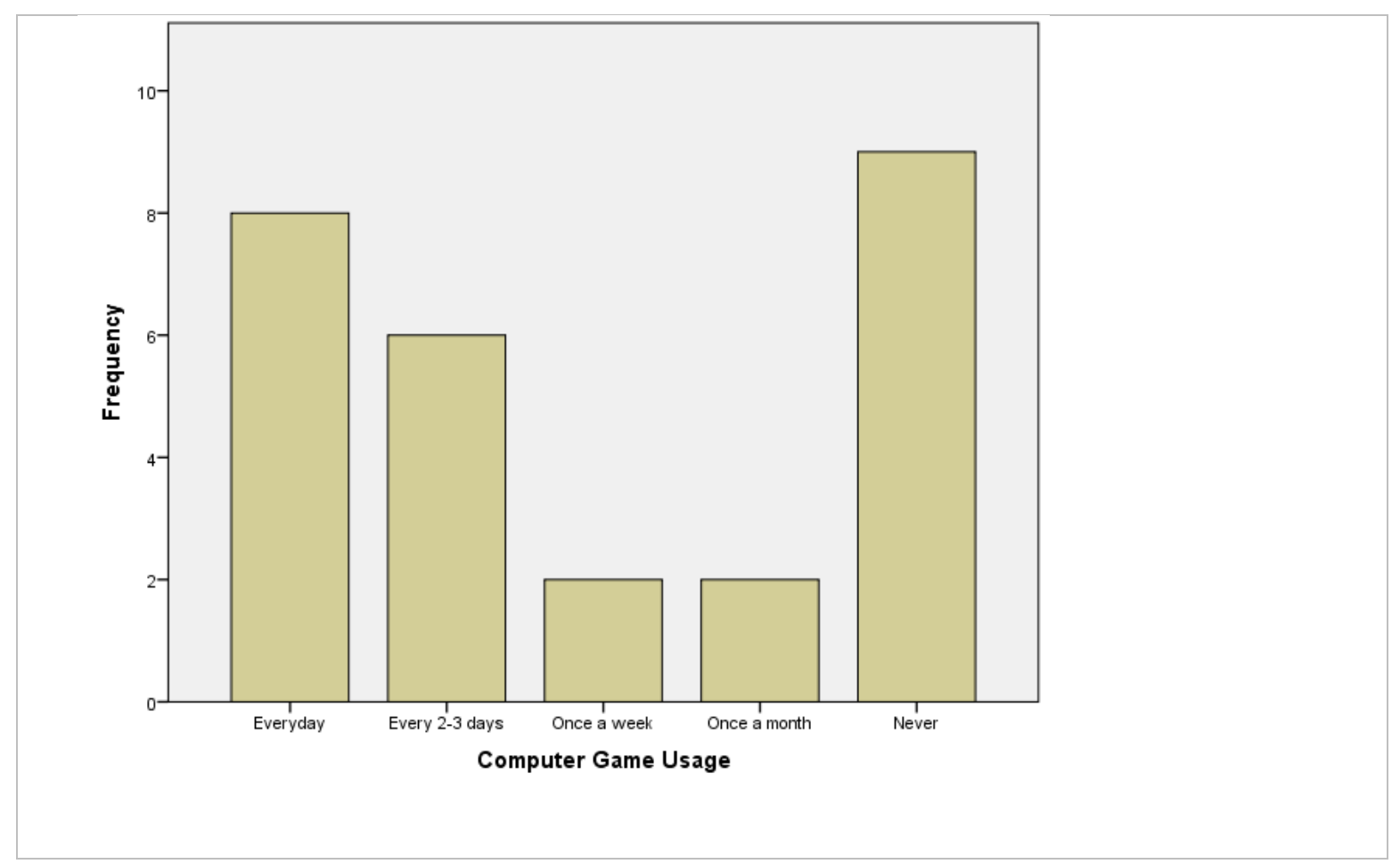

Figure 9: Frequency of computer gaming.

The main reason 18 of 27 (48\%) participants were motivated to play games was for entertainment; 13 of 27 (48\%) indicated that they played games to socialize with friends; 5 of 27 $(19 \%)$ indicated they were motivated for a distraction; 14 of $27(52 \%)$ indicated that they were motivated to pass time; 7 of $27(26 \%)$ indicated that they were motivated to play games to escape from reality and finally 3 of $27(11 \%)$ indicated that they had other reasons for playing games. 


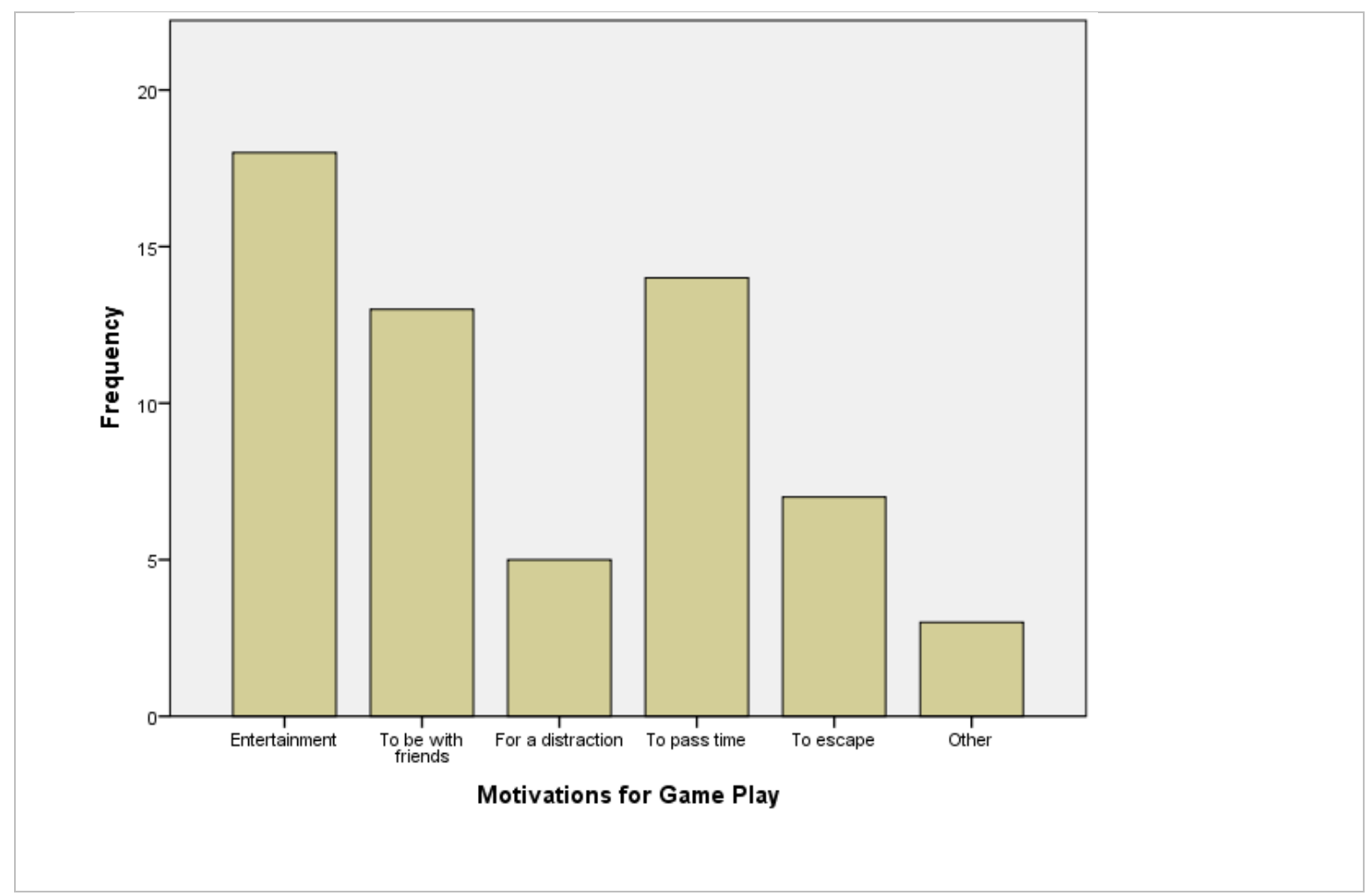

\section{Figure 10: Frequency of gaming motivations.}

After the consent forms were signed, participants were first introduced to other participants and then given a short (5 minute) presentation about what a game was and what researchers were hoping to discuss about games. At this stage of the Idea Jam, participants were introduced to the idea of creating a game with PMDs having a central game function. Participants were then asked to help develop a game that could be mediated by smartphones or other mobile devices within this gaming context.

Participants were then asked to discuss ideas around games they liked to play (this was not limited to video games) and what types of games could be feasible and fun to play with powered mobility devices. During the sessions the participants were encouraged to think out loud, and provide commentary and opinions about the games they had experienced in the past, what they liked about them, what they did not like about them and what game components they thought 
could be incorporated into a new game design. Researchers did not lead the conversation, but instead, let the participants speak among themselves in a free forum discussion. By the end of the sessions, participants had a final discussion and by group consensus determined their favourite game idea of the Idea Jam. Participants were then asked to complete the post-questionnaire.

All the Idea Jams were video taped to capture participants' comments. The Idea Jams were carried out over a four-month period in the various locations.

\subsection{Data Analysis}

Qualitative and quantitative data were collected and analyzed. Descriptive analyses and nonparametric statistical analysis were used to analyze the quantitative data from the questionnaires. Frequency charts and percentages were employed to display the distribution and trends in this data. Thematic analysis was used to analyze the video data.

\subsubsection{Qualitative data}

To assess user opinion and to compare the different gaming preferences among participants, the Idea Jam video data was subjected to a thematic analysis as outlined by Miles et al. (1994). First, an initial set of six themes was identified and defined using the entire video data set. Three independent raters then evaluated 30 minutes of two videos to assess reliability. There was considerable divergence in the ratings; the Intraclass Correlation Coefficients were below 0.4.

The themes were then modified through discussion and consensus by the three raters. The initial set of themes was then refined and distilled into six main themes (see Table 1). Next, two new independent raters were asked to evaluate the same 30 minutes from two videos. An ICC above 0.9 was achieved for all themes. One rater then completed the analysis of the remaining video content. 


\subsubsection{Themes}

Six main themes were identified from the video data. Table 1 shows the definitions and examples for each theme.

\section{Table 1: Defined Themes.}

\begin{tabular}{|c|c|c|}
\hline Theme & Definition & Examples \\
\hline $\begin{array}{l}\text { Theme 1: Motivations } \\
\text { for playing games }\end{array}$ & $\begin{array}{l}\text { The Motivational Aspect } \\
\text { theme consisted of why } \\
\text { people like to play games. } \\
\text { What people get out of } \\
\text { playing games and how it } \\
\text { affects them. This theme } \\
\text { consists of all the behaviours } \\
\text { and actions associated with } \\
\text { the rationales people have for } \\
\text { game play. }\end{array}$ & $\begin{array}{l}\text { Some examples include playing } \\
\text { games for competition, fun, } \\
\text { escape from reality, to keep in } \\
\text { shape, to play when I am sick or } \\
\text { injured, mental challenges, } \\
\text { random challenges, travelling, } \\
\text { to improve abilities, help us } \\
\text { remember how to get places, } \\
\text { improving sense of direction, } \\
\text { help expand ideas, help to stay } \\
\text { sharp and deal with stress. } \\
\text { Specific examples of general } \\
\text { game comments expressed in an } \\
\text { Idea Jams include: "I like a } \\
\text { specific type of game, cultural, } \\
\text { game theme." or "Having } \\
\text { colours to identify with teams is } \\
\text { a good idea." }\end{array}$ \\
\hline $\begin{array}{l}\text { Theme 2: Specific } \\
\text { game elements }\end{array}$ & $\begin{array}{l}\text { The Specific Game Elements } \\
\text { theme consisted of the } \\
\text { aspects of specific game } \\
\text { elements and genres, } \\
\text { something specific that } \\
\text { someone likes which could be } \\
\text { incorporated into a game. }\end{array}$ & $\begin{array}{l}\text { Some examples included types } \\
\text { of characters, scoring, artwork, } \\
\text { weapons, objects and control } \\
\text { types. Such as "It is the rank } \\
\text { system that makes things } \\
\text { interesting, having fair balance } \\
\text { teams is most important for a } \\
\text { game" or "I like when I am the } \\
\text { character playing the game. So } \\
\text { for instance I cannot see the } \\
\text { persons face when I am playing. } \\
\text { For example Gordon Freeman } \\
\text { from Fallout. He does not speak } \\
\text { and I just play as him. To me he } \\
\text { just seems like an average guy, }\end{array}$ \\
\hline
\end{tabular}




\begin{tabular}{|c|c|c|}
\hline & & $\begin{array}{l}\text { like me who gets placed in the } \\
\text { gaming world. I like that } \\
\text { because I get to identify with } \\
\text { him." }\end{array}$ \\
\hline $\begin{array}{l}\text { Theme 3: Social } \\
\text { aspect of games }\end{array}$ & $\begin{array}{l}\text { Consists of when individuals } \\
\text { described playing with others } \\
\text { to achieve game goals - it is } \\
\text { not necessarily designed into } \\
\text { the game. The Social Aspects } \\
\text { of games consisted of a } \\
\text { formed point in the game, } \\
\text { which is not designed but } \\
\text { instead left up to the players } \\
\text { to develop while playing. }\end{array}$ & $\begin{array}{l}\text { Some examples include: "I like } \\
\text { playing a game more when I am } \\
\text { solving puzzles with a friend" or } \\
\text { "I like the teamwork aspect of } \\
\text { games". }\end{array}$ \\
\hline $\begin{array}{l}\text { Theme } 4 \text { : } \\
\text { Incorporating more } \\
\text { inclusive game } \\
\text { designs }\end{array}$ & $\begin{array}{l}\text { The Inclusive Aspects theme } \\
\text { consisted of participant's } \\
\text { ideas on how gaming could } \\
\text { be made more inclusive and } \\
\text { accessible. }\end{array}$ & $\begin{array}{l}\text { Some examples from } \\
\text { participants include having } \\
\text { "different types of motor } \\
\text { challenges for people with } \\
\text { different levels of ability when } \\
\text { driving their scooters. Game } \\
\text { choice is very important. People } \\
\text { know there own abilities the } \\
\text { best, especially the disabled" or } \\
\text { "Captions helped me play } \\
\text { games a lot better, for instance } \\
\text { closed captioning would let me } \\
\text { know of an incoming attack." } \\
\text { The prior comment was from a } \\
\text { deaf individual who had } \\
\text { difficulty playing games, which } \\
\text { used sound to convey emotions } \\
\text { and the characters in a game. }\end{array}$ \\
\hline $\begin{array}{l}\text { Theme 5: } \\
\text { General/Generic } \\
\text { game elements }\end{array}$ & $\begin{array}{l}\text { The general game element } \\
\text { theme consisted of the types } \\
\text { of games players liked to } \\
\text { play. The theme was defined } \\
\text { by the ideas that are general } \\
\text { in relation to the game } \\
\text { design. Such as what types of } \\
\text { games people like to play and } \\
\text { was the opposite of the "why" } \\
\text { people like games which was } \\
\text { theme } 1 \text { (Motivations for } \\
\text { playing games). The General }\end{array}$ & $\begin{array}{l}\text { Some examples of general game } \\
\text { comments expressed in the Idea } \\
\text { Jams include: "I like a specific } \\
\text { type of game, cultural, game } \\
\text { theme." or "Having colours to } \\
\text { identify with teams is a good } \\
\text { idea." }\end{array}$ \\
\hline
\end{tabular}




\begin{tabular}{|l|l|l|}
\hline & $\begin{array}{l}\text { game aspects focuses on what } \\
\text { types of game play } \\
\text { participants prefer. }\end{array}$ & \begin{tabular}{|l|l|} 
How participants prefer to \\
play games.
\end{tabular} \\
\hline $\begin{array}{l}\text { Theme 6: Game } \\
\text { behaviour }\end{array}$ & $\begin{array}{l}\text { Some examples included: "I am } \\
\text { a more passive participant when } \\
\text { it comes to game play" or "I like } \\
\text { to see strategies emerge as I } \\
\text { play other people in games. I am } \\
\text { a more passive participant when } \\
\text { it comes to game play" or "I like } \\
\text { to see strategies emerge as I } \\
\text { play other people in games." }\end{array}$ \\
\hline
\end{tabular}

The videos of the Idea Jams were started as soon as participants were asked to discuss ideas around games they liked to play (this was not limited to video games) and what types of games could be feasible and fun to play with powered mobility devices. Each relevant comment participants made throughout the 1.5 hour Idea Jams was tabulated by the researcher and categorized into one of the six themes.

\subsubsection{Quantitative data}

Non-parametric statistical and descriptive analyses were carried out to examine differences in comment rates between themes and between two user groups.

The two user groups were the MPMD group (Mixed-Powered Mobility Devices) comprised of 13 participants who used power wheelchairs and scooters and the TPWHL group (Toronto Powered Wheelchair Hockey League) group, which consisted of 8 participants who only used powered wheelchairs. Because of the difference in participant numbers, the number of comments in each theme was normalized to be a comment rate per capita so that a comparison between groups for each theme could be made. Theme comment rate was calculated by dividing the number of comments made by each user group per theme by the number of participants in that 
user group (see Equation 1 for the comment rate calculation and Table 2 for the values used in the comment rate calculations).

$$
\mathrm{TCR}=\mathrm{TCIJ} / \mathrm{NG}
$$

Where: $\mathrm{TCR}=$ Total Comment Rate (comments per person)

$\mathrm{TCIF}=$ Total comments made in Idea Jam

$\mathrm{Ng}=$ Number of participants

Table 2: Values used in the Theme Comment Rate Calculations.

\begin{tabular}{|c|l|l|c|}
\hline Group & $\begin{array}{l}\text { Total Idea Jam } \\
\text { Comments }\end{array}$ & $\begin{array}{l}\text { Number of } \\
\text { Participants }\end{array}$ & $\begin{array}{l}\text { Calculated } \\
\text { Theme } \\
\text { Comment Rate }\end{array}$ \\
\hline TPWHL & 46 & 8 & 5.57 \\
\hline MPMD & 165 & 13 & 12.70 \\
\hline
\end{tabular}




\section{Chapter 4. Results}

This chapter provides the quantitative and qualitative data analysis derived from the Idea Jams carried out for my research. Quantitative analyses for the thematic analysis will be provided first followed by a descriptive and qualitative analysis of the theme data. A quantitative and qualitative analysis of the post Idea Jam questionnaires will then be presented. The results are all written in a way that makes the content accessible to screen readers and adaptive technology.

\subsubsection{Between themes for all participants}

The small sample size (21 participants in all of the Idea Jams combined) did not meet the normality assumptions for parametric statistical analyses, so nonparametric tests were used for the quantitative data analysis of this study. The comment rate from the Idea Jams was the independent variable while the dependent variables were the themes. A Kruskal-Wallis test was carried out to determine the difference in comment rates occurring in the Idea Jams between themes. The results showed that there was no significant difference in the level of discussion $(\mathrm{p}=0.06)$ between themes Table 3 and Table 4 of the Appendix for the Kruskal-Wallis results. However, analyzing the descriptive data provided some insights into trends and possible areas of focus for participants.

There was a total of 211 comments made by participants, which fit into the six different themes. More than 211 comments were made by participants throughout the Idea Jams but only comments pertaining to the defined themes were tabulated. The breakdown of the 211 comments by themes can be seen in Table 5 . 
Table 3: ALLP Kruscal-Wallis Theme Ranks.

\begin{tabular}{|l|l|l|}
\hline \multicolumn{1}{|c|}{ Theme } & \multicolumn{1}{|c|}{ N Mean Rank } \\
\hline $\begin{array}{l}\text { Motivations for playing } \\
\text { games (Theme 1) }\end{array}$ & 5 & 10.30 \\
\hline $\begin{array}{l}\text { Specific game elements } \\
\text { (Theme 2) }\end{array}$ & 5 & 17.50 \\
\hline $\begin{array}{l}\text { Social aspects of games } \\
\text { (Theme 3) }\end{array}$ & 5 & 16.30 \\
\hline $\begin{array}{l}\text { Incorporating more } \\
\text { inclusive game designs } \\
\text { (Theme 4) }\end{array}$ & 5 & 15.40 \\
\hline $\begin{array}{l}\text { General/Generic game } \\
\text { elements (Theme 5) }\end{array}$ & 5 & 24.80 \\
\hline $\begin{array}{l}\text { Game behaviour } \\
\text { (Theme 6) }\end{array}$ & 5 & 8.70 \\
\hline
\end{tabular}

Table 4: ALLP Kruscal-Wallis.

\begin{tabular}{|l|l|}
\hline Chi-square & 10.667 \\
\hline df & 5 \\
\hline Asymp. Sig & 0.06 \\
\hline
\end{tabular}

\subsection{Descriptive Analyses}

Table 5: Shows the Total Number of Comments for all Themes.

\begin{tabular}{|l|l|}
\hline Theme & Total Comments \\
\hline
\end{tabular}




\begin{tabular}{|l|l|}
\hline Motivations for playing games (Theme 1) & 15 \\
\hline Specific game elements (Theme 2) & 54 \\
\hline $\begin{array}{l}\text { Social aspect of games } \\
\text { (Theme 3) }\end{array}$ & 23 \\
\hline $\begin{array}{l}\text { Incorporating more inclusive game designs } \\
\text { (Theme 4) }\end{array}$ & 31 \\
\hline $\begin{array}{l}\text { General/Generic game elements (Theme 5) } \\
\text { Game behaviour } \\
\text { (Theme 6) }\end{array}$ & 77 \\
\hline Total & 11 \\
\hline
\end{tabular}

Figure 11 shows the per capita frequency of occurrence for each theme from the ALLP (all participants) group in the Idea Jams. It would seem that topics classified under the themes of General and Specific Game Elements respectively were most discussed. There was a discussion rate of 3.67 for the General Game Elements theme and a rate of 2.57 for the Specific Game Elements theme. Inclusive Aspects were discussed at a rate of 1.48, while Social and Motivation themes were discussed at a rate of 1.10 and 0.71 respectively. However, the least discussed theme was Game Behaviour Aspects with a rate of 0.52 comments per participant. 


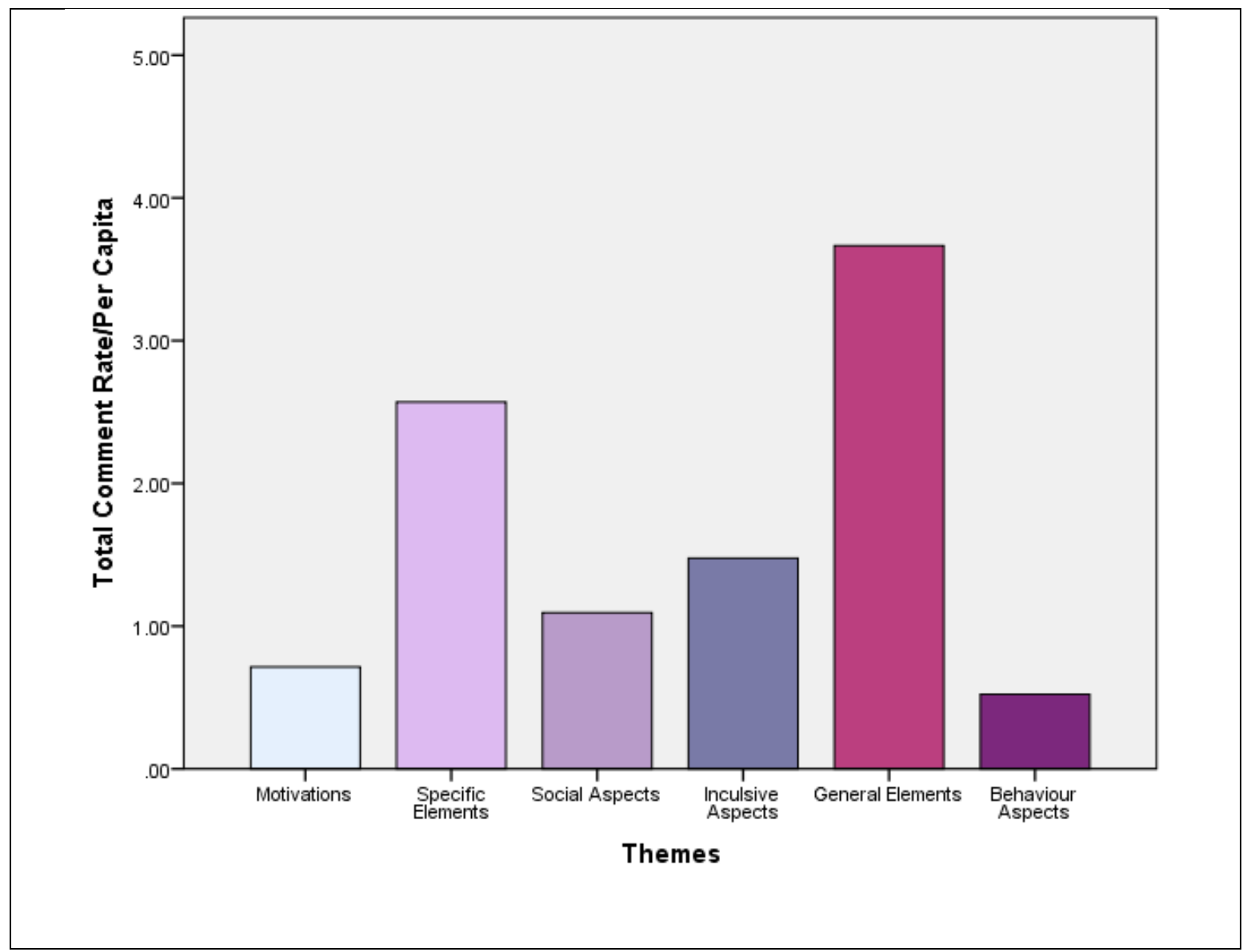

Figure 11: Total comment rate per captia for ALLP themes discussed in all Idea Jams.

\subsubsection{Differences in theme comments Between MPMD and TPWHL groups}

The participants in the Idea Jams could be broken into two significant groups. The TPWHL group consisting of participants who used powered wheelchairs exclusively and the MPMD group, consisting of participants who used both types of powered mobility devices (either a wheelchair or a scooter). The MPMD had a comment rate per capita of 12.69 and TPWHL had a 
lower comment rate at 5.75. Figure 12 shows the rate of comments for all themes for the MPMD and the TPWHL groups.

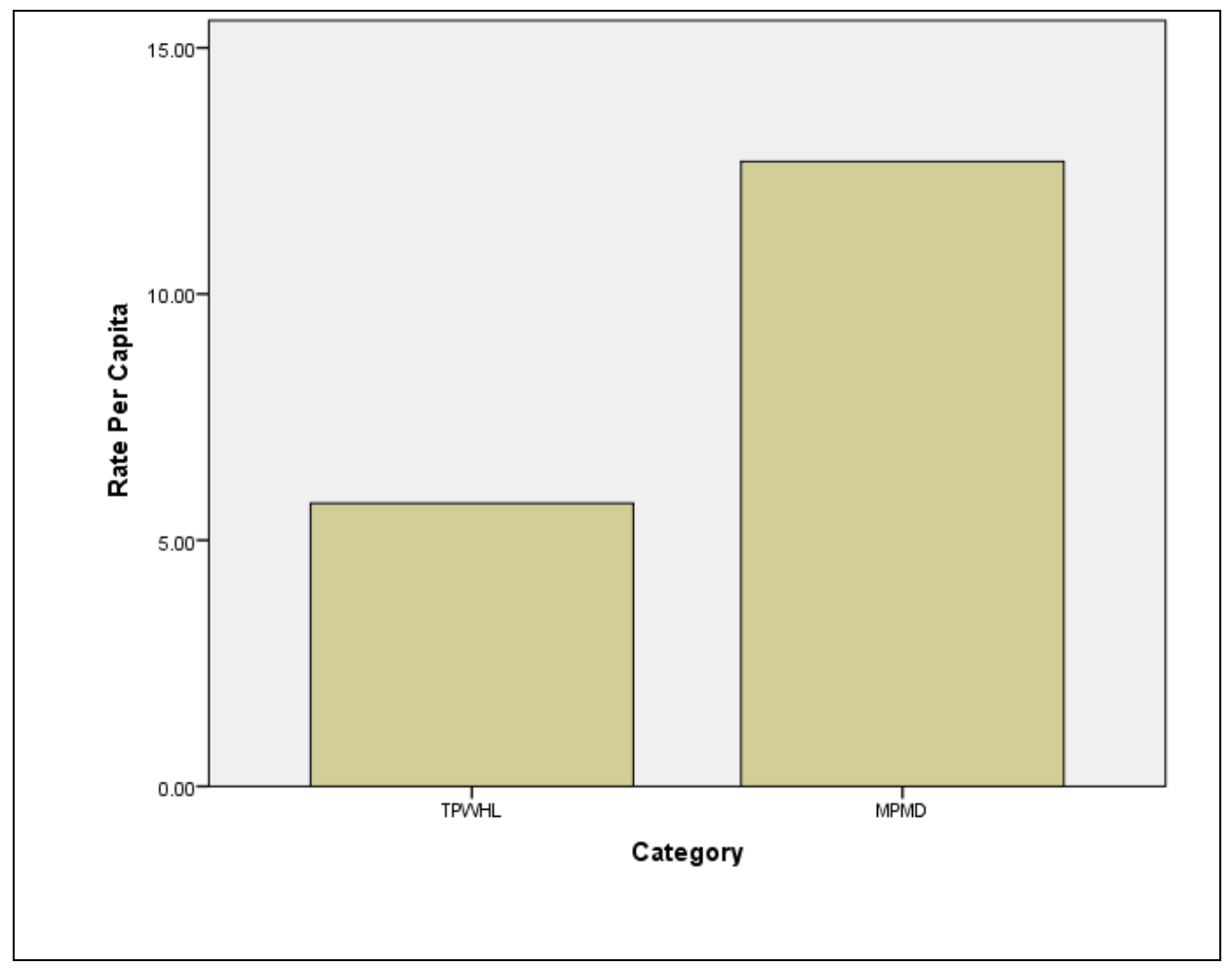

Figure 12: The different comment rates per capita for MPMD \& TPWHL.

\subsubsection{Theme Rate for MPMD}

Figure 13 illustrates the per capita frequency for each theme from the MPMD group (13 participants of mixed origin), once again the themes General and Specific Game Elements were most discussed. The discussion rate was 4.85 for the General Game Elements and 3.08 for the Specific Game Elements themes. Inclusive Aspects were discussed at a rate of 2.08, while Social and Behavioural Aspects were discussed at a rate of 1.23 and 0.77 . The least discussed theme was Motivations with a rate of 0.69 comments per participant. 


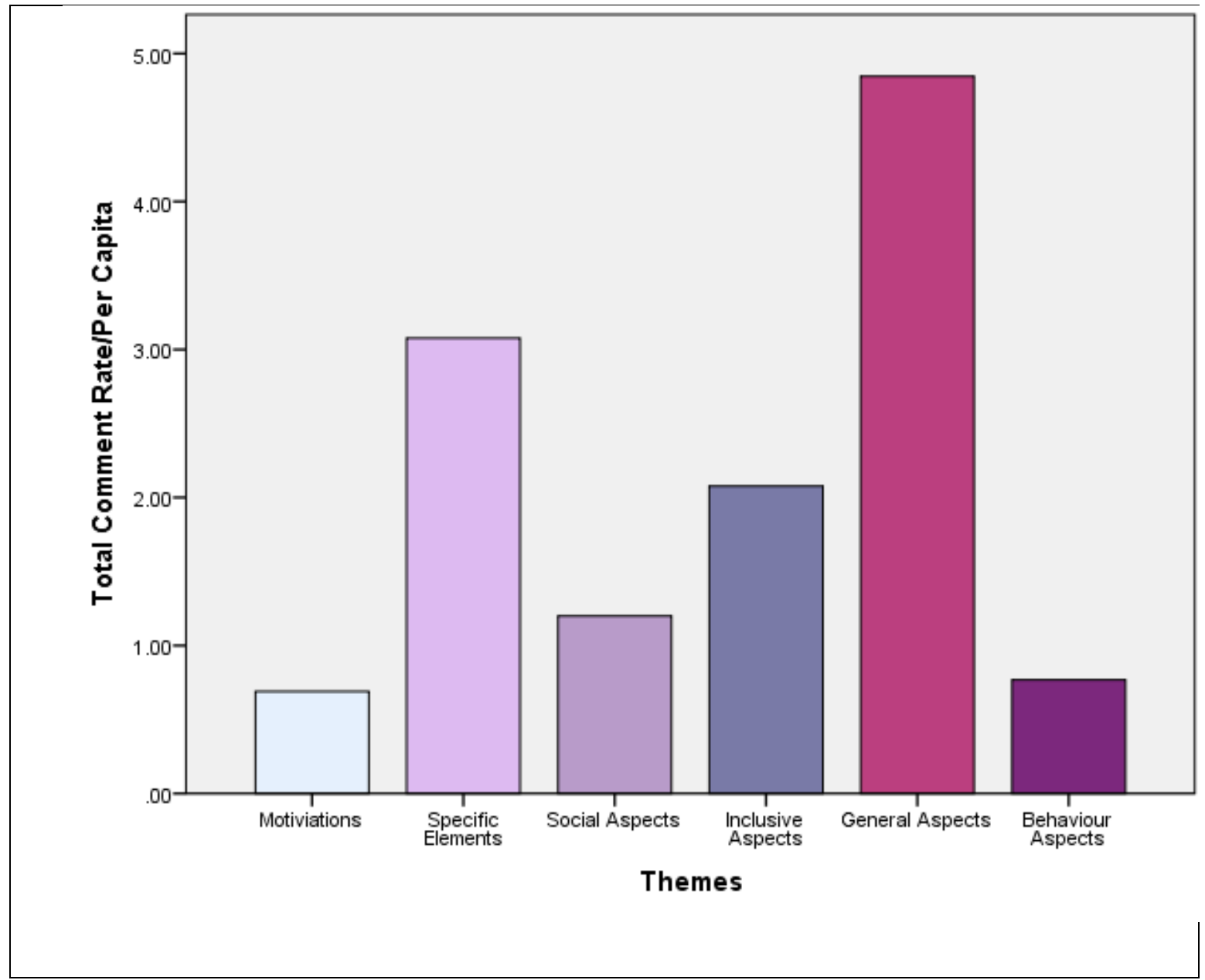

Figure 13: Total comment rate per capita for MPMD themes discussed in all Idea Jams.

\subsubsection{Theme Rate for TPWHL}

Figure 14 shows the per capita frequency of occurrence for each theme from the TPWHL group (8 participants using only a powered wheelchair) in the Idea Jams. The topics classified under the themes of General and Specific Game Elements were most discussed. The discussion rate for General Game Elements and Specific Game Elements were equally discussed at a rate of 
1.75. Social Aspects were discussed at a rate of 0.88 , while Motivations were discussed at a rate of 0.75 . The least discussed theme was Behavioural aspects with a rate of 0.13 comments per participant.

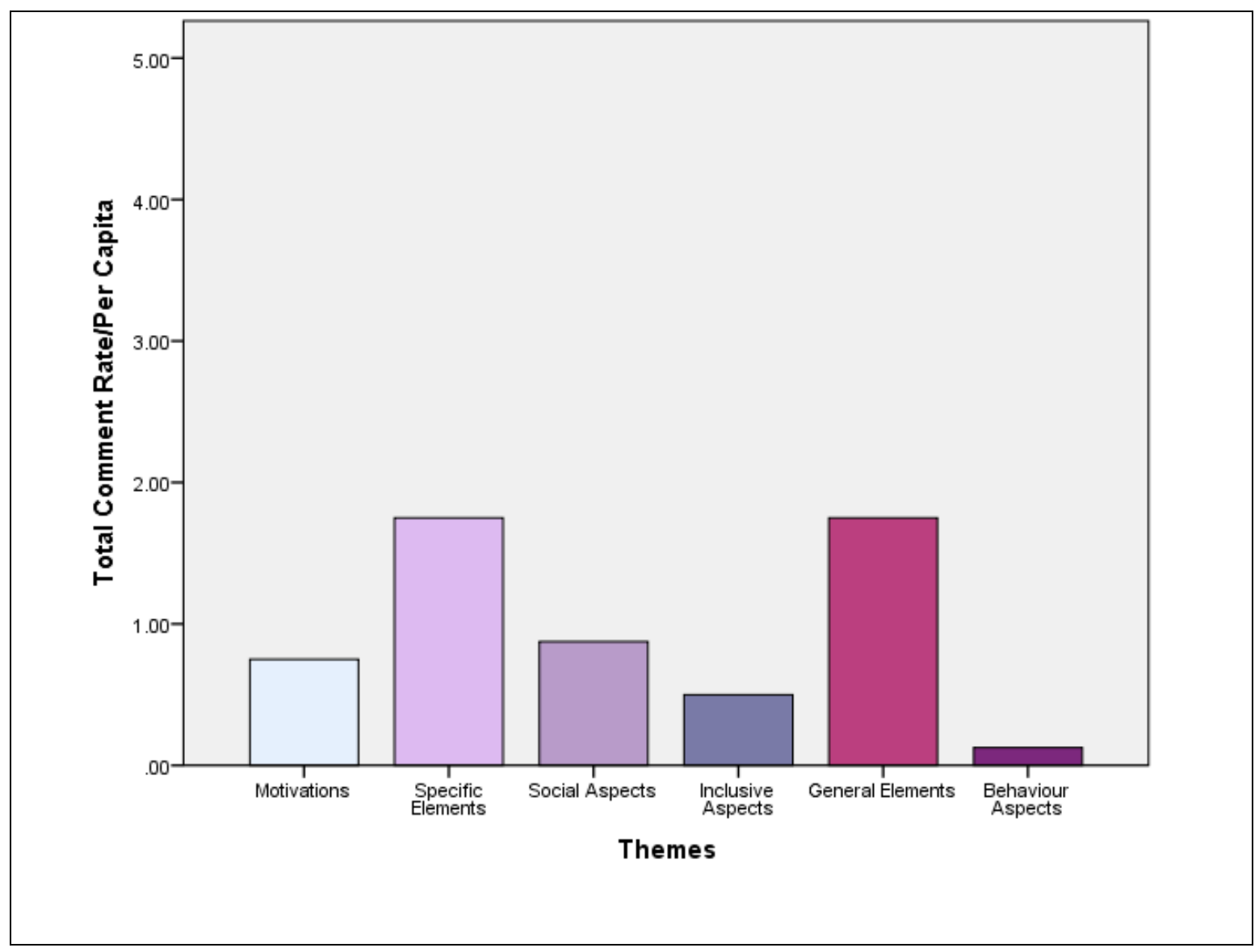

Figure 14: Total comment rate per capita for TPWHL themes discussed in all Idea Jams. 


\subsection{Post study Questionnaire Analysis}

Questions from the post study questionnaire are reported in two distinct groupings: 1) questions related to a participants ratings of the content of the Idea Jam discussion: and 2) questions related to a participants experience, participation and impact of the Idea Jam on them.

A chi-square $\left(\chi^{2}\right)$ analysis of response categories compared responses to the Likert scale questions with an expected frequency of equal distribution among all answer categories that measured experience, participation, effect and the content of the discussion collected in the postquestionnaires. The questions rated the positive or negative experience participants had while participating at the Idea Jams. Ratings were provided on a 5-point Likert scale, however, because of the low participant numbers the original five categories were condensed to three categories; positive, negative and neutral, to fit the assumptions of the chi-square test as recommended by Jacoby \& Matell (1971). The original two positive categories in the 5-point Likert rating scale were grouped together as one category and coded as "1" and the two negative categories were grouped together and coded as "3". The neutral category was coded as "2". A chi-square analysis was then performed and 9 significant results were found. The results are organized by questions related to the Idea Jam content and questions related to participant experiences with the Idea Jam setting; Table 6 shows the significant results report with an type 1 error probability level of 0.05 . 
Table 6: Chi-square table for rating the Idea Jam content where $1=$ positive and $3=$ negative (All SPSS tables can be viewed in Appendix D).

\begin{tabular}{|l|c|c|c|c|c|}
\hline Question & $\begin{array}{l}\text { Chi- } \\
\text { Square } \\
\text { Value }\end{array}$ & Mode & $\begin{array}{l}\text { Degrees } \\
\text { of } \\
\text { Freedom }\end{array}$ & $\begin{array}{l}\text { Mean } \\
\text { (Out of } \\
\mathbf{3 . 0 0})\end{array}$ & $\begin{array}{l}\text { Standard } \\
\text { Deviation }\end{array}$ \\
\hline $\begin{array}{l}\text { Level of Participation } \\
\text { (Question } \\
\text { 2/Participation) }\end{array}$ & 7.36 & 1 & 1 & 1.09 & 0.30 \\
\hline $\begin{array}{l}\text { How much difference } \\
\text { your input made } \\
\text { (Question 7/effect) }\end{array}$ & 7.36 & 1 & 1 & 1.18 & 0.60 \\
\hline $\begin{array}{l}\text { Liked the games } \\
\text { discussed } \\
\text { (Question 15/content) }\end{array}$ & 6.20 & 1 & 2 & 1.50 & 0.85 \\
\hline $\begin{array}{l}\text { Liked the idea of the } \\
\text { games discussed } \\
\text { (Question } \\
\text { 18a/content) }\end{array}$ & 6.20 & 1 & 2 & 1.50 & 0.85 \\
\hline $\begin{array}{l}\text { Liked the characters } \\
\text { discussed } \\
\text { (Question } \\
\text { 18b/content) }\end{array}$ & 6.20 & 1 & 2 & 1.50 & 0.85 \\
\hline $\begin{array}{l}\text { I liked how the game } \\
\text { could be played } \\
\text { (Question } \\
\text { 18c/content) }\end{array}$ & 5.44 & 1 & 1 & 1.22 & 0.67 \\
\hline $\begin{array}{l}\text { Found the Idea Jam } \\
\text { rewarding } \\
\text { (Question } \\
\text { 18d/content) }\end{array}$ & 10.00 & 1 & 0 & 1.00 & 0.00 \\
\hline $\begin{array}{l}\text { Thinking about the } \\
\text { games was fun }\end{array}$ & 6.40 & 1 & 1 & 1.20 & 0.63 \\
\hline & & & & & \\
\hline
\end{tabular}




\begin{tabular}{|l|l|l|l|l|l|}
\hline $\begin{array}{l}\text { Question } \\
18 \mathrm{e} / \text { content })\end{array}$ & & & & & \\
\hline $\begin{array}{l}\text { There were too many } \\
\text { people } \\
\text { (Question } \\
18 \mathrm{f} / \text { participation })\end{array}$ & 6.40 & 3 & 1 & 2.80 & 0.68 \\
\hline $\begin{array}{l}\text { I thought my ideas } \\
\text { were not well received } \\
\text { by the group } \\
\text { (18g/participation) }\end{array}$ & 5.44 & 3 & 1 & 2.78 & 0.67 \\
\hline
\end{tabular}


In the post-jam questionnaire provided to participants the second question asked participants their level of participation with their Idea Jam group. Out of the 11 participants who responded to the question, 1 participant indicated that they participated a bit in the Idea Jam, whereas 10 of the participants indicated that they participated a lot (see Figure 15). The chi-square value was $7.36(\mathrm{M}=1.09, \mathrm{SD}=0.30)$.

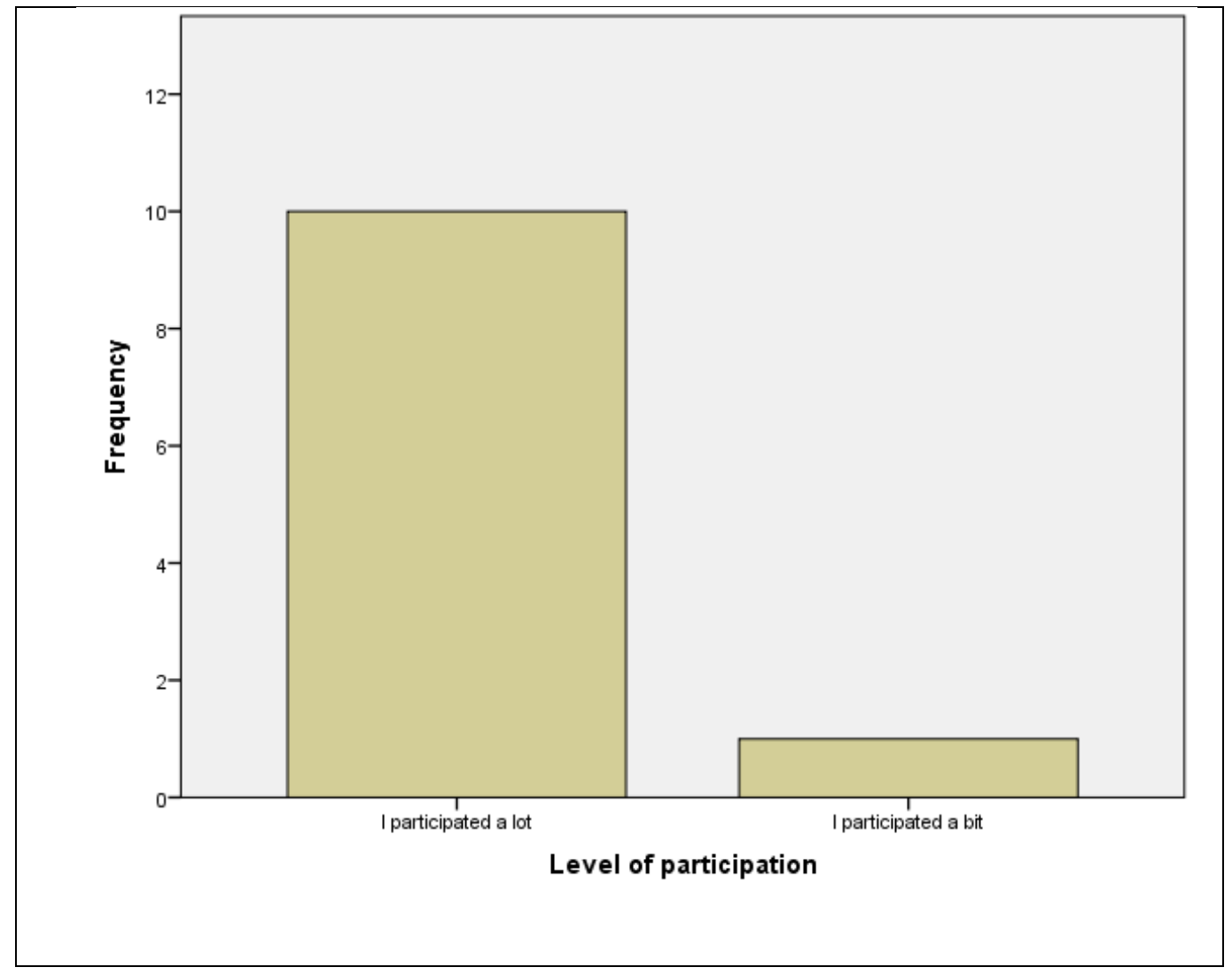

Figure 15: Frequency of the participant's level of participation with their Idea Jam group. 
In the post-jam questionnaire provided to participants question 7 asked participants how much difference the participants believed their input made in the Idea Jam. Out of the 11 participants who responded to this question, 1 participant indicated that they did not think their participation made a difference, whereas 10 of the participants indicated that they believed their input made a large difference. The chi-square value was $7.36(\mathrm{M}=1.18, \mathrm{SD}=0.60)$.

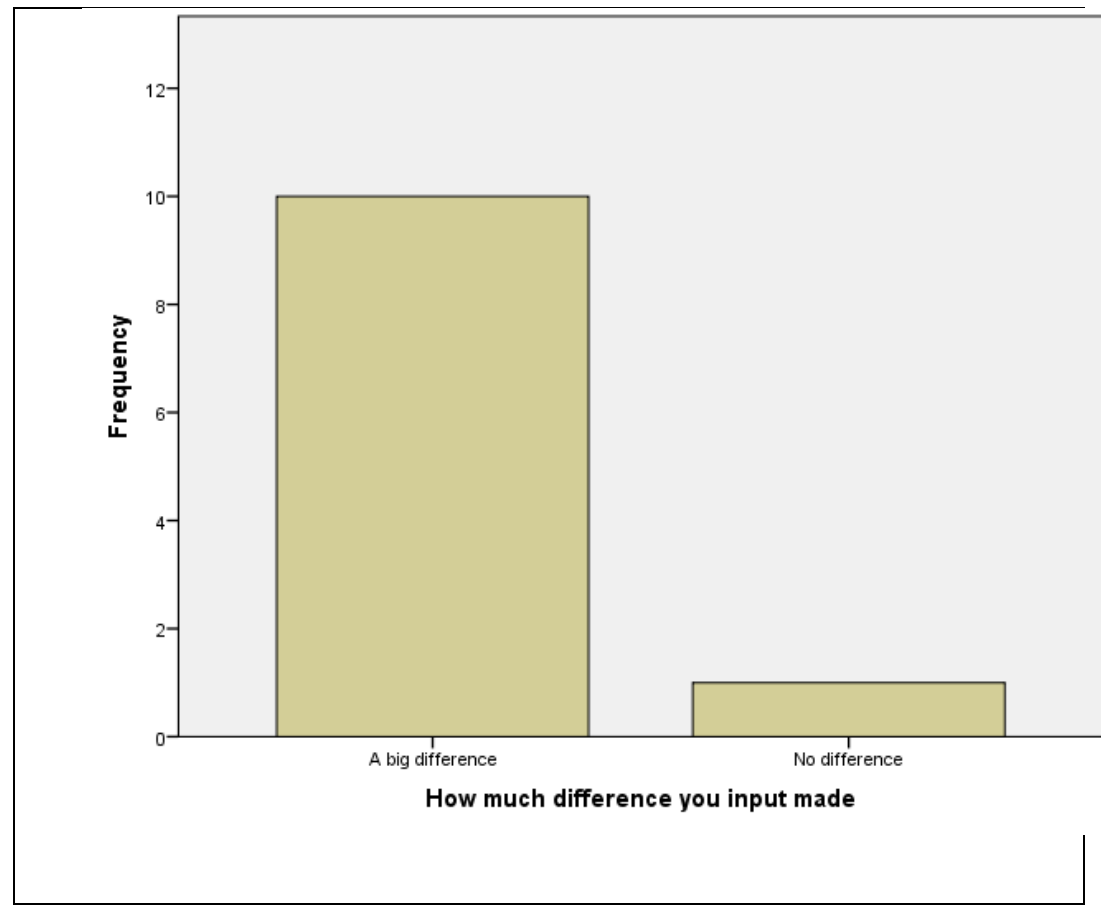

Figure 16: Frequency of how much difference the participants believed their input made in the Idea Jam.

In the post-jam questionnaire provided to participants question 18 related to how much participants liked the idea of the games discussed in the Idea Jam. Out of the 10 participants who 
responded to this question, 7 participants indicated they liked the games discussed, 2 participants indicated they did not care one way or another and 1 participant did not like the games discussed. The chi-square value was $6.20(\mathrm{M}=1.50, \mathrm{SD}=0.85)$.

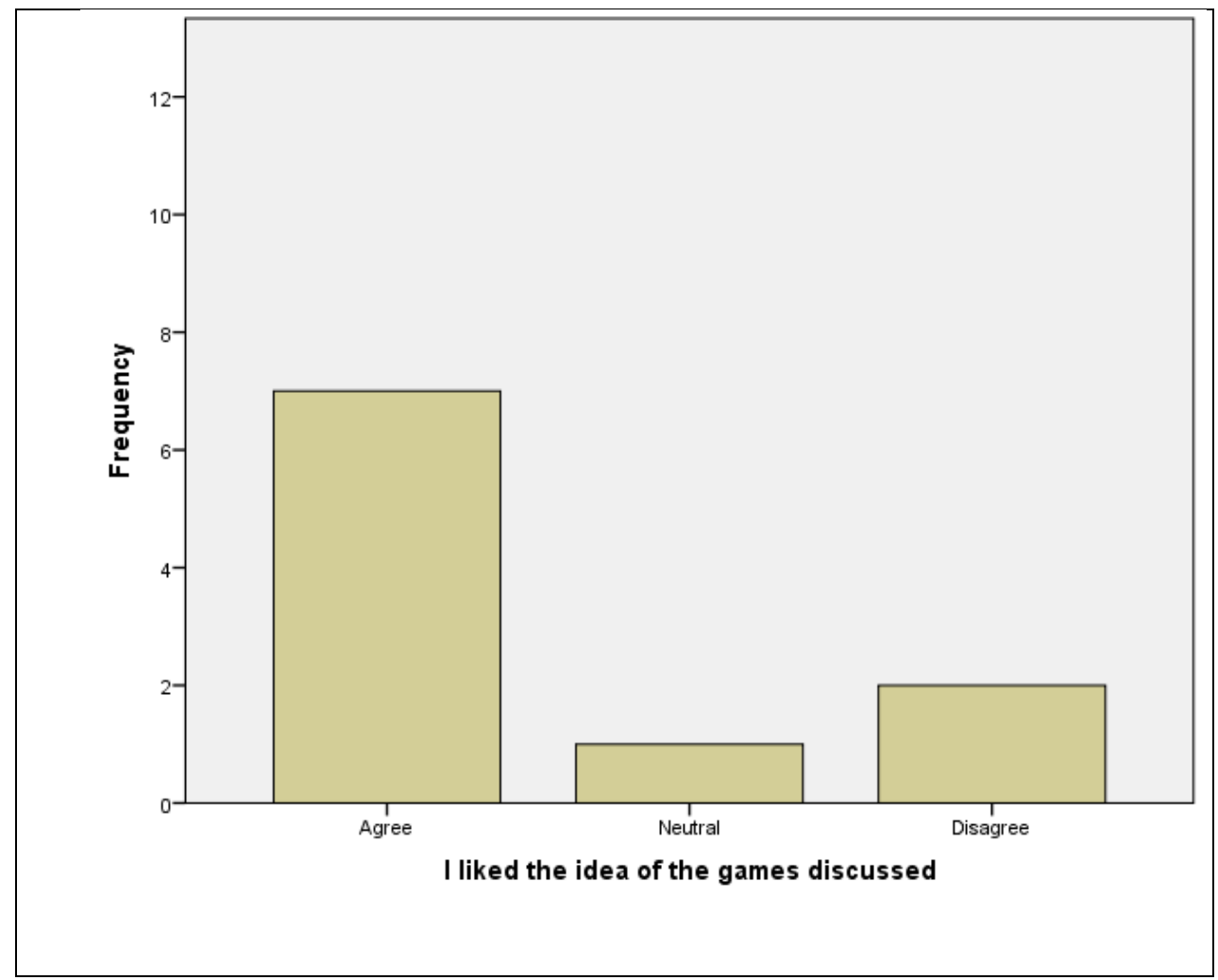

Figure 17: Frequency of how much participants liked the game discussed.

In the post-jam questionnaire provided to participants the eighteenth question asked participants how much they liked the characters discussed in the Idea Jam. Out of the 10 participants who responded to this question, 7 participants indicated they liked the characters 
discussed, 2 participants indicated they did not care one way or another whereas, 1 participant did not like the characters. The chi-square value was $6.20(\mathrm{M}=1.50, \mathrm{SD}=0.85)$.

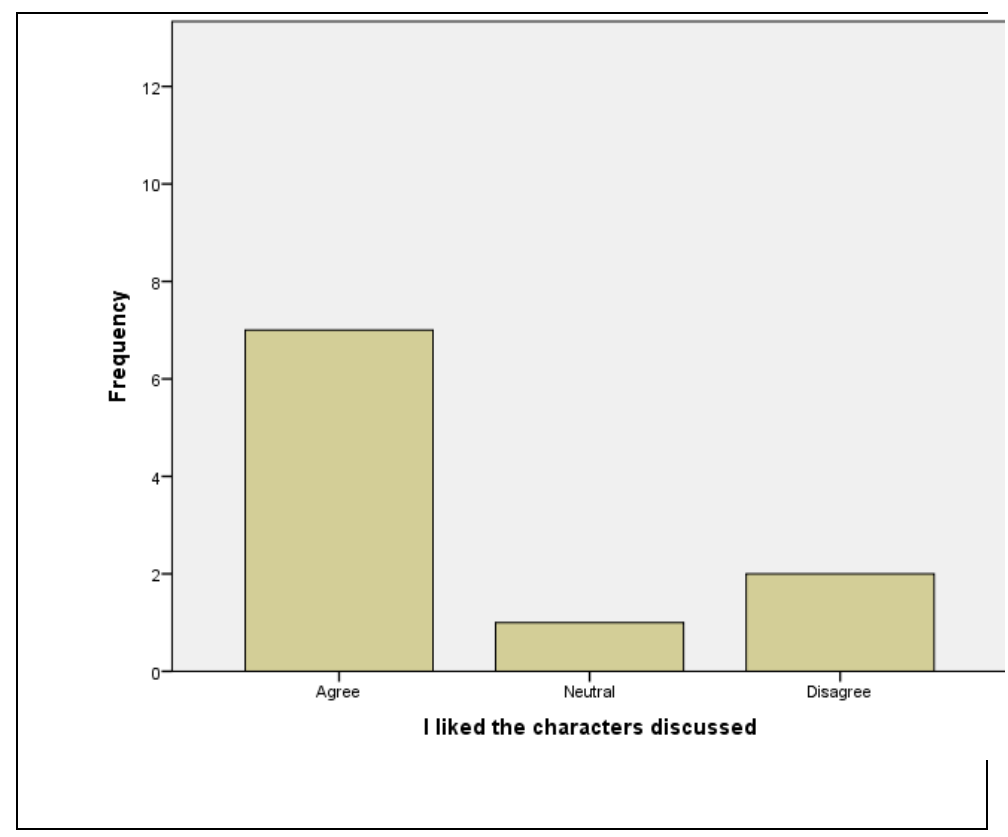

Figure 18: Frequency of how much participants liked the characters discussed in the Idea Jam.

In the post-jam questionnaire provided to participants the eighteenth question asked participants how much they liked how the game discussed in the Idea Jam could be played. Out of the 10 participants who responded to this question, 8 participants indicated they liked how the game could be played while 2 participants did not like how the game could be played. The chisquare value was $5.44(\mathrm{M}=1.22, \mathrm{SD}=0.67)$. 


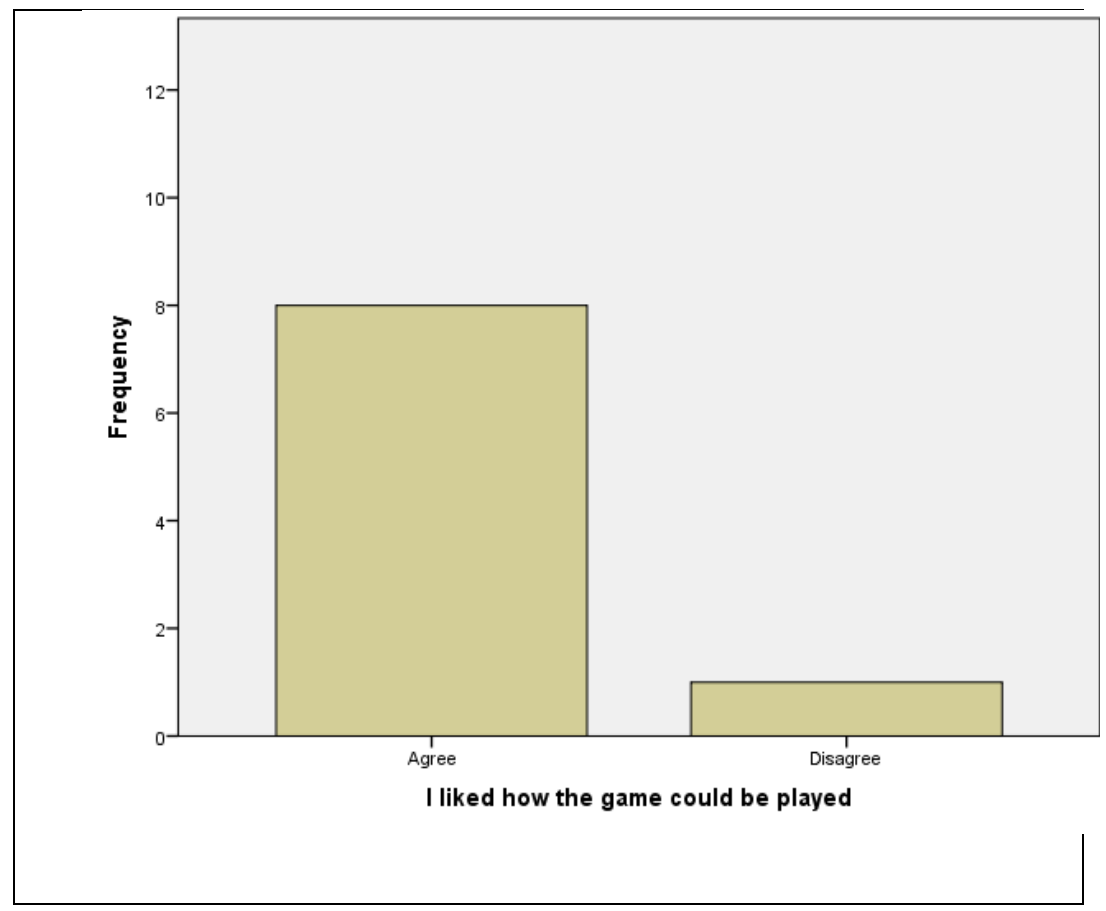

Figure 19: Frequency of how much participants liked how the game discussed in the Idea Jam could be played.

(In the post-jam questionnaire provided to participants the eighteenth question asked participants how fun thinking about games was for them. Out of the 10 participants who responded to this question, 9 participants indicated they agreed that thinking about games was fun, while 1 participant did not believe thinking about games was fun. The Chi-square value was $6.40(\mathrm{M}=1.20, \mathrm{SD}=0.63)$. 


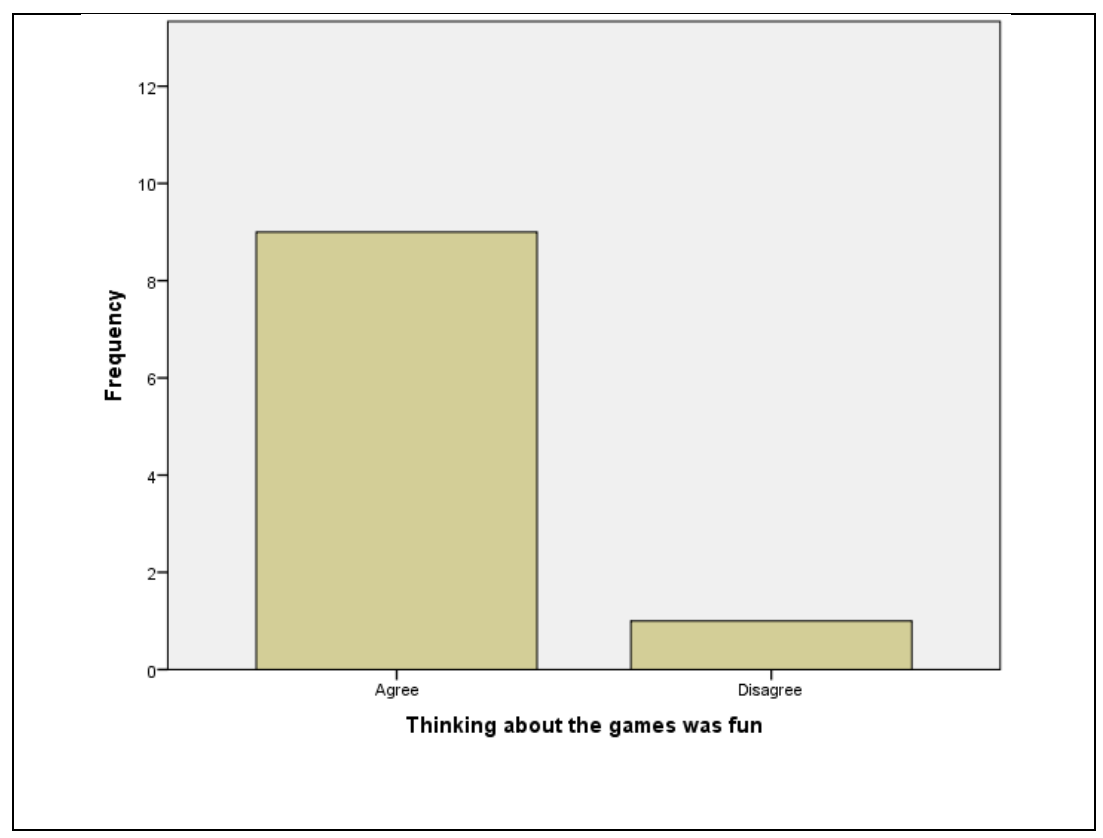

Figure 20: Frequency of how much fun participants had in the Idea Jam.

In the post-jam questionnaire provided to participants the eighteenth question asked participants how fun thinking about games was for them. Out of the 10 participants who responded to this question, 9 participants indicated they agreed that thinking about games was fun, while 1 participant did not believe thinking about games was fun. The Chi-square value was $6.40(\mathrm{M}=1.20, \mathrm{SD}=0.63)$

\subsection{Crosstabulation Analysis}

Eleven crosstabs analyses were carried out to examine the correlation between how the content of the Idea Jam discussions (questions 11, 13, 14, 15, 16 and 18) affected participant's experience of the Idea Jams in terms of level of enjoyment (question 1) and level of participation (question 2). Although no negative responses were observed, the level of enjoyment (Question 1) 
and participation (Question 2) provided a comprehensive analysis of the content discussed in the Idea Jams.

Table 7: Between groups comparison for significant experience and content post-jam questions where $1=$ positive and 3 = negative (All SPSS tables can be found in Appendix 4).

\begin{tabular}{||l|c|c|c|c|}
\hline Question & Chi-Square Value & $\begin{array}{l}\text { Degree of } \\
\text { Freedom }\end{array}$ & Pearson's R & Significance \\
\hline $\begin{array}{l}\text { Level of enjoyment } \\
\text { \& how much } \\
\text { participants liked } \\
\text { the games } \\
\text { represented in the } \\
\text { Idea Jams } \\
\text { (Questions 1\&15) }\end{array}$ & 6.88 & 2 & 0.62 & 0.03 \\
\hline $\begin{array}{l}\text { Level of enjoyment } \\
\text { \& I liked the idea of } \\
\text { the game we } \\
\text { discussed } \\
\text { (Questions 1\&18a) }\end{array}$ & 6.88 & 2 & 0.62 & 0.03 \\
\hline $\begin{array}{l}\text { Level of enjoyment } \\
\text { \& I liked the } \\
\text { characters we } \\
\text { discussed } \\
\text { (Questions 1\&18b) }\end{array}$ & 6.88 & 2 & 0.62 & 0.03 \\
\hline
\end{tabular}

Figure 21: Indicates the participant's level of enjoyment (question 1) with how much participants liked the games represented in the Idea Jam (question 15). The Pearson chi-square value was 6.88 and Pearson's R was 0.62 , while the significance value was 0.03 . 


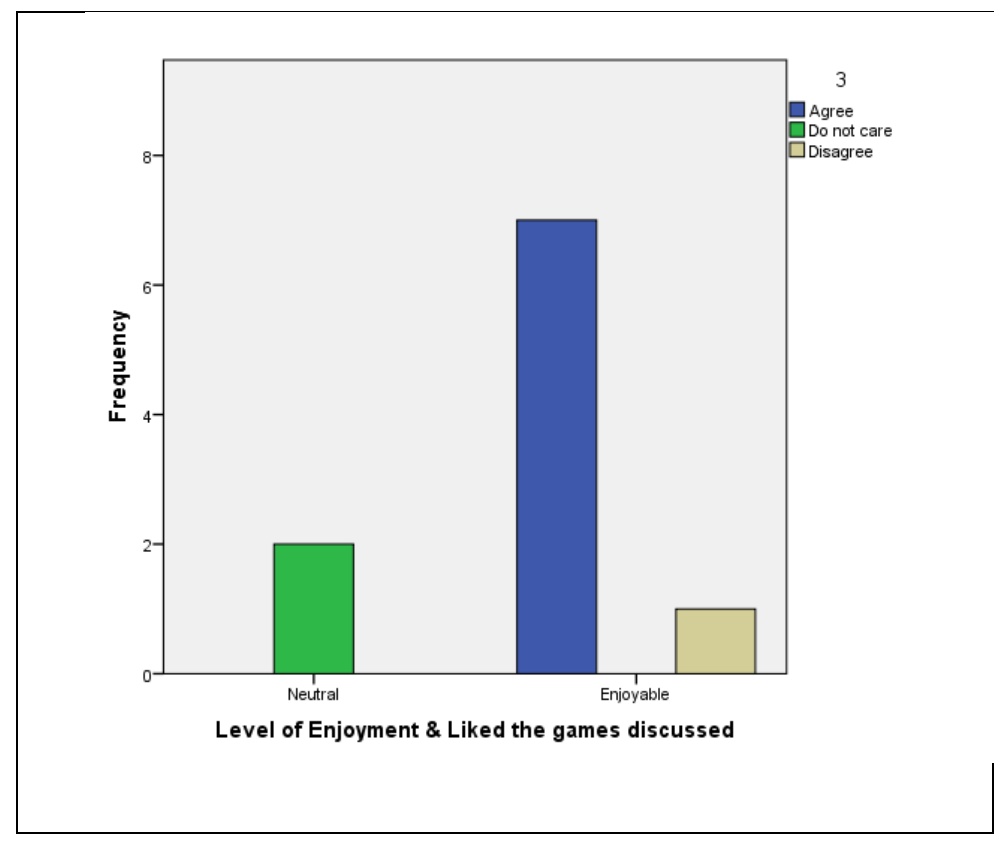

Figure 21: Frequency of the participant's level of enjoyment compared to how much participants liked the games which were discussed in the Idea Jam (1\&15).

Table 8: Number of questionnaire occurrences for the Level of enjoyment (Question 1) and how much participants liked the games discussed (Question 15).

\begin{tabular}{|l|l|l|l|c|}
\hline & Agree & Do not care & Disagree & Total \\
\hline Neutral & 0 & 2 & 0 & 2 \\
\hline Enjoyable & 7 & 0 & 1 & 8 \\
\hline Total & 7 & 2 & 1 & 10 \\
\hline
\end{tabular}


Figure 22: Indicates the participant's level of enjoyment (question 1) with how much participants liked the idea of the game discussed (question 18a). The Pearson Chi-square value was 6.88 and Pearson's R was 0.62 , while the significance value was 0.03 .

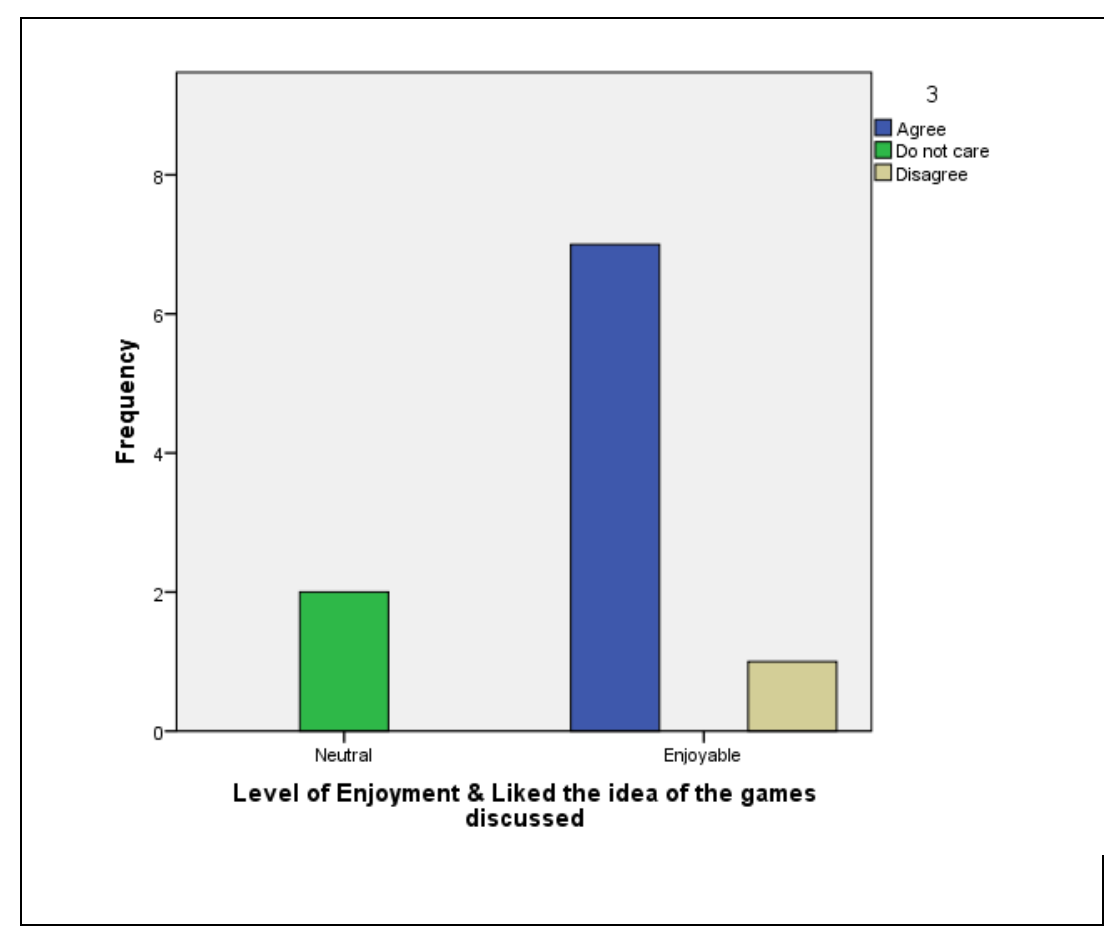

Figure 22: Frequency of the participant's level of enjoyment compared to how much participants liked the idea of the game which was discussed in the Idea Jam (1\&18a). 
Table 9: Number of questionnaire occurrences for the level of enjoyment (Question 1) and how much participants liked the idea of games discussed (Question 18a).

\begin{tabular}{|l|l|l|l|l|}
\hline & Agree & Do not care & Disagree & Total \\
\hline Neutral & 0 & 2 & 0 & 2 \\
\hline Enjoyable & 7 & 0 & 1 & 8 \\
\hline Total & 7 & 2 & 1 & 10 \\
\hline
\end{tabular}

Figure 23: Indicates the participant's level of enjoyment (question 1) with how much participants liked characters discussed in the Idea Jam (question 18b). The Pearson chi-square value was 6.88 and Pearson's $R$ was 0.62 , while the significance value was 0.03 .

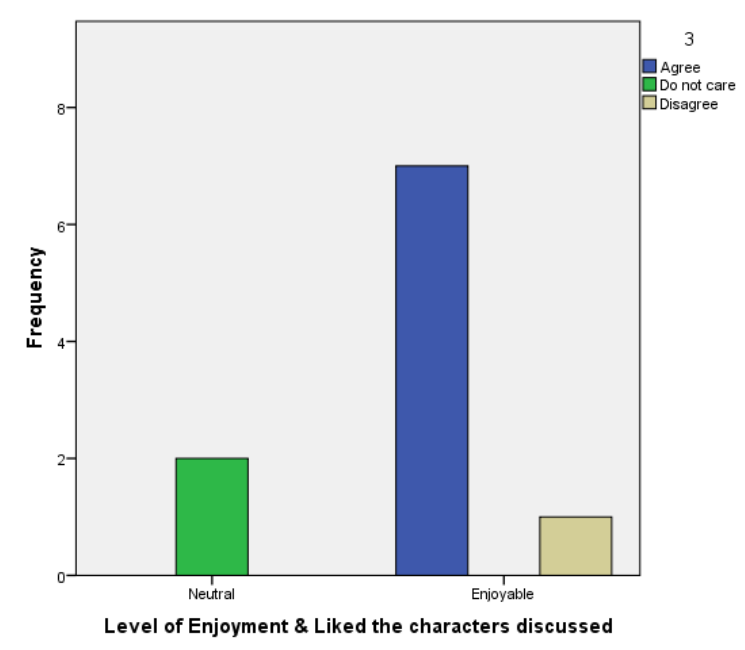

Figure 23: Frequency of the participant's level of enjoyment compared to how much participants liked the characters which were discussed in the Idea Jam (1\&18b). 
Table 10: Number of questionnaire occurrences for the Level of enjoyment.

(Question 1) and how much participants liked the characters discussed (Question 18b).

\begin{tabular}{|l|l|l|l|l|}
\hline & Agree & Do not care & Disagree & Total \\
\hline Neutral & 0 & 2 & 0 & 2 \\
\hline Enjoyable & 7 & 0 & 1 & 8 \\
\hline Total & 7 & 2 & 1 & 10 \\
\hline
\end{tabular}




\section{Chapter 5. Discussion}

The findings of the Idea Jam and the resulting game development process are discussed in relation to the research questions posed in this thesis where the research questions are:

1) What game genres and functionality (game objectives, characters, input/output, audience integration and rewards) would PMD participants be willing to consider using while driving their mobility device in indoor/outdoor spaces?

2) How can the ideas generated by PMD users be integrated into the design of game functionality and priorities?

The goal of the Idea Jam sessions reported in this thesis was to establish some directions to pursue for the development of a game for PMD users. Participants' ability to understand the concept of a game and their level of participation in the Idea Jams were critical factors in achieving this goal. The Idea Jam discussions were completely novel to all of the participants. However, the participants were familiar with answering questionnaires of the type provided before and after the Idea Jams. This was useful since their familiarity allowed the participants to spend time in the Idea Jam sessions getting to know the other participants rather than only focusing on completing the questionnaires. For most of the participants it was the first time they had been asked to think about how they could use their PMD in a game. This was important because the ideas generated from the participants were new and had not been biased from previous experiences.

In addition, since the method of the Idea Jams used to generate the comments was an open forum, comments could not be predicted in advance. As a result, the research is more explorative 
by allowing participants to control the conversation and the types of games they were most interested in discussing on their own. The first objective of the Idea Jams was to gain an understanding of what participants thought could be a good game for PMD users to play. This was achieved by collecting and analyzing participant's experiences and ideas.

The TPWHL participants had a lower comment rate that those in the MPMD group for: the General Elements, Specific Elements, Inclusive Aspects and Behavioural Aspects than the MPMD group, (see Figure 13 and Figure 14 in Chapter 4). However, they did have a higher comment rate in Social and Motivational Aspects. Based on this result, it was possible to make some comparisons between a more homogenous grouping (TPWHL) and a more diverse sample in the MPMD group. The differences compared showed how age, PMD familiarity and team orientation affected the priorities of game development in regards to genres, and how a PMD user's life experiences and perception of identity affected functionality.

\subsection{Idea Jam Process}

The participant's perception of what constituted a game and why they thought their favourite games were worth playing and how something similar could be developed was what was first discussed in the Idea Jams. By using existing games as a focal point of discussion participants often went from a specific game discussion to a broader conversation about games. For example, one participant spoke about how he enjoyed playing games like Super Mario in his youth which turned into a discussion about what made arcade style games fun to play. It was in the broader conversation that more complex gaming ideas emerged as well as how those ideas might be playable with their mobility devices. It was common in the Idea Jams for participants to begin the discussion by listing off many of their favorite games, most often card games or video games 
and with those ideas engaged other participants about their experiences with games. This process of discussion was similar to processes that have been reported in other Crowdsourcing sessions (Li et al., 2012).

In Li et al., (2012) branching scripts are normally used to begin an Idea Jam process. Branching scripts are linear narratives, such as stories in which people can begin to share relevant experiences in the Idea Jams. These linear narratives or stories are then used to provide step-by-step narratives which are applied to convey more complex information. As similar stories or events are identified by participants those events are used to create a partial order between stories or events, leading to more complex discussions. The knowledge gained from the Idea Jams are then understood by aggregating the narratives (Li et al., 2012). Stories are often used in Idea Jams to begin an Idea Jam discussion because it is a natural mode of communication (Gubrium, 2003). Furthermore, telling stories is found to be an effective means for human experts to share tacit knowledge, which is procedural knowledge that is hard to articulate even for experts (Li et al., 2012). These different types of knowledge are important for developers to understand so that a game design can reflect the users preferences for the construction of a game based on Inclusive design principles.

\subsubsection{General and Specific Game Elements}

Participants had different experiences with games. As a result, in order to come to some consensus on what type of game participants wanted to develop, each participant engaged in a type of storytelling about their different experiences with games. This discussion enabled other participants to gain some familiarity and comfort with the people in their groups so that they might question some of the underlying assumptions they may have had from their experiences, 
making the discussion more open and intuitive. Stories offer a personal account of a person's understanding of events, how they believe the events happened and why. Stories are a sequential form of understanding the world, meaning they have a beginning, middle and end (Li et al., 2012). Since it was much easier for participants to talk about past experiences and more difficult to discuss the social and behavioural aspects and motives associated with gaming due to the more complex nature of these elements, MPMD and TPWHL participants discussed the topics classified under the themes of General and Specific Game Elements most often as underlying stories (see Figures 13 and 14 for rates of discussion).

The criteria for a story consists of familiar elements to the people listening, is centered on the lesson in the story, the use of detail and finally how the detail is used to convey the ideas of the story teller (Li et al., 2012). In addition, stories usually contain five main elements: first, is the exposition where the author sets the stage of the situation and the characters. Second, is the rising action of the story, which is a series of actions that sets up the conflict of the main character and builds tension. Third, is the climax, which is the high point of the story where the conflict is decided. Fourth, is the stories falling action, which is the events that happen after the climax, wrapping up the story and leading to a conclusion. Finally there is the story's resolution, which is the point of closure for the story concluding the conflict (Gubrium, 2003).

Participants often broke down their experience into positive and negative gaming experiences based on these stories. For example, one participant stated, "I would have liked to play a lot more games with my sister but being in my chair makes it difficult for me to play with her. When she had a birthday party all of her friends came over and they started playing a bunch of games where I had to sit out because I couldn't take part because of my chair. How am I supposed to 
take part in games like Dance Dance Revolution. I can't get up on my feet and dance. That's why I think all games should be more inclusive. Otherwise, it's just not fair to people who are in their PMDs."

Participants spoke about their experiences in a way, which led up to the climax and a conclusion about whether the participant liked a game, or not. The positive and negative elements of their commentary served as an important foundation for more complex ideas to emerge later in the Idea Jam sessions, linking positive and negative game elements through storytelling together for more complex game designs. These positive and negative storytelling narratives brought problem solving to the forefront of the discussion allowing participants to explore non-linear game discussion topics such as the social, inclusive and behavioural themes in a deeper manner. This storytelling activity occupied about 40 minutes or a majority of the Idea Jam. Most of the elements in these stories were classified as General and Specific game elements and made up the majority of positive and negative comments in the Idea Jams.

The storytelling process introduced participants to the different game experiences of others, many of which were later transformed into broader game ideas, often linking game functions together in a type of chain. For instance, one participant stated, "Since different people like different aspects of all these games maybe we could put them all together into one big game. For example, we could have golf and dominos as challenges in a scavenger hunt." The scavenger hunt and dominos would have been discussed by different participants at an earlier point in the Idea Jam and counted as two general game elements in the analysis stage. The discussion often followed this particular pattern whereby participants listed their favourite games and discussed their motives for playing those games and why they perceived those games to be fun to play. 
Other participants then added their experience and suggestions were made about either combining entire games or extracting elements of them and putting them together.

Some of the most predominant suggestions for making a game fun included: working towards a goal, such as a "trophy" enduring "intense" competition to achieve it, working as a group and being able to solve a task together. Having fun in a game was closely linked to the player's goals. These goals were as diverse as the players themselves and included using games to develop skills, and learning and applying themselves to problem solving challenges, such as a participant's sense of direction. One participant provided a variety of possible goals, "improving my mind, travelling, relieving stress, to strategize, and get together with friends." For many participants the ability to spend time with family, friends and other people was also a prominent reason of what made games fun and a motive for playing a game. For instance, many older participants suggested creating cross-generational games so that they might be able to include their grandchildren in the game.

Genres were also very diverse; participants brought up a plethora of game types including: exploration, Star Trek, science fiction, music, cultural aspects such as playing a game inside a museum or art gallery, dance, treasure hunting, first-person shooters, random challenges and variations of current sport games, such as basketball or golf. This level of experience was good for the initial exploration phases of the Idea Jams when participants were using the General and Specific Game Elements to tell a story and familiarize themselves with the other participants in their groups. It provided participants with a broader insight to games they may not have personally experienced. It also increased the amount of participation because they all had past gaming experiences, increasing the amount of input from participants who may have otherwise 
not have communicated in the Idea Jam. Increased input from participants led to a more enjoyable experience by participants, which in turn increased the data derived for analysis.

Frasca (2003) distinguished two approaches to analyzing video games, the narrative and Ludological paradigms. He outlines the narrative paradigm as focusing on the narrative and representation strategies of the game. The Ludological paradigm states that video games are unlike narrative forms of literature and instead the model of understanding video games is better understood by the challenges inherent to the game system. In this regard it is not the characters and genres which are most important to understanding game development, but rather the challenges the player faces when interacting with the game that are more important. He promotes the idea that video games should be defined by the set of challenges laid out in the game and classified independently of their content. The games structure and game elements, specifically the games rules and environment make up the challenges in a gaming system. How the player reacts to the environment within the gaming system determines the difficultly of the challenges and by extension creates feelings of enjoyment/excitement for players overcoming those challenges.

In the Idea Jams the games discussed were categorized based on the experiences of the participants and by extension how the gaming interactions made the participants think and feel; a Ludological approach. The actions of players when gaming were linked to how the gaming experience provides the players with enjoyment. The players level of enjoyment was based on the meaning derived from the gaming experience, which is in turn linked to the player's state of flow (Csikszentmihalyi, 1990). As the participant interacts in a game it is the balance between challenge and problem solving administered by the game system, which provides the player with 
an avenue to test their skills and abilities and relate those experiences in the form of a story. Those experiences were influenced by the structure and game elements in which the categorization of themes in this study were based upon, as well as used to influence the development of a new game.

\subsubsection{Group Discussion}

Although the MPMD and the TPWHL groups had a wide variety of demographic characteristics such as age, educational level and computer experience, the TPWHL group were more a homogeneous demographic in that they were younger (18-35 years of age), computer savvy individuals that all played hockey. Since this unexpected stratification occurred with the TPWHL Idea Jams, it unintentionally provided two groups (MPMD and TPWHL) in our analysis. This was of benefit because it provided me with an opportunity to explore data from a homogenous group using one type of PMD with a group that used both PMDs.

The variety of demographics and experience in the MPWD group may have allowed for different views and consideration of how their mobility devices could be used. The MPWD groups were thoughtful and open about the implications of using their mobility devices in a gaming role. The TPWHL participants, however, were less inclined to view their PMD as a central tool in a game. This demographic and experience variation in the MPWD group may have allowed for different views and consideration of how their mobility devices could be used. The MPWD groups were thoughtful and open about the implications of using their mobility devices in a gaming role. The TPWHL participants, however, were less inclined to view their PMD as a central tool in a game. They seemed to perceive their PMD as a part of who they were and as a secondary facet of their identity. For instance, according to Rousseau-Harrison (2012), 
PMD users often embodied their PMDs as part of their identity after they had used their devices for a certain length of time, such as after five years of mobility use (Rousseau-Harrison, 2012). For example, one individual stated that without his mobility device he would be confined to a bed. Some users also referred to their mobility device as a new body part, for example, stating that the device was "now my legs" and a part of who they were. As a result, they wanted to have the PMD as a part of a game but were more disposed to having the choice to play the same games other non-PMD users had access too.

Because most of the MPWD users were newer to using a mobility device, they may have been able to divorce themselves from the device seeing it as a tool rather than a part of their identity. Some examples include suggestions about creating games like treasure hunting at cultural institutions such as the Royal Ontario Museum (ROM) in which the focus of the game would be developing an inter-generational game in which older adults would interact with younger children. In this game the mobility device would be used for travelling longer distances that an older adult might not normally travel.

This game suggestion went beyond the individual and tried to engage different demographic groups, which may not interact with one another at these levels. Another example included the use of the mobility device in a game, which could incorporate dancing, and romantic gestures. The mobility device would be used to dance and express a participant's romantic interest in a partner as the players danced together.

Overall, the commenting rate for the MPMD group was higher than for the TPWHL group (mean rate was 12.69 comments per capita and 5.76 respectively). A possible rationale for this may be because of the way the TPWHL participant's viewed their mobility devices. These 
individuals had used their mobility devices from birth, averaging 18 to 35 years of PMD experience. Sapey et al. (2006) indicated that the longer a person used his mobility aid the more likely he was to consider the mobility device as being part of his identity. As a result, the MPMD group was more likely to comment on more subjects in the Idea Jams because they may have been more willing to consider other uses of their mobility device compared with the TPWHL participants who were not use to thinking about their PMDs as a separate entity and a central game element within the game they were developing in the Idea Jams. Since these participants viewed their mobility devices as an extension of themselves, they may have been less inclined to comment at all in the Idea Jams. Moreover, these participants may have been less likely to comment on the Inclusive Aspects theme because they did not think that their mobility device should or would play a central role in a game.

Participants in the TPWHL group also thought that by creating a game focused on their PMD others would be excluded from playing the game, similar to their own experience with conventional video games. Although their limitations restricted the types of conventional games that they could play, the feeling of being left out of game play experiences discouraged discussion about how to use the PMD in a game. An illustrative example from one TPWHL participant was, "it is games like hockey that work because it is all based on our abilities," suggesting that the participant would rather focus on his abilities and be engaged through those abilities than focusing on his PMD in a game. This suggestion turned into a conversation about how the rules of the game enabled all players with different abilities to be important to the functioning of a team. 
When the TPWHL participants discussed team play they focused on how skill sets unique to each player were important to the whole team suggesting that the ability to have players ranked based on their skills were what made their hockey league fun and competitive, and motivated their participation. One player even went so far as to suggest that he was the only player on his

team who could shoot and that if there were more players on his team that could shoot that would make his team unfair and unbalanced which he would not like. It was the comments on what was a good and functioning team from the perspective of a player on a team that framed the motives and elements of a game's content from this group and that could be useful for game development. For example, participants said that they "liked to play games as a group" or it's "the competition aspect which makes a game fun."

\subsubsection{Team Discussion}

The team oriented discussion also differentiated the TPWHL group from the MPMD group. Since the TPWHL group participated in the Idea Jams together right after playing hockey, some of the emotions experienced by the team play prior to the Idea Jams may have influenced the topics of conversation in the TPWHL group discussion. For example, having the common team experience enabled participants to compare and relate other prior gaming experiences to the sport of hockey. The MPMD group did not have this common 'hockey' experience and did more explorative discussion to learn from each other and compare gaming experiences during their Idea Jams.

The process focus on team play and the special skills that individuals brought to a team seemed to steer the conversation in the direction of comparison rather than exploration. For example, most TPWHL participants referenced the activity level and the ability to play 
physically with one another as favourable qualities of hockey and for the games they enjoyed playing outside of hockey, these were social aspects. One participant said "I like the physicality of the game and being able to play one-on-one with others." Hockey was a common focal point in the discussion providing a point of reference for more sports-type games/activities being considered in this group. For example, one participant commented that he would be most interested in creating a favourite scenario of a paintball game where the team player's would equip their PMD with paintball guns and use tactics to gain strategic advantages. The player wanted to use his PMD "as a heavy support game element with larger guns but a slower amount of manoeuvrability" using his PMD in a unique way to gain advantages for his team's strategy.

This participant seemed to be considering how he could play with his teammates in the paintball scenario showing the preference for a team oriented game that would include his teammates; it also indicated the desire for development of a competitive shooting type of game. For example, TPWHL participants referenced how members of a team used their different skill sets to win in hockey and how skills such as goal tending or blocking the advance of other players could be comparable to skills needed in soccer, football or capture the flag.

Furthermore, team strategies are different than individual strategies in games. On a team, members are required to form units and work together to achieve different goals (Backer \& Cote 2003). As a result, there are some players who have more responsibility for strategies than other players in team sports. These players would naturally take on more leadership roles. Leadership is often closely linked to a player's level of experience playing team sports and based on this leadership, more complex strategies would be developed by these players. As a result, leadership and experience would influence how members of the TPWHL commented in the Idea Jams. 
However, since not everyone in a team sport is a leader, the comments from the Idea Jams would likely reflect this difference. For example, players on a hockey team may be told by a coach/captain to wear out the opposing team's defense by consistently using strategies that require a lot of activity. The coach or captain (the team leaders) of the team could decide on the different plays made during a game but other players usually have little to no input into those decisions or understanding of the purpose of them. In such a case it would be more difficult for the coach/captain to discuss his expert understanding of the strategies used in the TPWHL game in the Idea Jam because other participants would not be up to their level of understanding of team strategies. This would be true particularly because the population of the TPWHL group consisted of mainly non-leadership players.

In contrast, the MPMD Idea Jams were made up of older participants (ranging from 30-60 years of age) and would have been a more mature and experienced group of individuals who may have once been in leadership or decision-making roles in games or other facets in life. These leadership roles may have provided the MPMD participants with a broader understanding of a diverse range of games and experiences which aided them in conceptualizing more complex themes, such as strategies employed to encourage players to carry out specific game behaviours. Additionally, the older adults in the MPMD Idea Jams did not know each other prior to the Idea Jam. This may have encouraged more honest opinions being shared within the group, making the discussion more open and explorative. Since the TPWHL group already knew one another from their hockey league it affected how the participants communicated their ideas to one another (House et al., 1988). Not only would the participants have had an idea of the predispositions of their friends and colleagues opinions but also the TPWHL participants may have been less willing to question some of the underlying assumptions about games their friends liked or 
wanted to develop to avoid conflict or humiliation. The MPMD participants were not in a position where they were required to maintain relationships, either as friends or teammates. As a result, the MPMD group was perhaps less concerned about questioning the assumptions on other participants in their group because they did not need to uphold a reputation or avoid conflict for an underlying reason.

This final difference between the TPWHL group and the MPMD group was in the rating of Game Behaviour Aspects where the TPWHL group had a lower comment rate than the mixed PWD group ( 0.13 comments per capita and 0.77 respectively). This theme required participants to link seemingly different gaming functions/game behaviours together into a single game design or concept. This type of reflection/thinking about different aspects of game behaviours would or would not fit together was a relatively complex game design concept (Apperley, 2006). It required an understanding and/or reflection on game behaviours as independent entities, which, in turn, required considerable game play experience. It was not expected that there would be extensive comments in this category since the game behaviour theme was more complex, specifically because the Idea Jams were meant to be an idea-generating phase of game development. This was primarily because the people in the study were not gaming experts. There was no need for game development experts since the primary function of the Idea Jams was to brainstorm new ideas, which could be used for game development.

\subsection{Post Jam Analysis}

Participants were asked to rate their level of agreement with each of the following nine statements on a 3-point Likert-scale ranging from "1-positive" to "3-negative". Nine significant results were found to the following questions: 
1. What was your level of Participation in the Idea Jam (Question 2/Participation)

2. How much difference do you think your input made (Question 7/effect)

3. I liked the games discussed (Question 15/content)

4. I liked the idea of the games discussed (Question 18a/content)

5. I liked the characters discussed (Question 18b/content)

6. I liked how the game could be played (Question 18c/content)

7. I found the Idea Jam rewarding (Question $18 \mathrm{~d} /$ content)

8. I found thinking about the games was fun (Question 18e/game ideation)

9. I think there were too many people in my group (Question 18f/participation)

By examining the results of the levels of agreement with participation, content and game ideation topics in the post study questionnaire, it appears that a majority of the participants, regardless of age, PMD familiarity, game familiarity and educational level, found the Idea Jam experience and topics of discussion rewarding. These results indicate to game developers that the Idea Jam experience provided participants with a positive game development experience.

\subsubsection{Participation}

Participants appeared to agree that their level of participation helped them experience the Idea Jams in a positive way $(\mathrm{M}=1.09, \mathrm{SD}=0.30)$. Since participants agreed that the amount of input they provided in the Idea Jams influenced how positively they perceived their experience in the Idea Jams $(\mathrm{M}=1.18, \mathrm{SD}=0.60)$ and did not think there were too many participants in their groups $(\mathrm{M}=2.80, \mathrm{SD}=0.68)$. It indicates that the more participants interacted with one another in the Idea Jam, influenced how positively they perceived their Idea Jam experience. This could have been the result of participants being better able to relate to one another from their groups increased 
amount of participation. Furthermore, the more participants interacted could have allowed more information to be exchanged about gaming ideas enabling more creative game development ideas to be established in the groups Idea Jams. This increased creative process through more discussion may have made the Idea Jam experience more rewarding and a more positive experience for the participants as a result.

\subsubsection{Content}

What participants spoke about in their Idea Jams influenced how positively or negatively they felt about their experience. For instance the more likely participants spoke about how game elements they enjoyed in previous games they had played in the past could be incorporated in a new game design influenced how much the participants enjoyed their Idea Jam experience. This may have been for a variety of reasons, some being that perhaps they thought their contributions were being put to good use, making them feel good about themselves or because they felt that the game produced would be something they might like playing in the future. Either way the topics of discussion in the Idea Jams positively influenced the perception of their Idea Jam experience. Some evidence for this statement can be viewed from the participants favourable perception of the ideas of the game discussed, how much participants liked the characters discussed ( $M=1.50$, $\mathrm{SD}=0.85$ ) and how much participants were positively influenced by discussion on how the game could be played $(\mathrm{M}=1.22, \mathrm{SD}=0.67)$.

\subsubsection{Game ideation}

The majority of participants agreed that thinking about games was fun $(\mathrm{M}=1.20, \mathrm{SD}=0.63)$. The positive experience participants received from talking about games in the Idea Jams could be related to a variety of factors. Some of these could be the result of the social experience, sharing stories with others, learning about new things or being able to share similar interests with others. 
It could have also been the result of participants being able to discuss favourite game elements, genres or even the perception that participants were involved with an activity, which had the potential for them to see the benefits in the future.

\subsubsection{Crosstabulations}

Eleven crosstabs analyses were carried out to examine the correlation between how the content of the Idea Jam discussions (questions 11, 13, 14, 15, 16 and 18) affected participant's experience of the Idea Jams in terms of level of enjoyment (question 1) and level of participation (question 2). The first significant relationship was found between the participant's level of enjoyment in the Idea Jam (question 1 in Appendix 3) with how much participants liked the games discussed in the Idea Jam (question 15). This relationship was supported by a second significant correlation between the level of participant's enjoyment in the Idea Jams (question 1) with how much participants liked the idea of the games discussed in the Idea Jams (question 18a). This relationship indicated that the more participants liked the games discussed in the Idea Jams the more they enjoyed their experience as supported by Solomon (2003).

The second significant relationship found was between the participant's level of enjoyment (question 1) with how much participants liked the characters discussed in the Idea Jam (question 18b). This indicates that participants were influenced by how they viewed characters and how they thought characters should be portrayed in the game being developed. It is possible that the participant's view of characters could be linked to perceptions of identity since participants referenced that they liked different characters for reasons associated with their identity. For example, one of the participants liked Gordon Freeman from the game Fallout because he was 
better 'able to relate to him.' whereas another participant stated that she liked comparing herself to her favourite Star Trek heroes when playing games.

Participants seemed to gain a greater emotional experience from being able to participate in Idea Jams because of their ability to relate to the various topics and to participate in idea generation. This section explores how the discussion of game genres and functionality affects how participants feel about the Idea Jam process as a way of exploring ideas. It also relates to the priorities of the Idea Jam participants by exploring how game elements can generate new ideas, which are not directly seen in the data. For example, this section explores how associations between variables in the post jam questionnaire were the result of how the participants felt about their experience after the session. It provides some insight to how the participant's feelings and thoughts led to the discussion topics addressed in the Idea Jams.

\subsection{Capture the Flag}

The capture-the-flag (CTF) game developed, called Powered to Play, drew upon previous efforts in mixed reality game play with smartphones and the CTF-style genre, e.g. Cheok et al. (2006). Powered to Play was designed as a multiplayer mixed reality game played in teams and modeled after the well-known CTF game (see Section 5.3.1 Game play for a description of the commonly known CTF game and its rules).

The game components such as the geo-location, virtual gaming elements, smartphones and the use of publicly available digital services were developed based on the participants feedback gathered in the Idea Jams. In this discussion Powered to Play is described using the mobile systems taxonomy developed by Benford et al. (1998) in conjunction with the Idea Jam drivers of this game. The taxonomy proposes creating a shared mixed reality based 
on the construction of transparent boundaries between real and virtual spaces. The taxonomy is based on the shared spaces of transportation, artificiality and specificity.

As a reminder, Transportation refers to the extent to which a group of participants and objects leave behind their local space and enter into some new remote space to meet with others. For example, a face-to-face meeting in augmented reality is the meeting taking place in the physical world, although a meeting is also occurring in the virtual space. Artificiality refers to the extent to which space is either synthetic or based on the physical world. For example, video conferencing streams real images from the physical world. On the other hand, virtual art is an abstraction of virtual data and on the other synthetic extreme. Specificity refers to the level of support for fundamental physical spacial properties such as containment, topology, distance, orientation and movement in regards to the space a user navigates. In Powered to Play these domains are illustrated in the game play, interface and the platform in which the player works within. The domains are represented by: 1) the transportation through the physical environment the game is played in 2) the artificiality through the interface where the player is viewing the networked locations of other entities on a screen; and 3) the speciality through the platform of the game, which encompasses the location of the entities within the virtual space.

\subsubsection{Game play}

CTF-style games involve two teams competing for each other's flag. The main task of the game is for the player to capture the flag from the opposing team's territory and return it to their home territory. Other tasks include defending the home territory and preventing members from the opposing team from taking a captured flag back to their home territory. 


\subsubsection{Traditional CTF}

Traditional CTF is an outdoor game where two teams each have a flag or type of marker an opposing team is trying to capture. Each team's objective is to locate their opposing teams "base" where the flag is placed and bring the flag back to their "home" base. The enemy players can be "tagged" by players in their home territory and depending on the rules sent back to their own territory (which is the case in the Powered to Play game), frozen in the space they were caught until freed by a team member or taken to a "jail" (jails are an area on each team's territory where captured players must remain until a friendly player "frees" them). CTF requires a physical space of some type, which is divided into two designated halves, called territories. Players form two teams, one team per territory. Each team has a "flag" which can be a piece of fabric or other type of object, which a person can transport on his or her own. The objective of the game is for players to venture into their opponent's territory and take their opponents flag without being tagged. The flag can be defended by tagging players attempting to take it. Players on their own territory are safe and cannot be "tagged" by opposing players, although once they go on to enemy territory they are vulnerable (Cheok 2006).

\subsubsection{Powered to Play version of CTF}

To provide Idea Jam participants with the opportunity to demonstrate behaviours in physical team sports, such as 'paint ball' or 'Dance Dance Revolution'. Developers wanted to develop a game conducive to player communication and coordinated play. After much thought traditional CTF was chosen to be emulated by the development team for the design of a new mixed reality game for the Powered to Play project. CTF was chosen because of its capacity to incorporate many players, be played outside and have the potential of having spectators such as the player's 
friends and families watch the game. Participants indicated that having friends and family should be possible in the game because it was common that these individuals would often accompany their family members to watch or take part in PMD activities. For instance, although the game was developed primarily for PMD users, it was inclusive of non-PMD users by allowing players to participate in the game using other wheeled devices such as skateboards and in-line skates. In addition, people on foot could also participate although they would be slower than those on wheeled devices and may need to run rather than walk.

CTF was also chosen for its viability to be played by a wide range of age groups. This age range allowed different demographic groups to compete fairly with one another. Many Idea Jam participants were eager to create a cross-generational game, which could be equally and fairly shared across age groups. Fair competition and enjoyment were primary game play components that Idea Jam participants indicated were important to them. For example, one participant referenced that "he was the only person on his team who could shoot." But if there were more players who could shoot that would make his team unfair and he would not enjoy playing wheelchair hockey as much on a team because it would be unbalanced and unfair to other teams, making the game play less enjoyable. The level enjoyment participants received from participation in a game was often indicated as a primary motivation for them to be immersed in a game and continue playing. For instance, one participant suggested that when he played dominos with others the enjoyment he got from socializing with his opponents often made him want to continue playing dominos for longer periods of time.

The social theme identified in the Idea Jam data indicated that participants were eager to play games with others and that games like CTF, which had a team component, were a useful way to 
engage participants with each other. For instance, social behaviours could occur as players worked collaboratively with each other to try and strategize how they might capture the opponent's flag or by how individuals would try to capture an opposing player invading their team's territory. To accomplish these tasks some level of trust was required among team members to play a role or use team players 'unique' skills required to fulfill a task together. Trust is one of the foundational qualities needed to nurture the development of new relationships as supported by Green \& Brock (1998). The activity of working together and requiring team members to use their "unique skill sets" as referenced in the Idea Jams to accomplish team goals was thought to help foster new friendships, and increased trust and the use of social skills in games.

\subsubsection{Interface}

The game takes place in physical space that is augmented by virtual elements visible through the smartphone app. A full list of these elements is available in Figure. 24. The primary elements are: (1) the player and flag icons; (2) the game boundary and team territories; (3) the player's energy, timer and health bar; (4) the team and player points; and (5) the map controls. Each player icon is encased by a gray circle that indicates their area of influence (or "personal bubble"). A captured flag is represented in the player icon with a smaller version of the flag. The energy and health meter slowly (in that order) decreases when the player is in proximity to a player from the opposing team and increases when the player is in their home territory. The background is a simple representation of the physical environment generated in real-time by the Google Maps API. 


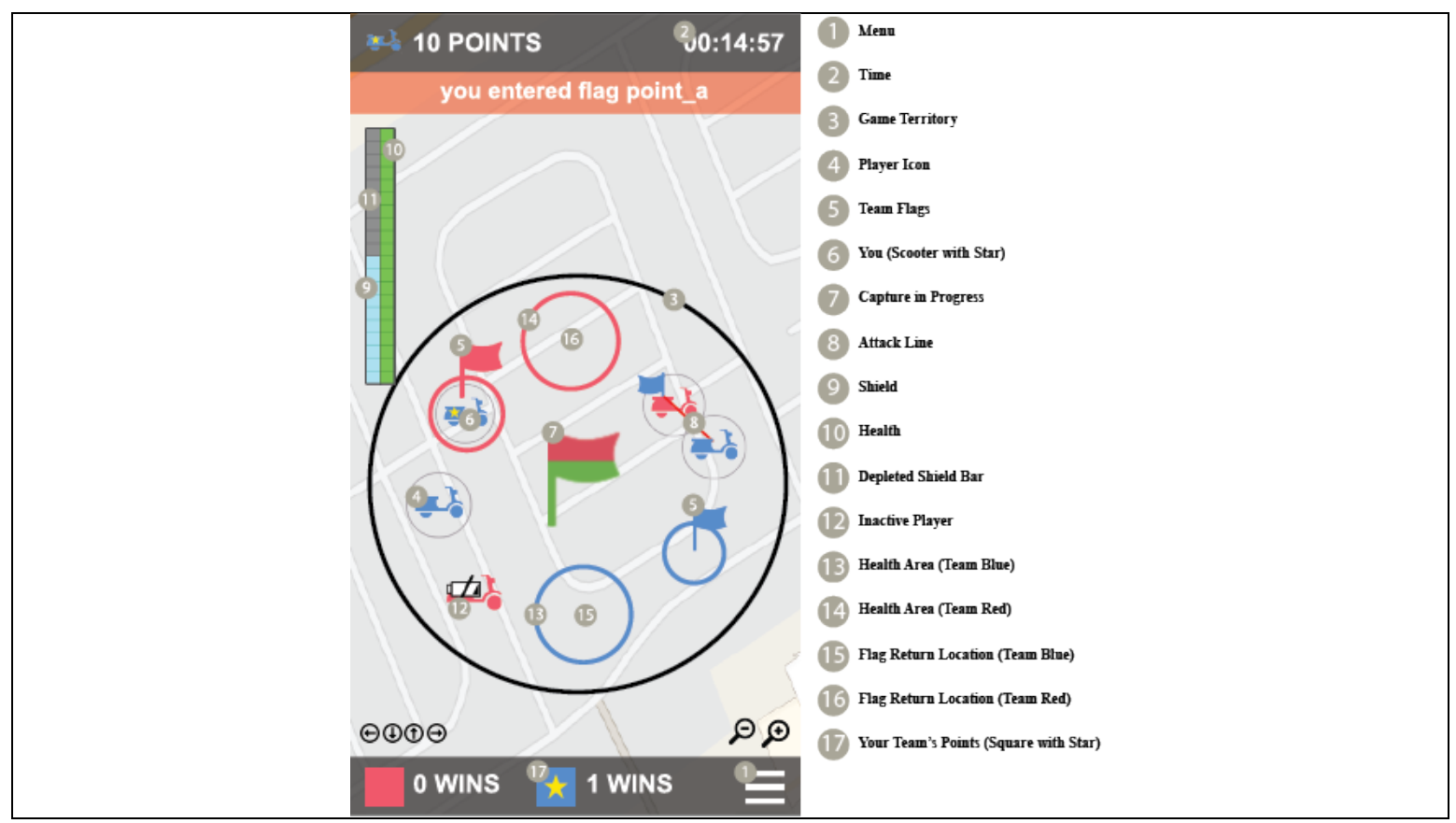

Figure 24: Main game screen with legend of game elements.

\section{The player, flag and game icons}

Each player is provided an icon shaped like a PMD. The PMD icons are differentiated by colour, one team red and one blue. The flags are also provided a corresponding colour, which players capture and return for points. The coloured icons added to the aesthetics while helping players distinguish their geographic position, teammates and game elements (such as the flags) relative to themselves.

Each time a PMD user followed a specific path towards the flag it changed the challenges the PMD user encountered in the game. Not only did the new paths change the physical obstacles (such as trees or roads the player encountered or) but also the virtual playing space, such if a player captured the virtual flag and moved it across the map, changing how players reacted in a game trying to either help or hinder the players advance back to their home territory. The path 
also influenced the way PMD users experienced the "unknown" where the unknown is how a player chooses to do things differently each time they play the game. For instance, the different steps a player takes to return to their territory would always be a challenge with what could "unknowingly" happen next for the player in the previous example.

An example of one of the choices could be crossing the road in the open as opposed to going through a hidden path to enter enemy territory. If a player entered the territory by road there may have been a higher chance that they were seen by their opponents and as a result drained of energy before they could get to the flag. However, the road pathway was the shortest distance with the fewest obstacles so it could be the fastest path but it may not have been familiar with the player who often crossed the road in a different location previously, making the crossing a confrontation with the unknown.

Interacting with the unknown was a primary motivation for players to play games since new challenges were presented each time the unknown became a game factor. Many Idea Jam participants stated that interacting with the unknown was a challenge, which helped them to escape from reality when they played games. For example, having random challenges and facing the unknown increased their level of anxiety, which immersed them deeper into a game until they were able to find a solution to the challenge. One participant referenced a console game called Portal, where the main quest of the protagonist was to solve puzzles - the harder the puzzles were the more immersed in the game he became because he liked trying to solve the puzzles. Csikszentmihalyi (1990) indicates that there should be a balance between the level of anxiety and challenge for a player to experience an optimal level of flow when playing a game. One of the main challenges which can be offered in a game is a experience with the unknown. 
When something happens unexpectedly a player must adopt their game play to overcome the challenge. If a player does not experience enough challenge than she/he will get bored with playing the game, whereas if there is too much challenge the player will become frustrated and likely give up. As a result, there needs to be a balance between skills and abilities whereby the player is challenged enough to keep playing the game and remain interested in solving the problems encountered.

\section{(2) The game boundary and team territories}

To ensure that the game was consistently challenging as indicated by Csikszentmihalyi (1990) and the player was engaged, developers created a safe place within the players own boundaries to provide a resting point if needed. The safe place was used in two ways: 1) to give players a tension reducing break from the game if they require one; and 2) to operate as a mock "jail" where players had to go to recharge their energy/health levels. This offered a punitive component to the game which players were challenged to avoid.

The safe place was visually represented as a circle or health area within the friendly territory of each player's team boundaries (see Figure. 24). The player could recharge his/her shields and health after remaining within that circle for about one minute. This forced players to consider how they spent their health points because depleting them would require players to temporarily be removed from game play. However, if players did not defend their team's flag by depleting the other team player's health, then there was a chance that the other team would score a point by capturing their flag. The depletion rate of health and energy levels was different depending on the game task: coming close to another player would rapidly deplete both player's levels while just driving around the game field depleted the health/energy levels more slowly (levels would 
be depleted in about 2 minutes). This setup a trade-off between defending a team's flag by driving close to the other team's players who were trying to capture the team's flag thereby reducing everyone's health/energy points quickly and trying to capture the other team's flag and avoid other players which reduced a player's health points more slowly. Having a penalty or a cost of play increases the challenge in the game because players were required to work fast enough to avoid depleting their health and energy levels. Idea Jam participants were in favour of this cost because it allowed more skillful teams to capture their opponent's flags. Idea Jam participants suggested "that all players on a team be able to use their skills and abilities" regardless of their limitations or capabilities. Some players could be assigned or play different roles depending on their skills and/or abilities - some would be better defenders while others better flag capturers because of their speed or agility. The team that could take advantage of different skill sets may then have a higher chance of capturing their opponent's flag more often because of the better delegation of skills within their team dynamic.

\section{(3) The player's energy, timer and health bar}

To encourage individual play, developers provided the players with health and shield indicators in which to compete with other individual opponents. Health is required for the players to capture the flag or interact with other players. Players are provided shields which (like their health) begin at $100 \%$ and are depleted if players come within a 2 meter radius of each other or if players are in the enemy territory over time (the amount of time is based on the size of physical space in which the players are playing). If the player's health reaches 0 the player is considered "dead" and can no longer interact with the game. The purpose of this feature is to encourage individual challenges of opponents and personal interaction as well as safety. The 
opportunity for players to act alone and see the results of their actions on the game world was indicated as important in the Idea Jams and supported by Csikszentmihalyi (1990) since it made players feel more responsible for their actions and part of the game, making games more engaging and enhancing the players state of flow. For example, participants referenced that being able to see where their character travelled on a map made them feel more connected to the game world because it made them think that their actions made a difference. In addition, being able to see other players on a map helps to address a safety concern of players coming too close to each other. Finally, seeing other players on a map helped participants find different players with whom they may want to interact or socialize.

\section{(4) The team and player points}

Many of the participants in the Idea Jams indicated that they enjoyed the social benefits employed in team play. To accommodate this desire the game developers used the CTF team dynamic to the players' advantage. For example, there are ample choices and actions available for individual play, but playing as a team is also encouraged by the gaming system. For example, team strategies are often more effective at capturing the flag than independent play. One possible strategy could be that some members of the team try and deplete the energy of opposing team members forcing them to return to their health area (defending the flag) and other team members will try and capture the flag (offensive group). Idea Jam participants said they were more interested in the team oriented strategies that could emerge in games because it provided them a chance to be social and also to learn from one another. One participant went so far as to say that his favourite part of games was to "watch new strategies emerge and see how clever other players were". 


\section{(5) The map controls}

The map controls were designed to make the game as inclusive as possible as recommended by Idea Jam participants. Participants were very vocal about trying to include as many people as possible in the game design of Powered to Play. For instance, one participant stated that people with disabilities "needed to make a game where everyone could play regardless of limitations, skills or abilities." Another participant also stated that people with disabilities "know their skills and limitations the best," so it would be optimal to have a game where they could decide how to use these skills and limitations to their own advantage however they chose. The map controls were designed in a way to incorporate the many skills and limitations of the players. For example, the Tecla Shield was used. The Tecla Sheild is a wireless interface that allows users with disabilities to control smartphones and tablets using their wheelchair-driving controls, one switch device or other types of assistive products. The Tecla shield was used to allow players with different limitations to access the user interface and use their skill sets to the greatest benefit of the team.

Idea Jam participant's comments were categorized in the Inclusive Aspects theme and as a result it became one of the most important game elements to be developed. It was also unanimously agreed upon that any game developed should be inclusive of as many different types of players as possible. Many participants referenced experiencing being left out of game play at some point in their lives. For example, one participant referenced his sister's birthday party and how being in his mobility device stopped him from participating from playing Dance Dance Revolution with his sister. Experiences such as those in the example above increased the participant's desired to have all games developed to be as inclusive as possible. 


\subsubsection{Platform}

The game was developed for Android and iOS-based smartphones using a crossplatform environment called Appcelerator Titanium. A dedicated server was setup for the game. Through this, each instance of the game app running on individual smartphones was aware of any other apps running at the same time (Seaborn, 2014). Powered to Play involved using a GPS to map out a virtual gaming field based on the boundaries and restrictions of the physical space (e.g., park, parking lot, etc.). Players used an app on a mobile technology (e.g., smartphone, tablet, etc.) attached to their PMD that displayed the field. The app displayed their location within the game and other player's positions, home area, points, energy and health levels and the virtual team flags. As players moved in real-time, the game used global tracking system (GPS) navigation to send coordinates from the PMD to the onscreen game map, which showed the player's avatar moving on the virtual playing field. The player could then track his/her movements in the game as well as view her/his teammates and opponents moving on the same map. Smartphone location was determined through the Global Position System (GPS) while the use of a proximity circle enclosing each player icon was used to mitigate position inaccuracies. 


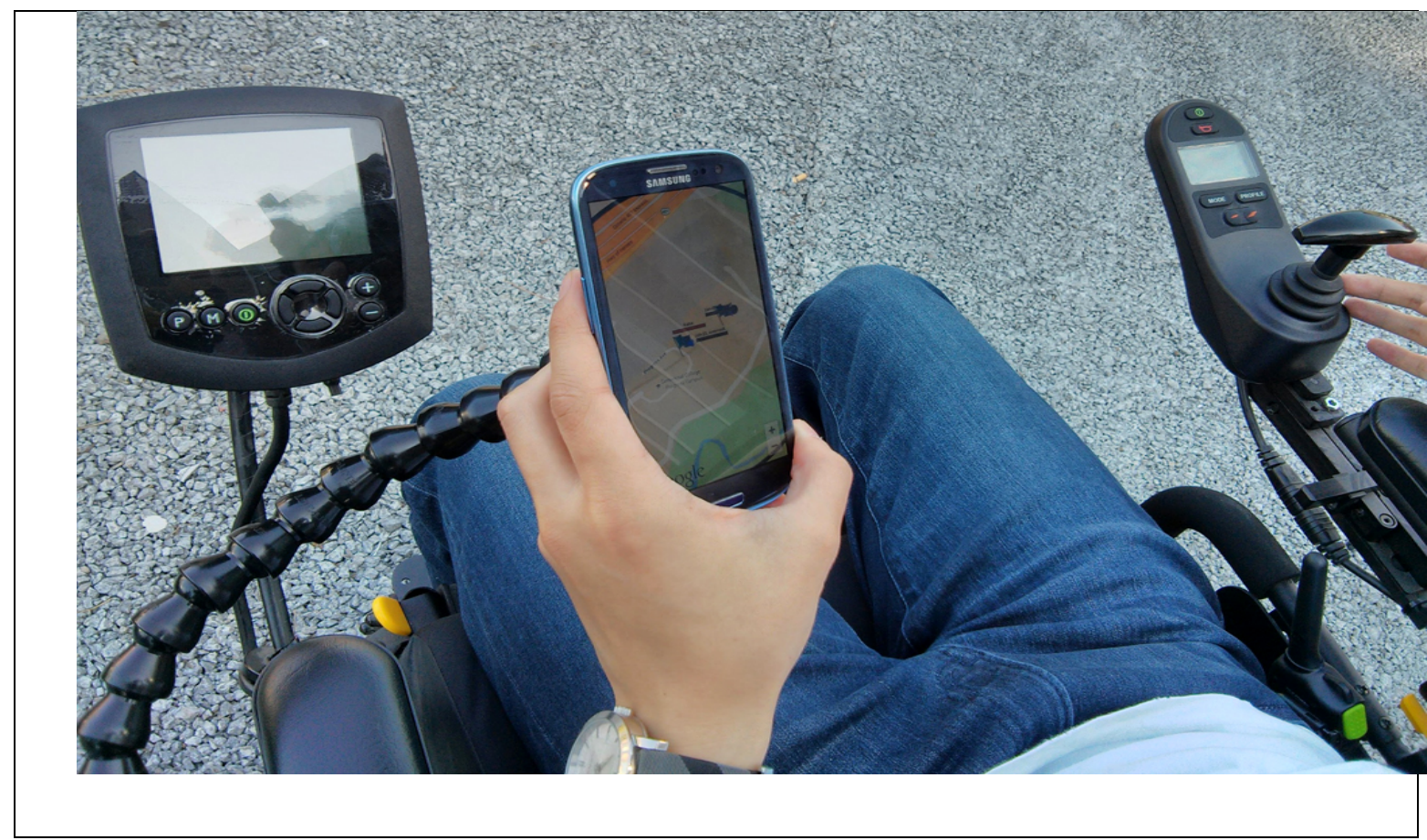

Figure 25: A smartphone used by Powered to Play players: The Galaxy S3, 4.7-inch display with 1.2 GHz quad-core processor using Android Jellybean 4.1 software.

The goal of creating a game where players using PMDs could be active in a larger space made GPS a desirable tool. As the development team explored the comments contributed from the Idea Jams which indicated that participants wanted to play a game in an outdoor space and that physical games were a place they normally felt most restricted, GPS coupled with a mobile display technology became a favourable choice of tool for the platform. One rationale for why the outdoor active game was chosen was because Idea Jam participants wanted to use their PMD driving skills in a game but normally had little opportunity to do so. To provide an outlet for this desire, developers provided players the opportunity to challenge their opponents in a style that allowed for "one-on-one combat" in addition to the team play. To "win" this combat the player 
with the more skillful driving was either able to escape a defender of the flag or to deplete an intruders health and shields trying to capture that players team flag forcing them to retreat.

The Idea Jam data suggested that PMD users desired a variety of different game genres, functionalities (game objectives, characters, input/output, audience integration and rewards) to be used in indoor/outdoor spaces. Idea Jam participants contributed suggestions to the categories of General and Specific game elements as well as a number of Social, Motivational, Inclusive and Behavioural aspects through their Idea Jam input which aided in the development of Powered to Play. Many of these preferences and user input influenced the design of the actual games functionality and priorities.

The user priorities and functionalities contributed by Idea Jam participants had influenced the actual game design and development of Powered to Play in important ways. These included: suggestions regarding game play, its interface and its platform. For example, PMD users suggested the preference of playing a team oriented game, which could incorporate a wide range of age groups for cross-generational games and a social component in the game play dynamic. Another example was the participant's desire to play more physical games that used a player's skills and abilities to their maximum potential regardless of their limitations. The interface design and development was affected through ideas such as how the player and flag icons, the game boundary and team territories, the player's energy, timer and health bar, the team and player points, and the map controls all adhered to the Inclusive design principles which put the user first in the game development stage. Finally, participants influenced the development of Powered to Play through their comments on the type of game/operating platform they preferred. They wanted to play a physical game in the outdoors where it 
would be useful to use technologies such as a GPS. The use of the GPS platform enabled developers to track participant's use and position in a physical space and display those positions on a virtual screen/location allowing for a game such as CTF to be implemented in a mixed reality setting. Each of these contributions illustrates the many benefits of having PMD users as part of the early stages of the design process as well as the level and richness of their contributions to the development of the inclusive and social, Powered to Play mixed reality game. Figure 26 illustrates many of these Idea Jam contributions, which were included into the Powered to Play game. 
1. Inclusive game/as many people included as possible (Theme 4 Inclusive)

2. Cross-generational gaming (Theme 3 \& 4 - Inclusive/Social)

3. Socialize with others (Theme 3 Dominos/Social)

4. Fairness, balance of skills and ability ex. Shoot (Inclusive, Specific -Theme $2 \& 4)$

5. Challenging - Random Challenges, hard puzzles, strategies (Portal)

(Behavioural - Theme 6)

6. Equipment to be accessible (Inclusive - Theme 4)

7. Play games outside (General - Theme 5)

8. Gain skills, individual play elements (Motivations - Theme 1)
1. Spectators, PMD central role, did not want to leave others out, all player abilities useful to the team

2. Rules made it fair for everyone

3. Play on teams (new friendships/collaborations)

4. Different skills and abilities for different roles, rules

5. Experience with the unknown (path to the flag), strategies for team play

6. Map controls were made accessible, one-switch devices available

7. GPS was used

8. One-on-one combat

Figure 26: Idea Jam contributions in Powered to Play. 


\subsection{Limitations}

As with any study, there were a number of limitations, which may have affected the results. These include the limited number of participants and trials, the Idea Jam methodology, the demographic sample and the quality of the post-study questionnaire. Each of these limitations along with suggestions for future work to address these limitations is presented in this section.

\subsection{Study Limitations}

\subsubsection{Limited Participants}

The small sample size of the Idea Jam is the most prominent limitation of this study. The study consisted of 21 participants, with only 11 participants completing the entire study. Of these participants, 21 of them completed the pre-jam questionnaire and took part in the Idea Jams, while only 11 provided the researcher with their follow-up post-jam questionnaires. As a result, non-parametric statistical analyses were used to analyze the Idea Jam's data. Some trends were identified but they could not be generalized, although generalizations were not necessary to provide direction to the mobility game development. Recruitment was difficult for a number of reasons, including scheduling the location and appropriate times for Idea Jams. One example was logistics and transportation inconsistencies. PMD users often rely on public transportation such as Wheeltrans, which can be unreliable, late or slow. As a result, researchers had to host Idea Jams at locations accessible for PMD users where participants had already coordinated transportation to the facility, such as where the TPWHL hockey league met to play at a local gym. It may be possible in the future to provide transportation for participants to ensure a secure, reliable and comfortable means of travel to and from the study.

The financial motivation for engaging Idea Jam participants may have served as a limitation because the participants may have agreed to participate only for the financial compensation or 109 
have caused participants to bias their viewpoints to be more conducive to the researcher's thoughts and opinions. In future Idea Jams it might be more appropriate to make the goals of the Idea Jam less clear, have less participation by researchers, or not to incentivize the participants solely through financial means, for example it might be possible to recruit participants who may accept gaming incentives such as more game development opportunities in the future.

\subsubsection{Demographics}

In addition to the small sample size, the distribution of the participants was not balanced in terms of age, demographics, computer experience, game experience and PMD experience. This was due to the recruitment strategy for the Idea Jams as well as the demographic biases. For instance, most people who use a PMD are usually older adults (Sapey, 2006), making the task of finding appropriate numbers of participants in a younger demographic challenging, in fact, highly unlikely. However, older adults are also less likely to have any experience with video games (Khoo, 2008). As a result, it was not possible to predict the number of participants in the Idea Jams or how experienced the users would be with technology, games or even with their PMDs. There was an unbalanced representation of participants who had used their PMD from birth in comparisons to participants who had used a PMD starting at a later point in their life. These two groups of participants demonstrated a very different type of discussion in the Idea Jams on the use of their PMD and of technologies associated with gaming. This conceptual difference between the two groups led to disparate ideas on the type of games the participant's thought should be developed. Although this was beneficial in some ways, for instance it provided two groups to compare data on, it would have been more useful to have the TPWHL and MPMD groups engage with one another so that their viewpoints could be distributed across the Idea Jams and their experiences shared amongst the different PMD users. 
Although some of the difference in the discussions may be attributable to demographics there was also a fundamental difference between the TPWHL players and the participants in other groups. The TPWHL players tended to be younger and were all experienced powered wheelchair users. The younger participants had more experience with video games as well as were more recently engaged in physical game play were as most of the older participants were less knowledgeable and experienced with video games and were less likely to be recent game players of any kind. Most of the younger participants took part in the Idea Jams right after their participation in a team-oriented sport, through the TPWHL. As a result, not only did most of these participants have more experience with computer games and physical games, such as team sports, but for these participants, hockey became a main topic of discussion in the Idea Jam, which likely skewed the content of the Idea Jam discussion and ultimately what type of game the participants thought should be developed. To avoid biasing results based on demographic or environmental variables future studies should attempt to recruit sufficient numbers of equal proportions of different demographic groups, game type experience and technological capability.

\subsection{Methodology Limitations}

\subsubsection{Video Analysis}

Another limitation of this study is that only six game themes were identified, explored and evaluated in the video analysis. These themes were developed by the researcher post hoc and based on the discussion capture during the Idea Jams. It did not necessarily represent all possible themes that could have occurred if more data were collected. However, the themes identified addressed the research questions and provided data to analyse them. However, future research could consider other research questions and resultant themes. In addition, more data could allow for the expansion of themes and/or better population of them. In addition, future researchers 
should evaluate how the different themes impact the development of more inclusive games for PMD users.

\subsubsection{Idea Jam Consistency}

One of the issues that recurred in the Idea Jam sessions was that of consistency. In some Idea Jams the discussion time was shorter than planned because completion of the pre-study questionnaire and consent form took longer than expected, reducing the time for discussion. To accommodate this inconsistency more time must be allocated in the study protocol and corresponding ethics application to provide participants with a chance to fill out the appropriate paper work prior to and after the Idea Jam sessions.

A longer time period for the Idea Jam sessions ( 2 hours instead of 1.5 hours) would aid in allowing for differences in completing the consent process and the pre-study questionnaire at the beginning and the post-study questionnaire at the end. It would also allow participants to extend transportation requests. For example, older adults were less familiar with different types of games and encountered a steep learning curve when trying to understand how the technology and game system worked in video games as opposed to physical games. Extending the time for the Idea Jam could allow for more explanation and examples to be provided and discussed. The introductory discussion of game types and the story telling aspect of games contributed most to the general and specific game elements and took much of the allotted time which may have skewed the results. By structuring the time of the Idea Jams differently and having more time for discussion a more diverse and in-depth discussion could occur.

Finally, the Idea Jams, unlike other Crowdsourcing activities was not offered online. Typically, Crowdsourcing activities are offered online so participants can question the 
assumptions of other participants in the privacy of their own space (Howe, 2006). However, in this study the participants engaged each other face-to-face. This made the study more susceptible to "group think" and "group consensus" (Byren, 2013), which is similar to critiques found for focus groups. Groupthink may have been more likely to occur since participants engaged each other as a group, face-to-face. When groups meet face-to-face there is a more likely possibility that members communicate with each other about topics not related to the Idea Jam, than when online. This natural social communication can create aspects of groupthink by creating an ingroup and a out group based on social interaction instead of the Idea Jam discussion topic (Byren, 2013).

Implementing the Idea Jams in person was a more socially engaging experience compared with an online discussion forum since participants were engaged face-to-face and the Idea Jams were conducted over a 1.5 hour time period. Discussion forums can last for weeks or months at a time and participants often would not know who they were conversing with. In the future, it would be useful to have Idea jams online and in person to compare results and ensure that the credibility of the process is not diminished due to group consensus. Furthermore, since participants were asked to think about topics and concepts that were beyond their experience and skills it would be useful to have professional designer data collected online to compare with PMD user Idea Jam data. Professional designer data would offer some insight into the traditional design process of game development. This data might aid the comparison between novel and more common ideas brought up by the Idea Jam participants.

A limitation of questionnaire designs and Idea Jams implementation was that the questionnaire and Idea Jams were developed and led by a non-PMD user. This may have 
inadvertently introduced biased thinking or missed critical elements that would have helped a PMD users identify or understand the questions, making the answers more genuine since participants would be able to empathize with the researcher and provide more reliable responses. Having a PMD researcher or educator participate in the development of the questionnaire or aiding in the Idea Jams may mitigate this concern for future research, such as ensuring that no assumptions are made about PMD use by a non-user. Researchers and volunteers were also required to read all of the survey questions to some of the participants and fill-in or check off answers as directed by the participants before and after the Idea Jams. This may be one of the reasons why so few of the post-questionnaires were completed.

At the Idea Jam locations, the group setting did not allow for use of computer-based technologies for answering the survey questions because most computer-based assistive technology is not available for mobile devices. This was desirable because it could have allowed participants to complete the questionnaire online ahead of time and independently without help from researchers and shorten the introductory time allowing more time for discussion. Not enabling participants to complete the questionnaires independently may have also introduced research bias as participants may not have wished to tell the researcher their honest opinions of the Idea Jams. Whether the bias be introduced through discussion between the participant and researcher or reading of the survey questions to the participant, it would be preferable that participants be confident of their privacy when answering questionnaires or participating in the Idea Jams and be allowed to complete their survey by taking as much time as necessary. Furthermore, the financial compensation for participating in the Idea Jam may have interfered with more participants not using the online questionnaires. Financial compensation was only offered at the location of the Idea Jam and not once the final post-jam questionnaire was returned 
if done online. In the future, financial compensation should only be distributed once all of the material is returned to the researcher.

The questionnaires were designed to be as easy as possible for participants to comprehend and answer; however, the language used in the questionnaires may have been still too complicated for some participants. One problem was that it was difficult for game designers to describe some gaming elements in technical terms to people who may not be familiar with video games or game design concepts. A solution to this was to use more abstract terms and phrases when explaining game development at the beginning of the Idea Jam process however, this may have overcomplicated the discussion of the Idea Jams and did not achieve the effect of simplifying the gaming development process for Idea Jam participants. A better process of describing game development would be useful for future Idea Jams, such as by having a PMD user and Professional game designers assist with the study.

The working questions in the questionnaires, while vetted through ethics and other researchers, may have been confusing to some participants causing internal validity issues. Additional pilot testing of the questions could mitigate this issue in future studies. However, even though there were several limitations, there was sufficient, high quality and informative information to begin the game development process of Powered to Play. 


\section{Chapter 6. Contributions, Conclusion \& Future Directions}

\subsection{Contributions}

In this research I carried out a study exploring how PMD users can affect the design process of inclusive game development. The results of this study provided evidence that PMD users are both interested in developing and playing games. PMD users also have unique insights useful for game design. PMD users were able to contribute to General, Specific, Social, Inclusive, Motivations and Behavioural themes present in the Powered to Play game designed and developed by the Inclusive Media Design Centre.

The data collected in the Idea Jams also provided evidence that Crowdsourcing is a viable means to collecting information for game development. The analysis contributes to the growing field of Crowdsourcing being used in a variety of industries. Furthermore, the unexpected stratification between TPWHL and MPMD groups found in the Idea Jams point to different gaming preferences and age related desires for game purpose, development and elements. Also, present were differences in perception of identity and how it affected the game development process by using the PMD as a central point of game development.

Aspects of how team orientation also dominated the Idea Jam conversations in the TPWHL groups. The experience of participants being from a team sport and wanting to develop a game based on the social aspects of team play were found to be closely associated in the Idea Jams. The questionnaires also provided feedback on how including users at the beginning stages of design can be both a rewarding and motivating factor for people to play games. 
Finally, another contribution is that the focus on PMD user's perspectives is in line with inclusive design principles and that PMD users can provide feedback and suggestions that designers overlook, and make game development more user-centered.

\subsection{Conclusion}

A smartphone-based mixed reality game; Powered to Play, was developed based on a popular genre of game, capture-the-flag (CTF), and developed using a Crowdsourcing methodology. This thesis presents evidence of how PMD users can impact the early stages of the design process. It demonstrates how game genres and functionalities can be applied according to a usercentric and Inclusive design approach. PMD users are interested in playing games and game development but feel that they are being left out of this growing entertainment sector due to their diverse needs and limitations. This thesis provides the initial empirical evidence of the success of mixed reality game play for PMD users and establishes a method for user-centric game development.

The Crowdsourcing methodology used to determine the direction for the development of a game for PMD users offers a unique insight to user-centric design. Crowdsourcing enabled designers to include users' feedback from Idea Jam discussions and aligned them with the principles of Inclusive design in the game ideation development phase. Crowdsourcing offered a unique advantage because users were considered at the beginning stages of game development and were able to influence the design process through their own unique gaming experiences. Crowdsourcing through Idea Jams offers one example of how accessibility can be introduced at the beginning of the game design process. Although there were some limitations in this research, it is a starting point for studies on the application of user-centric game development. 
In the Idea Jams it was found that participants spoke the most about general and specific game elements such as the genres, characters and rules they enjoyed in all of the Idea Jams, which was expected as all individuals have unique preferences on the types of games and game characters they prefer. Since it was easier for participants to draw from their own game experiences in the form of stories in the discussions this allowed participants to get to know one another better and lead to more complex discussions later in the Idea Jam sessions. The length of time a person had used their device seemed to have an impact on the different priorities for game development and participant's ability to imagine a game that impacted their preference for the use of powered mobility devices. As a result, the narratives and stories illustrated how age, PMD familiarity and team orientation affected the priorities of game development in regards to genres, and functionality in relation to the PMD users life experiences and perception of identity.

This research began with a questionnaire that attempted to gather the opinions of PMD users on demographic information such as their age, computer use and gaming familiarity. The Idea Jam than provided the data on what types of PMD game genres, functionalities, (game objectives, characters, input/output, audience integration and rewards) PMD users desired to be used in indoor/outdoor spaces. In the Idea Jam phase participants contributed a number of General and Specific game elements as well as a number of Social, Motivational, Inclusive and Behavioural aspect contributions which aided in the development of Powered to Play. Many of these preferences and user input influenced the design of the actual games functionality and priorities through the collection of Idea Jam comments. These user priorities and functionalities commented on by Idea Jam participants had a significant influence on game development. The design of Powered to Play was influenced by these comments in a number of different ways, including: the participant's suggestions regarding game play, it's interface and its platform. Each 
of these contributions illustrated the many benefits of having PMD users as part of the early stages of the design process, which made Powered to Play a more inclusive and social game. These revelations point to the need for considering access to games for disabled users from a user-centric game design perspective. In addition, it provides some evidence for how Inclusive design elements can be used in creating accessible entertainment.

\subsection{Future Directions}

From the feedback from participants who participated in this study it was clear that PMD users were in favour of more inclusive entertainment. As considered in the discussion chapter, the relationship between participants' comments and their experiences with their PMD could be reviewed in future studies. For example, it could be explored further how people who are new to their PMDs want more opportunities to play games with their PMD with a central role. Whereas users who had used their PMDs from birth may have a different perspective on how they believe their PMD can be used in a game. This difference of PMD users identity should be examined in future studies.

Furthermore, other factors such as access to technology, economic, educational background, and political and social attitudes that might influence people's perceptions of games could also become variables to examine in future studies. Larger sample sizes and more game development projects would also provide additional evidence and support stronger conclusions on the future game development directions for PMD user entertainment options. Availability and access to daily living services and assistive technologies are likely important factors that would also influence participants' comments and preferences in the future. 
A comparison of themes collected in the Idea Jams is another method by which to further understand the difference between game development and PMD preferences. For instance, it would be useful to compare the comments from Idea Jams with professional game designers and PMD users to compare results and see if there are any differences which may be incorporated in game development. In this analysis it might be useful to use different methods of Idea Jams such as by comparing online discussion with face-to-face discussions to review any possible differences. It would also be useful to assess the themes explored in this research to see if there are any other themes that may have been missed or which could impact further game development in the future.

Finally another direction that would be worth investigating relates to the business of game development and PMD use. A business model that can proposed how production companies market games for PMD users would require game developers to consider creating, launching, and sustaining new products in line with Inclusive design principles. In order to determine if this is a viable option, market research into possible uses for the product with PMD users is required, as well as, an in depth analysis of the gaming industry, and the likelihood of profitability.

In summary, while there is much research to carry out for the inclusive gamer the development of Powered to Play offers a new direction in the development of accessible gaming and entertainment products. This thesis offers one example of how a game can be developed from the ground-up with PMD users in mind and as part of the game development process. 


\section{References}

1. Abascala, J. and Nicolleb. C. (2005). Moving towards Inclusive design guidelines for socially and ethically aware HCI. Journal of Computers 17, 5, 484-505.

2. Apperley, T. (2006). Genre and game studies: Toward a critical approach to video game genres . Simulation \& Gaming, 37(1), 6-23.

3. Atkinson, T., Gucukoglu, S., Machin, C., \& Lawrence, A. (2006). Making the mainstream accessible: Redefining the game. Sandbox '06 Proceedings of the 2006 ACM SIGGRAPH symposium on Videogames, 21-28.

4. Baker J., \& Cote, J. (2003). Sport-specific practice and the development of expert decision-making in team ball sports. Journal of Applied Sports Psychology, 15, 12-25.

5. Barlet, M. \& Spohn, S. (2011). Includification: The practical guide to game accessibility. http//www.includification.com/ablegamers_Includification.pdf

6. Benford, S., Greenhalgh, C., Reynard, G., Brown, C., \& Koleva, B. (1998). Understanding and constructing shared spaces with mixed-reality boundaries. $A C M$ Transactions on Computer-Human Interaction, 5(3), 185-223.

7. Bevin, J., Loukas, K., \& Faota, M. (2009). Adolescents with disability in school-based practice: Psychosocial intervention recommendations for a successful journey to adulthood . Journal of Occupational Therapy, Schools, \& Early Intervention, 2, 119-132.

8. Bjork, S., Falk, J., Hansson, R., Ljungstand, P. (2001). Pirates! Using the physical world as a game board. Proceedings of Interact 2001, ACM, 423-430.

9. Boudreau, K \& Lakhani, R. (2013). Using the crowd as an innovation partner. Harvard Business Review. 
10. Brabham, D. (2012). The myth of amateur crowds: A critical discourse analysis of Crowdsourcing coverage. Information, Communication \& Society.

11. Breen, H. (2009). Senior citizen bingo players in Australian registered and licensed clubs: A case study at tweed heads, new south wales. Journal of Travel \& Tourism Marketing, 26(4), 383-394.

12. Behrend, T., Sharek, D., Meade, A. (2011). The viability of Crowdsourcing for survey research. Springer, 43, 800-813.

13. Brisenden, S. (1986). Independent living and the medical model of disability. Disability, Handicap and Society', 1(2), 173-178.

14. Brubaker, C. (1986). Wheelchair prescription : An analysis of factors that affect mobility and performance. Journal of Rehabilitation Research and Development, 23(4), 19-26.

15. Byren, E. (2013). Internal Crowdsourcing for innovation development.

16. Care2. Retrieved on August 12, 2014 from the: http://www.care2.com

17. Charlton, J., \& Michalko, R. (2000). Disability: The Reluctant Identity. Journal of Health Politics and Law, 25(6), 1158-1167.

18. Chen, J. (2007). Flow in games (and everything else). Communications of the AMC, 50 (4).

19. Cheok, A., Wan, F., Yang, X. (2002). Game-City: A Ubiquitous Large Area MultiInterface Mixed-reality Game Space for Wearable Computers. Proceedings of the sixth International Symposium on Wearable Computers, IEEE, 156-157.

20. Cheok, A. (2006). Capture the flag: Mixed-reality social gaming with smartphones. Published by the IEEE CS and IEEE COMSOc, 1536-1268.

21. Clark, Ebran, Graham \& Thornton. (2003). The seniors' games: An innovative Australian 
community program. 27(3/4), 53-63.

22. Crawford, A., Hollingsworth, H., Morgan, K., \& Gray, D. (2008). People with mobility impairments: Physical activity and quality of participation. Disability and Health Journal, $1,7-19$.

23. Csikszentmihalyi, M. (1990). FLOW: The psychology of the optimal experience.

24. Derboven, J., Van Gils, M., \& De Grooff, D. (2011). Designing for collaboration: A study in intergenerational social game design. Springer-Verlag, 11, 57-65.

25. Edwards, K., \& McCluskey, A. (2010). A survey of adult power wheelchair and scooter users. Disability and Rehabilitation: Assistive Technology, 5(6), 411-419.

26. Employment and Social Development (2012). Canadians in Context - People with disabilities. Retrieved on September 2014 from the: http://www4.rhdcc.gc.ca/indicator.jsp?\&indicatorid=40

27. Finlayson, M., \& van Denend, T. (2003). Experiencing the loss of mobility: Perspectives of older adults with MS . Disability and Rehabilitiation, 25(20), 1168-1180.

28. Fitzgerald, S., Cooper, R., Zipfel, E., Spaeth, D., Puhlman, J., Kelleher, A., et al. (2006). The development and preliminary evaluation of a training device for wheelchair users: The GAMEWheels system . Disability and Rehabilitation: Assistive Technology, 1(1), 129-139.

29. Flynn, S., \& Lange, B. (2010). Games for rehabilitation: Voice of the players. International Conference of Disability, Virtual Realities \& Associated Technologies, 8, 185-194.

30. Frasca, G. (2003). Simulation versus narrative. (pp. 222-235).

31. Gamberini et al. (2006). Cognition, technology and games for the elderly: An 
introduction to ELDERGAMES project. PsychNology, 4(3), 285 -308.

32. Gibson, B. (2006). Disability, connectivity and transgressing the autonomous body. Springer-Verlag, 27, 187-196.

33. Green, M., \& Brock, T. (1998). Trust, mood, and outcomes of friendship determine preferences for real versus ersatz social capital. Political Psychology, 19(3), 527-544.

34. Gubruim, J. (2003). What is A good story? (pp. 21-24).

35. Hughes, B \& Paterson, K. (1997) The social model of disability and the disappearing body: Towards a sociology of impairment. Disability \& Society, 12(3), 325-340.

36. House, L. \&. U. (1988). Social relationships and health. (241(4865)), 540-5.

37. Howe, J. (2006). Crowdsourcing, why the power of the crowd is driving the future of business. Wired.

38. Johnson, D., \& Wiles, J. (2003). Effective affective user interface design in games. Ergonomics, 46(13), 1332-1345.

39. Kane, S., Wobbrock J., Gajos, K., Harada, S., \& Forehlich, J. (2011). Ability-based design: Concept, principles and examples. ACM Transactions on Accessible Computing, $3(3)$.

40. Keates, S., \& Clarkson, J. (2003). Countering design exclusion through Inclusive design.

41. Kee, N. (2010). How companies can use web 2.0 for innovation and protect their intellectual property rights.

42. Khoo, E., Cheok, A., Nguyen, T., \& Pan, Z. (2008). Age invaders: Social and physical inter-generational mixed reality family entertainment. Springer-Verlag, 12, 3-16.

43. Koon, N. (2003). The design of typology of power attachment unit for wheelchairs.

44. Li, B., Lee-Urban, S., Appling, D., \& Reidl, M. (2012). Crowdsourcing narrative 
intelligence. Advances in Cognitive Systems, 1, 1-18.

45. Lipson, J., \& Rogers, J. (2000). Cultural aspects of disability. Journal of Transcultural Nursing, 11(3), 212-219.

46. Matell, M., \& Jacoby, J. (1971). Is there an optimal number of alternatives for Likert scale items? Reliability and Validity. Sage, 31.

47. McLaughlin, A. \&. W. (2012). Putting fun into video games for older adults. Ergonomics in Design: The Quarterly of Human Factors Applications.

48. Miles, M., Huberman, M., \& Saldana, J. (1994). Qualitative data analysis. (pp. 275-322).

49. Morgan, D. (1998). The focus group guidebook. SAGE Publications.

50. Nilsen, T., Linton, S., \& Looser, J. (2004). Motivations for augmented reality gaming.

51. Norco. Retrieved on August 12, 2014 from the: http://www.norcoinc.com/content/custom-manual-wheelchairs.

52. Ravneberg, B . (2009). Identity politics by design: Users, markets and the public service provision for assistive technology in Norway. Scandinavian Journal of Disability Research, 11(2), 101-115.

53. Reid, D., Angus, J., McKeever, P., \& Miller, K. (2003). Home is where their wheels are: Expirences of women wheelchair users. American Journal of Occupational Therapy, 57, 186-195.

54. Reid, D., Lalmerta-Rudman, D., \& Herbert, D. (2002). Impact of wheeled seated mobility devices on adult users' and their caregivers' occupational performance: A critical literature review. Canadian Journal of Occupational Therapy, 69(5), 261-280.

55. Rieber, L. (1996). Seriously considering play. Educational Technology Research \& Development, 44(2), 43-58. 
56. Rossol, N., Cheng, I., Bischof., Basu, A. (2011). A framework for adaptive training and games in virtual reality rehabilitation environments. Proceedings of the $10^{\text {th }}$ International Conference on virtual reality continuum and it's applications in industry, ACM, 343-346.

57. Rousseau-Harrison, K., Rochette, A., Routhier, F., Dessureault, D., Thibault, F., \& Cote, O. (2012). Perceived impacts of a first wheelchair on social participation. Disability and Rehabilitation: Assistive Technology, 7(1), 37-44.

58. Sapey, B., Stewart, J., \& Donaldson, G. (2006). Increases in wheelchair use and perceptions of disablement. Disability \& Society, 20(5), 489-505.

59. Schlieder, C., Kiefer, P. \& Matyas S. (2006). Geogames - designing location-based games from classic board games. IEEE Intelligent Systems, Special Issue on Intelligent Technologies for Interactive Entertainment.

60. Shim, N., Baecker, R., Birnholtz, J., \& Moffatt, K. (2011). TableTalk poker: An online social gaming environment for seniors. Futureplay '10 Proceedings of the International Academic Conference on the Future of Game Design and Technology, pp. 98-104.

61. Solomon, M. (1983). The role of products as social stimuli: A symbolic interactionism perspective. Journal of Consumer Research, 10(3), 319-329.

62. Sweetser, P., \& Wyeth, P. (2005). GameFlow: A model for evaluating player enjoyment in games . ACM Computers in Entertainment, 3(3).

63. Taleporos, G., \& McCabe, M. (2002). Body image and physical disability personal perspectives. Social Science \& Medicine, 54, 971-980.

64. Toronto power wheelchair hockey league. Retrieved September 11, 2013 from the: http://www.tpwhl.com.

65. UK Wheelchairs. Retrieved August 14, 2014 from the: http://www.uk-wheelchairs.co.uk. 
66. Vareity village. Retrieved September 11, 2013 from the: http://www.varietyvillage.ca.

67. Voida, A., \& Greenberg, S. (2011). Console gaming across generations: Exploring intergenerational interactions in collocated console gaming. Springer-Verlag, 11, 45-56.

68. Von Hipple, E. (2005). Democratizing innovation MIT Press.

69. Vorderer, P., Klimmt, C., \& Ritterfeld, U. (2004). Enjoyment: At the heart of media entertainment. Communication Theory, 14(4), 388-408.

70. Walls, J., Widmeyer, G., \& Sawy, O. (1992). Building a information system design theory for vigilant EIS. The Institute of Management Science, 3 (1).

71. Weiss, P., Bialik, P., \& Kizony, R. (2003). Virtual reality provides leisure time opportunities for young adults with physical and intellectual disabilities. CyberPsychology \& Behaviour, 6(3), 335-342.

72. Wiart, L., Darrah, J., Hollis, V., Cook, A., \& May, L. (2004). Mothers’ perceptions of their Children's use of powered mobility. Physical \& Occupational Therapy in Pediatrics, 24(4), 3-21.

73. Woude, L., Groot, S., Janssen, T. (2006). Manual Wheelchairs: Research and innovation in rehabilitation, sports, daily life and health. ScienceDirect, 28, 905-915.

74. Woods, B., \& Watson, N. (2003). A short history of powered wheelchairs. Assistive Technologies, 15, 164-180.

75. Wressle, E., \& Samuelsson, K. (2004). User satisfaction with mobility assistive devices. Scandinavian Journal of Occupational Therapy, 11, 143-150.

76. Yuan, B., Folmer, E., \& Harris, F. (2011). Game accessibility: A survey. Springer-Verlag, 10, 81-100.

77. Yuen, M., King, I., Leung, K. (2011). A survey for Crowdsourcing Systems. Springer. 


\section{Appendix A: Ethics Approval}

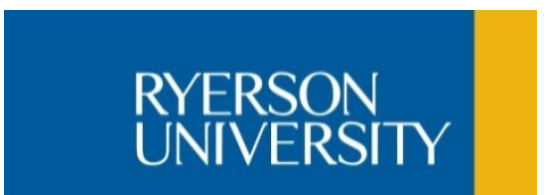

From: rebchair@ryerson.ca

To: gdolinar@ryerson.ca

Cc: rebchair@ryerson.ca

Subject: REB 2013-012

Status

Date: February 28, 2013 03:02:20 PM

\section{REB 2013-012}

\section{Project Title: Powered to Play}

Dear Gregory Dolinar,

The Research Ethics Board has completed the review of your submission. Your research project is now approved for a one year period as of Feb 28, 2013.The approval letter is attached in Adobe Acrobat (PDF) format.

Congratulations and best of luck with the project.

Please note that this approval is for one year only and will expire on February 28, 2014. Shortly before the expiry date a request to complete an annual report will be automatically sent to you. Completion of the annual report takes only a few minutes, enables the collection of information required by federal guidelines and when processed will allow the protocol to remain active for another year.

Please quote your REB file number (REB 2013-012) on future correspondence. 
If you have any questions regarding your submission or the review process, please do not hesitate to get in touch with the Research Ethics Board (contact information below).

No research involving humans shall begin without the prior approval of the Research Ethics Board.

Record respecting or associated with a research ethics application submitted to Ryerson University.

Yours sincerely,

Nancy Walton,

Ph.D.Chair, Research Ethics Board Associate Professor

Ryerson University

POD470B 350 Victoria St.,

Toronto, ON

(416) 979-5000 ext. 6300

nwalton@ryerson.carebchair@ ryerson.ca

http://www.ryerson.ca/research

Toni Fletcher, MA

Research Ethics Co-Ordinator

Office of Research Services

Ryerson University

(416)979-5000 ext. 7112

toni.fletcher@ryerson.ca

http://www.ryerson.ca/research 


\section{Appendix B: Consent Form}

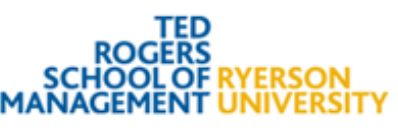

RYERSON

UNIVERSITY

\section{CONSENT AGREEMENT SUMMARY}

You will have the opportunity to participate in the development, creation, and evaluation of a multi-player interactive and mixed reality game ideas(s).

The researchers are interested in your experience with mobility aids (such as scooters and/or power wheelchairs), your opinion of these devices, and then what types of games you could imagine playing with them.

This is a Graduate Student Research Project: Professor Deborah Fels is the supervisor for this study.

Agenda: Consent Form, Pre Questionnaire, Game Idea Session, and Post Questionnaire

Participation is voluntary and you can stop at any time.

Everything you say will remain confidential.

\section{Consent Agreement}

Principal Investigators: Gregory Dolinar, Ryerson University

gdolinar@ryerson.ca

Supervisor: Deborah Fels, Ph.D., P.Eng. Ryerson University 
(416)-979-5000 ext.7619 or dfels@ryerson.ca

Co-Investigators: Margot Whitfield, Ryerson University

margot.whitfield@ryerson.ca

Carmen Branje, Centennial College

cbranje@ ryerson.ca

Project Title: Scooter gaming

You are being asked to participate in a research study. Before you give your consent to be a volunteer, it is important that you read the following information and ask as many questions as necessary to be sure you understand what you will be asked to do.

Purpose of the Study: We are developing a multi-player interactive and mixed reality game(s) for mobility device users and their friends and families. Your ideas and participation in the games' development process and game ideas produced will contribute to a better understanding of mobility user entertainment needs and interests. By conducting this study, we want to discover participants' impression of entertainment of games and/or video games, and ideas of how to combine games and mobility devices such as scooters. We want to learn participants' motives for engaging in gaming.

Description of the Study: First, you will be asked to complete a pre-study questionnaire to collect background information and to collect your opinions on, and experience with, various forms of game entertainment. This will take about 10 minutes of the study time. You will then be given time to think about gaming yourself and work with others on ideas. You are welcome to 
ask as many additional questions as necessary. The entire session will be video-recorded and being video recorded is a requirement of participation.

You will then be asked to participate in a brief game idea generation session that will last about an hour and twenty minutes in length. In groups, you will be asked questions and given time to develop ideas for a preliminary game design. There will be items to use such as paper, plasticine, markers to make a mock-up of your ideas. There will be a short break during the two hour session. After the break, you will be asked to try out your game design ideas in groups. Throughout the study, you will be asked to communicate your thoughts and to create sample games on paper using manipulative. You will also be asked to provide your opinion and feedback on the experience as part of the post-study questionnaire, which will take about another 10 minutes to complete.

We will setup a camera system, once you have signed the permission form, in areas around the room to capture all of the participants and what you are saying and doing. We will be analyzing video recordings for common themes and common actions using analysis software. All information obtained in this study will be confidential and only shared for the purposes of the game development process.

The total time for this study is about two hours.

Risks or Discomforts: The risks associated with the study are minimal. Participants will not be asked to use their motorized vehicles for the purposes of the study. You might feel uncomfortable or fatigued while participating in idea game development, and/or responding to the questionnaires. You may take a break to rest or discontinue participation in the study either temporarily or permanently, for any reason. You may also feel uncomfortable being video-taped. 
If so, then we will ask you to not participate in the study. We will turn on the camera during the pre-questionnaire so that you can become used to it being on. If that does not help, then we will stop the study and you can discontinue your participation.

Benefits of the Study: We cannot guarantee any direct benefits to individual participants. The results from this research may contribute to the development of meaningful and entertaining game designs for multi-player interactive and mixed reality games for people using mobility aids.

Confidentiality: While we will make every effort to maintain confidentiality, and we will ask all participants to maintain confidentiality, we cannot guarantee that all participants will respect that request.

Data will only be presented in summary form and individual participants will not be named. All data, including video recordings, consent forms and questionnaires, will be secured at the Inclusive Media and Design Centre at Ryerson University and destroyed after five years. Consent forms will be stored separately from all other data to avoid linking names with participants. Signed recites confirming payment are required for accounting purposes to be shared with the finance office at Ryerson. However, participant codes will not be shared.

The entire study will be video-recorded. The video recordings will be stored on our password protected lab sever when not in use and will be destroyed after five years. The video will only be viewed by the researchers and will not be used in any public setting.

Costs and/or Compensation for Participation: We will offer you travel compensation within reason if you provide us with a taxi receipt and notify us by e-mail 24 hours in advance. We also will offer you compensation of $\$ 25$ to participate in one research session. Another $\$ 25$ is available for participants if they attend a second session. This second session will be 90 
minutes including another pre and post study questionnaire set. If you are interested, we would like your permission to keep your contact information on file and contact you for the second study.

Voluntary Nature of Participation: Participation in this study is voluntary. Your choice of whether or not to participate will not influence your future relations with Ryerson University or any of the agencies or organizations through which you were recruited. If you decide to participate, you are free to withdraw your consent and to stop your participation at any time without penalty or loss of benefits to which you are allowed. You will still be paid the entire $\$ 25$. At any particular point in the study, you may refuse to answer any particular question or stop participation altogether.

Questions about the Study: If you have any questions or concerns, please do not hesitate to call Gregory Dolinar at 416-979-5000 ext. 2523. In addition to the student researchers and their supervisor, The Research Ethics Board (REB) may also be contacted if you have any questions or concerns about your rights as a research participant, c/o Toni Fletcher, REB Coordinator, Office of the Vice President, Research and Innovation, Ryerson University, 350 Victoria St., Toronto, ON M5B 2K3, Tel: 416-979-5042, E-mail: toni.fletcher@ryerson.ca. 


\section{Agreement}

Your signature below indicates that you have read the information in this agreement, have had a chance to ask any questions you have about the study, and know that your participation is entirely voluntary. Your signature also indicates that you agree to be in the study and have been told that you can change your mind and withdraw your consent to participate at any time. You have been given a copy of this agreement.

You have been told that by signing this consent agreement you are not giving up any of your legal rights.

Name of Participant (please print)

Signature of Participant

Date

Signature of Investigator

Your signature below indicates that you agree to be video-taped during the study and are willing for the video of you to be shown in academic presentations.
Signature of Participant
Date 
Your signature below indicates that you agree to be contacted about participation in the games as they are developed over the next 2 years.

Signature of Participant Date 


\section{Appendix C: Questionnaires}
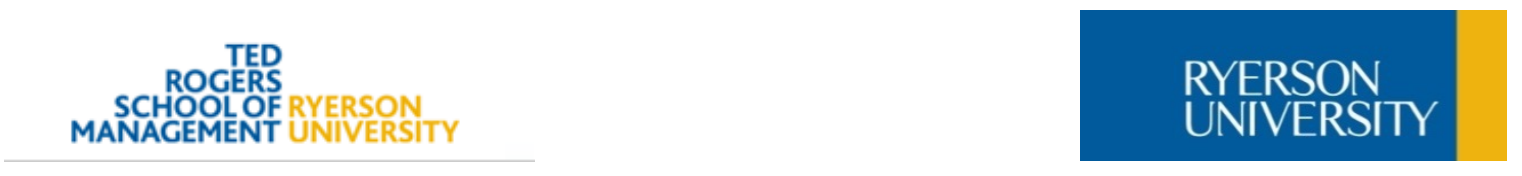

\section{Powered to Play: Pre-jam Questionnaire}

Purpose of pre-study questionnaire: The purpose of this questionnaire is to collect general information about you, and your experience driving a scooter or powered wheelchair and with games (video or other). It should take less than 10 minutes to complete this questionnaire.

1. Please indicate your age: (please check one)
$18-24$
$\square \quad 25-34$
$35-44$
$45-54$
$55-64$
$65+$

2. Please indicate your sex or gender: (please check one)

$\square$ Male

$\square$ Female

$\square$ Other

3. What is your highest level of education completed? (Please check one)

No formal education

Elementary school 


\author{
High School \\ $\square$ College \\ $\square$ University \\ $\square$ Graduate School \\ 4. For what purpose do you use your scooter? \\ Please check all that apply: \\ I use my scooter all the time to get around \\ Just when I am tired or feeling sick \\ Only for long distances \\ At work
}

5. What do you like most about using a scooter?

6. What do you like least about using a scooter?

7. How often do you use a computer? (Please check one)

Everyday

$\square$ Every $2-3$ days

$\square$ Once a week

$\square$ Once a month

$\square$ Never

8. How often do you play video/online games? (Please check one)

Everyday 
$\square$ Every $2-3$ days

$\square$ Once a week

Once a month

$\square$ Never

9. What types of video/online games do you play? (Please check all that apply)

I don't play video games.

Puzzles (e.g., crossword, Sudoku, Brain Teasers)

Non-gambling card games (e.g., bridge)

Casino games (e.g., poker, slots, blackjack)

Role-playing game (e.g., Dungeons and Dragons, Second Life)

First-person shooters (e.g., Call of Duty, Assassin Creed, Halo)

Strategy games (e.g., World of Warcraft)

Platformers (e.g, Mario)

Exergames (e.g., Wii bowling, tennis)

Sports games (NFL,

Music games (e.g., Rock Band, Guitar Hero)

Other:

10. What hardware do you use most often to play video games? (choose one)

I don't play video games

Internet and computer

Computer by itself 
$\square$ Console (e.g., Xbox)

$\square$ Portable console (e.g., Gameboy)

$\square$ Mobile device (e.g., cell phone, tablet)

$\square$ Other, please specify

11. How often do you play physical games such as cards, shuffleboard, board games, pool where you play the game with your hands or body?

$\square$ Everyday

Every $2-3$ days

Once a week

Once a month

Never

12. What types of physical games do you play? (check all that apply)

Card games (e.g., bridge)

Casino games (e.g., slots at a casino)

Board games (e.g., Monopoly, Settlers of Catan, chess)

Sports (e.g., hockey, football, waterpolo, shuffleboard, pool, darts)

Card games (e.g., bridge, Euchre)

$\square$ Other, please specify

I don't play physical games

13. Why do you play video or physical games? (check all that apply) 
$\square$ Entertainment

$\square$ To be with friends

$\square$ Distraction

$\square$ To pass time

$\square$ To escape from reality

$\square$ Other, please specify

14. How often have you played a video or physical game using your scooter?

$\square$ Everyday

$\square$ Every $2-3$ days

$\square$ Once a week

$\square$ Once a month

$\square$ Never

15. What games did you play while on your scooter?

16. If you were allowed to be any character in any video game, who would you want to be and why? 


\title{
Powered to Play: Post-Jam Questionnaire
}

\author{
Participant ID:
}

Purpose of the post-jam questionnaire: The purpose of this questionnaire is to collect your feedback about your involvement in the Idea Jam. The feedback will be used to further understand how your experiences contributed to your understanding of gaming and of what you think of the concept of Powered to Play. There are 20 questions and it should take about 10 minutes to complete them.

\section{Idea Jam experience}

1. What was your level of enjoyment with the Idea Jam experience (please check one)?

Not enjoyable at all

Not that enjoyable

Neutral

Somewhat enjoyable

Very enjoyable 
2. What was your level of participation in the group?

I did not participate at all

I mostly listened

I participated a bit

I participated as much as everyone else

I participated a lot

3. What level do you think others were able to participate?

One person talked most of the time while everyone else listened

Two or three people talked most of the time

Everyone participated equally

4. How relevant was the conversation to the topic of discussion?

Not relevant at all

Occasionally relevant to topic

Extremely relevant and then completely off topic

Consistently relevant to topic

Always extremely relevant to topic

5. How useful were the materials provided to work on a game idea? 
$\square \quad$ Not useful at all

$\square$ Not that useful

$\square$ We didn't use any materials

$\square$ Somewhat useful

$\square$ Very useful

6. Which materials did you use most (check all that apply)

$\square$ Pens
$\square$ Markers
$\square$ Pencils
$\square \quad$ Plastacine
$\square \quad$ Lego
$\square$ Post-it notes
$\square$ Scissors
$\square$ Pieces of paper
$\square$ Paper draped on the table
$\square$ Popsicle sticks

7. How much of a difference do you think that your input in the Idea Jam made?

$\square$ No difference

$\square$ Not much difference 
Don't care

Some different

A lot of difference

8. Do you think that there was enough time for discussion in the Idea Jam session?

$\square \quad$ I would have liked more time for discussion

$\square$ There was just enough time for discussion

$\square$ There was too much time for discussion

9. What stage of the Idea Jam did you find most rewarding to be a part of?

10. What stage of the Idea Jam did you find least rewarding?

\section{Impact on you}

11. What effect did your participation in the Idea Jam have on you? 

$\square$ No effect
$\square$ Some effect
$\square$ Great effect

12. In a few sentences, please tell us what those effects were?

13. What effect do you think that your participation in the Idea Jam had on how you could use your scooter?

$\square$ No effect

$\square$ Some effect

$\square$ Great effect

14. In a few sentences, please tell us what those effects were?

15. The games I like were represented in the Idea Jam. 

$\square$ Agree
$\square$ Somewhat agree
$\square$ Don't care
$\square$ Somewhat disagree
$\square$ Disagree

16. Did participation in the Powered to Play Idea Jam change your level of interest in playing games?

$\square$ Much more interested than before

$\square$ Somewhat more interested than before

$\square$ Not more interested than before

$\square$ I became less interested than before

$\square$ I am became a lot less interested than before

17. Which type of games would you now be interested in trying? (Please check all types that you would be interested in exploring)

I did not become more interested

Puzzles (e.g., crossword, Sudoku, Brain Teasers)

Non-gambling card games (e.g., bridge)

Casino games (e.g., poker, slots, blackjack) 
Role-playing game (e.g., Dungeons and Dragons, Second Life)

First-person shooters (e.g., Call of Duty, Assassin Creed, Halo)

Strategy games (e.g., World of Warcraft)

Platformers (e.g, Mario)

Exergames (e.g., Wii bowling, tennis)

Sports games (NFL,

Music games (e.g., Rock Band, Guitar Hero)

Other:

18. Please check your level of agreement/disagreement with the following statements:

\begin{tabular}{|c|c|c|c|c|c|}
\hline & Agree & $\begin{array}{l}\text { Somewhat } \\
\text { agree }\end{array}$ & $\begin{array}{l}\text { Do not } \\
\text { care }\end{array}$ & $\begin{array}{l}\text { Somewhat } \\
\text { disagree }\end{array}$ & Disagree \\
\hline $\begin{array}{l}\quad \text { I liked the } \\
\text { idea of the } \\
\text { game we } \\
\text { discussed in } \\
\text { my group }\end{array}$ & & & & & \\
\hline $\begin{array}{l}\text { I liked the } \\
\text { characters we } \\
\text { discussed }\end{array}$ & & & & & \\
\hline $\begin{array}{l}\text { I liked how } \\
\text { the game we } \\
\text { discussed } \\
\text { would be } \\
\text { played }\end{array}$ & & & & & \\
\hline $\begin{array}{l}\text { I found the } \\
\text { Idea Jam }\end{array}$ & & & & & \\
\hline
\end{tabular}




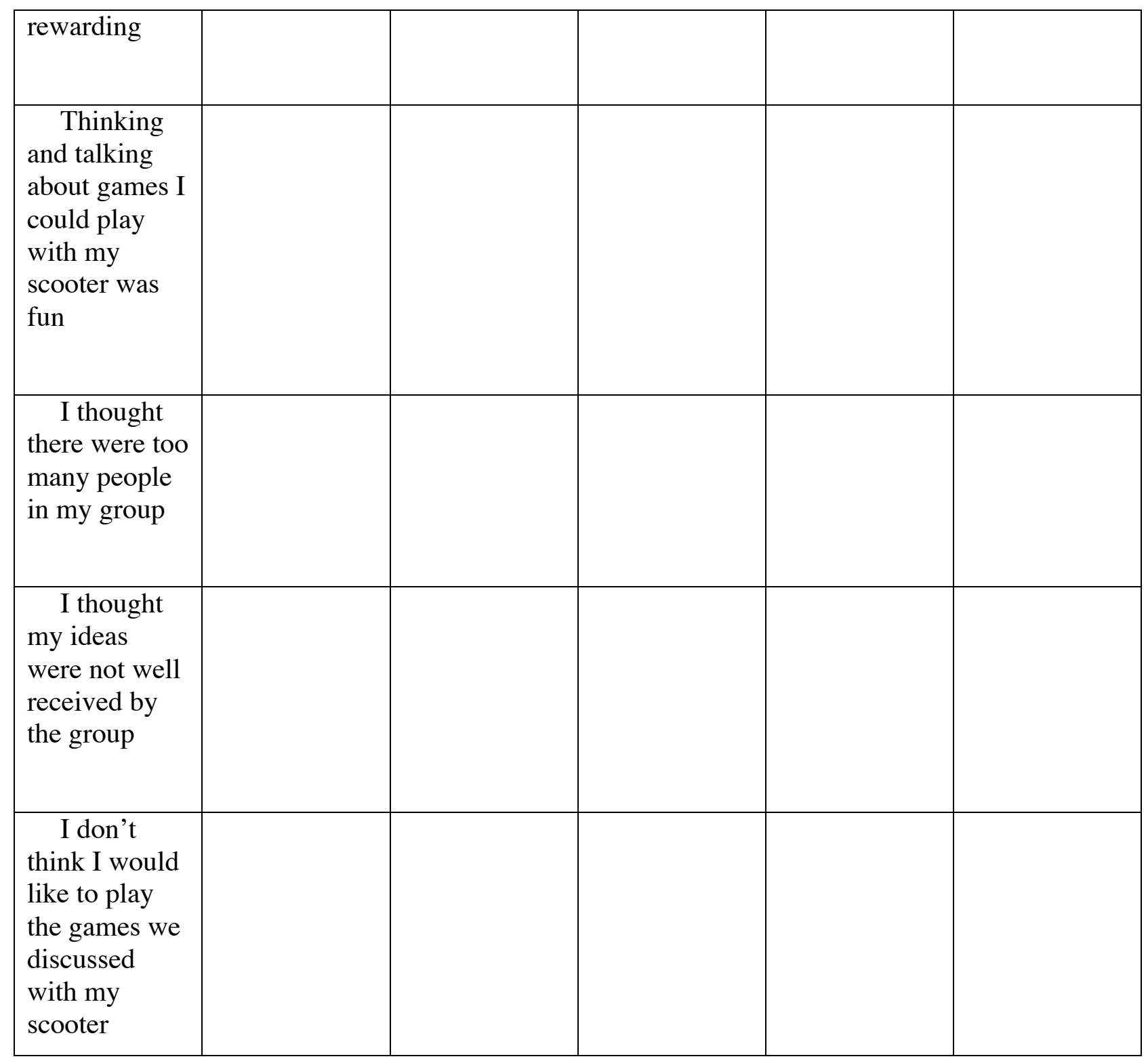

19. What is your level of interest in participating in the actual design of the game?

Not interested

Somewhat interested

Very interested 
If you are interested, please let us know what you might be willing to contribute to. Check all that apply.

$\square$ Advising the project

Providing creative input or work

Learning about building games

Programming

$\square$ Testing prototypes

$\square$ Playing the game when it is finished

$\square$ Other, please specify

20. If you are interested, please provide your contact information

Any other comments you wish to make? 


\section{Appendix D: SPSS Tables}

Chi-square SPSS Tables: Rating the Idea Jam Content

\begin{tabular}{|l|r|r|r|r|r|r|r|r|r|}
\hline & Q2 & Q7 & Q15 & Q18a & Q18b & Q18c & Q18e & Q18f & Q18g \\
\hline Chi-Square & $7.364^{\mathrm{a}}$ & $7.364^{\mathrm{a}}$ & $6.200^{\mathrm{d}}$ & $6.200^{\mathrm{d}}$ & $6.200^{\mathrm{d}}$ & $5.444^{\mathrm{e}}$ & $6.400^{\mathrm{c}}$ & $6.400^{\mathrm{c}}$ & $5.444^{\mathrm{e}}$ \\
$\mathrm{df}$ & 1 & 1 & 2 & 2 & 2 & 1 & 1 & 1 & 1 \\
Asymp. Sig. & .007 & .007 & .045 & .045 & .045 & .020 & .011 & .011 & .020 \\
\hline
\end{tabular}

Descriptive Statistics

\begin{tabular}{|c|c|c|c|c|c|c|c|c|}
\hline & \multirow[t]{2}{*}{$\mathrm{N}$} & \multirow{2}{*}{$\begin{array}{l}\text { Mea } \\
\mathrm{n}\end{array}$} & \multirow{2}{*}{$\begin{array}{c}\text { Std. } \\
\text { Deviation }\end{array}$} & \multirow[t]{2}{*}{ Minimum } & \multirow[t]{2}{*}{ Maximum } & \multicolumn{3}{|c|}{ Percentiles } \\
\hline & & & & & & 25th & $\begin{array}{r}\text { 50th } \\
\text { (Median) }\end{array}$ & 75th \\
\hline Q2 & 11 & 1.09 & .302 & 1 & 2 & 1.00 & 1.00 & 1.00 \\
\hline Q7 & 11 & 1.18 & .603 & 1 & 3 & 1.00 & 1.00 & 1.00 \\
\hline Q15 & 10 & 1.50 & .850 & 1 & 3 & 1.00 & 1.00 & 2.25 \\
\hline Q18a & 10 & 1.50 & .850 & 1 & 3 & 1.00 & 1.00 & 2.25 \\
\hline Q18b & 10 & 1.50 & .850 & 1 & 3 & 1.00 & 1.00 & 2.25 \\
\hline Q18c & 9 & 1.22 & .667 & 1 & 3 & 1.00 & 1.00 & 1.00 \\
\hline Q18d & 10 & 1.00 & .000 & 1 & 1 & 1.00 & 1.00 & 1.00 \\
\hline Q18e & 10 & 1.20 & .632 & 1 & 3 & 1.00 & 1.00 & 1.00 \\
\hline Q18f & 10 & 2.80 & .632 & 1 & 3 & 3.00 & 3.00 & 3.00 \\
\hline Q18g & 9 & 2.78 & .667 & 1 & 3 & 3.00 & 3.00 & 3.00 \\
\hline
\end{tabular}




\section{SPSS Crosstabulation Tables}

\section{SPSS Output on the frequency of the participant's level of enjoyment compared to how}

much participants liked the games, which were discussed in the Idea Jam (1\&15)

\begin{tabular}{|c|c|c|c|c|c|}
\hline \multicolumn{6}{|c|}{ Crosstab } \\
\hline \multicolumn{6}{|l|}{ Count } \\
\hline & & \multicolumn{3}{|c|}{ Q15 } & \multirow[t]{2}{*}{ Total } \\
\hline & & 1 & 2 & 3 & \\
\hline \multirow{2}{*}{ Q1 } & 1 & 7 & 0 & 1 & 8 \\
\hline & 2 & 0 & 1 & 1 & 2 \\
\hline Total & & 7 & 1 & 2 & 10 \\
\hline
\end{tabular}

\section{Chi-Square Tests}

\begin{tabular}{|l|r|r|r|}
\hline & Value & df & \multicolumn{1}{c|}{$\begin{array}{c}\text { Asymp. Sig. } \\
\text { (2-sided) }\end{array}$} \\
\hline Pearson Chi-Square & $6.875^{\mathrm{a}}$ & 2 & .032 \\
Likelihood Ratio & 7.235 & 2 & .027 \\
Linear-by-Linear & 3.462 & 1 & .063 \\
Association & 10 & & \\
N of Valid Cases & & \\
\hline
\end{tabular}

a. 5 cells $(83.3 \%)$ have expected count less than 5 . The minimum expected count is 20 .

\section{Symmetric Measures}

\begin{tabular}{|cc|r|r|r|r|}
\hline & Value & $\begin{array}{c}\text { Asymp. Std. } \\
\text { Error }^{\mathrm{a}}\end{array}$ & $\begin{array}{c}\text { Approx. } \\
\mathrm{T}^{\mathrm{b}}\end{array}$ & $\begin{array}{r}\text { Approx. } \\
\text { Sig. }\end{array}$ \\
\hline Nominal by & Phi & .829 & & & .032 \\
Nominal & Cramer's V & .829 & & & .032 \\
Interval by Interval & Pearson's R & .620 & .253 & 2.236 & $.056^{\mathrm{c}}$ \\
Ordinal by Ordinal & Spearman & & & \\
& Correlation & .699 & .238 & 2.767 & $.024^{\mathrm{c}}$
\end{tabular}



a. Not assuming the null hypothesis.
b. Using the asymptotic standard error assuming the null hypothesis.
c. Based on normal approximation.

SPSS Output on the frequency of the participant's level of enjoyment (question 1) with how much participants liked the idea of the game discussed (question 18a)

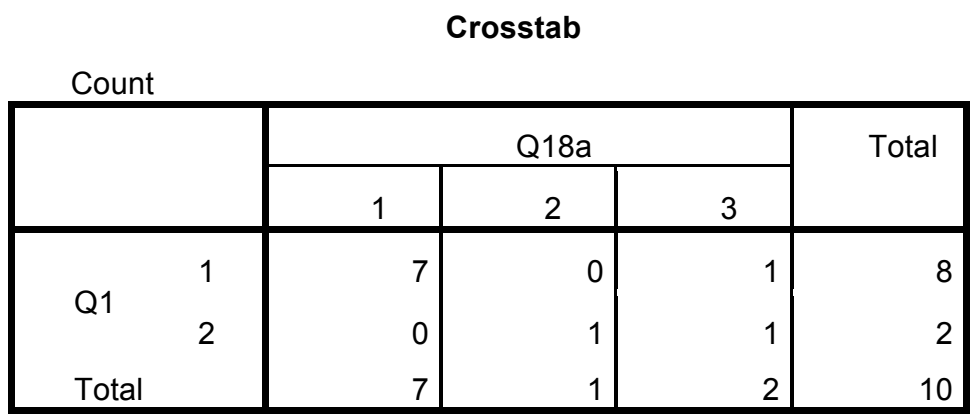

\section{Chi-Square Tests}

\begin{tabular}{|l|r|r|r|}
\hline & Value & df & \multicolumn{2}{|c|}{$\begin{array}{c}\text { Asymp. Sig. } \\
\text { (2-sided) }\end{array}$} \\
\hline Pearson Chi-Square & $6.875^{\mathrm{a}}$ & 2 & .032 \\
Likelihood Ratio & 7.235 & 2 & .027 \\
Linear-by-Linear & 3.462 & 1 & .063 \\
Association & 10 & & \\
N of Valid Cases & & & \\
\hline
\end{tabular}

a. 5 cells $(83.3 \%)$ have expected count less than 5 . The minimum expected count is 20 .

Symmetric Measures

\begin{tabular}{|ll|r|r|r|r|}
\hline & & Value & $\begin{array}{c}\text { Asymp. Std. } \\
\text { Error }^{\mathrm{a}}\end{array}$ & $\begin{array}{c}\text { Approx. } \\
\mathrm{T}^{\mathrm{b}}\end{array}$ & $\begin{array}{c}\text { Approx. } \\
\text { Sig. }\end{array}$ \\
\hline Nominal by & Phi & .829 & & & .032 \\
Nominal & Cramer's V & .829 & & \\
Interval by Interval & Pearson's R & .620 & .253 & 2.236 & .032 \\
\end{tabular}




\begin{tabular}{|l|r|r|r|r|}
\begin{tabular}{ll|r|r|} 
Ordinal by Ordinal \\
Correlation
\end{tabular} & .699 & .238 & 2.767 & $.024^{c}$ \\
\hline N of Valid Cases & & 10 & & \\
\hline
\end{tabular}
a. Not assuming the null hypothesis.
b. Using the asymptotic standard error assuming the null hypothesis.
c. Based on normal approximation.

SPSS Output on the frequency of the participant's level of enjoyment (question 1) with how much participants liked characters discussed in the Idea Jam (question 18b)

\section{Crosstab}

Count

\begin{tabular}{|c|c|c|c|c|c|}
\hline & & \multicolumn{3}{|c|}{ Q18b } & \multirow[t]{2}{*}{ Total } \\
\hline & & 1 & 2 & 3 & \\
\hline \multirow{2}{*}{ Q1 } & 1 & 7 & 0 & 1 & 8 \\
\hline & 2 & 0 & 1 & 1 & 2 \\
\hline Total & & 7 & 1 & 2 & 10 \\
\hline
\end{tabular}

Chi-Square Tests

\begin{tabular}{|l|r|r|r|}
\hline & Value & df & $\begin{array}{c}\text { Asymp. Sig. } \\
\text { (2-sided) }\end{array}$ \\
\hline Pearson Chi-Square & $6.875^{\mathrm{a}}$ & 2 & .032 \\
Likelihood Ratio & 7.235 & 2 & .027 \\
Linear-by-Linear & 3.462 & 1 & .063 \\
Association & 10 & & \\
N of Valid Cases & & & \\
\hline
\end{tabular}

a. 5 cells $(83.3 \%)$ have expected count less than 5 . The minimum expected count is .20 .

Symmetric Measures

\begin{tabular}{|ll|r|r|r|r|}
\hline & Value & $\begin{array}{c}\text { Asymp. Std. } \\
\text { Error }^{\mathrm{a}}\end{array}$ & $\begin{array}{c}\text { Approx. } \\
\mathrm{T}^{\mathrm{b}}\end{array}$ & $\begin{array}{c}\text { Approx. } \\
\text { Sig. }\end{array}$ \\
\hline $\begin{array}{l}\text { Nominal by } \\
\text { Nominal }\end{array}$ & Phi & .829 & & & .032 \\
.829 & & & .032 \\
\hline
\end{tabular}




\begin{tabular}{|c|c|c|c|c|c|}
\hline Interval by Interval & Pearson's R & .620 & .253 & 2.236 & $.056^{\mathrm{c}}$ \\
\hline Ordinal by Ordinal & $\begin{array}{l}\text { Spearman } \\
\text { Correlation }\end{array}$ & 699 & .238 & 2.767 & $.024^{\mathrm{c}}$ \\
\hline $\mathrm{N}$ of Valid Cases & & 10 & & & \\
\hline
\end{tabular}
a. Not assuming the null hypothesis.
b. Using the asymptotic standard error assuming the null hypothesis.
c. Based on normal approximation. 